Camilla Luiza Batista

\title{
Diversidade genética em Plasmodium vivax: variação temporal e espacial em uma comunidade rural Amazônica
}

Dissertação de Mestrado apresentada ao programa de Pós-Graduação em Biologia da Relação Patógeno- Hospedeiro do Instituto de Ciências Biomédicas da Universidade de São Paulo para obtenção do título de Mestre em Ciências. 
Camilla Luiza Batista

\section{Diversidade genética em Plasmodium vivax: variação temporal e espacial em uma comunidade rural Amazônica}

Dissertação de Mestrado apresentada ao programa de Pós-Graduação em Biologia da Relação Patógeno- Hospedeiro do Instituto de Ciências Biomédicas da Universidade de São Paulo para obtenção do título de Mestre em Ciências.

Área de Concentração: Biologia da Relação Patógeno- Hospedeiro

Orientador: Marcelo Urbano Ferreira

Versão Original 
DADOS DE CATALOGAÇÃO NA PUBLICAÇÃO (CIP)

Serviço de Biblioteca e Informação Biomédica do Instituto de Ciências Biomédicas da Universidade de São Paulo

(C) reprodução total

Batista, Camilla Luiza.

Diversidade genética em Plasmodium vivax: variação temporal e espacial em uma comunidade rural Amazônica / Camilla Luiza Batista. - São Paulo, 2014.

Orientador: Prof. Dr. Marcelo Urbano Ferreira.

Dissertação (Mestrado) - Universidade de São Paulo. Instituto de Ciências Biomédicas. Departamento de Parasitologia. Área de concentração: Biologia da Relação Patógeno-Hospedeiro. Linha de pesquisa: Genética de populações em Plasmodium vivax.

Versão do título para o inglês: Genetic diversity of Plasmodium vivax over time and space: a community-based study in rural Amazonia.

$\begin{array}{lll}\text { 1. Plasmodium vivax } & \text { 2. Malária } & \text { 3. Genética de populações } 4 .\end{array}$ Microssatélites 5. Surto 6. Amazônia Brasileira I. Ferreira, Prof. Dr. Marcelo Urbano II. Universidade de São Paulo. Instituto de Ciências Biomédicas. Programa de Pós-Graduação em Biologia da Relação Patógeno-Hospedeiro III. Título. 
Candidato(a):

Título da Dissertação:

Orientador(a):
Camilla Luiza Batista.

Diversidade genética em Plasmodium vivax: variação temporal e espacial em uma comunidade rural amazônica.

A Comissão Julgadora dos trabalhos de Defesa da Dissertação de Mestrado, em sessão pública realizada a ..................., considerou
( ) Aprovado(a)
( ) Reprovado(a)

Examinador(a): Assinatura:

Nome:

Instituição:

Examinador(a): Assinatura:

Nome:

Instituição:

Presidente: Assinatura:

Nome:

Instituição: 
São Paulo, 21 de setembro de 2012.

\section{PARECER 1068/CEP}

A Comissão de Ética em Pesquisas com Seres Humanos do ICB, nesta data APROVOU o projeto intitulado: "Diversidade genética em Plasmodium vivax: variação temporal e associação com a expressão clinica" dos autores Prof. MARCElo urbano FerReira $\Theta a$ aluna CAMILA LUIZA BATISTA.

Cabe aos Pesquisadores executantes elaborar e apresentar a este Comitê, relatórios anuais (parciais ou final), de acordo com a resolução 196/06 do Conselho Nacional da Saúde, item IX. 2 letra c. (modelo no site:icb.usp.br). Em não havendo um biorepositório e se houver retenção de material deverá ser solicitado o devido cadastro conforme modelo constante site do ICB.

O primeiro relatório deverá ser encaminhado à Secretaria deste CEP em 21.09.2013.

Atenciosamente,

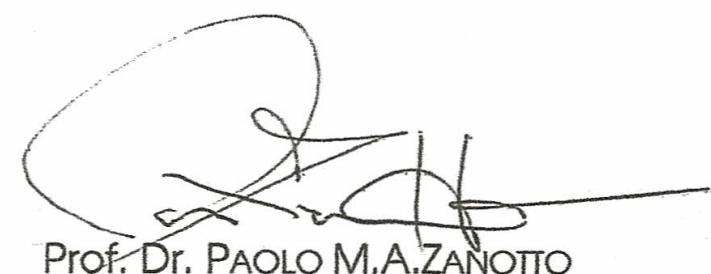

Coordenador da Comissão de Ética em

Pesquisas com Seres Humanos - ICB/USP 


\section{AGRADECIMENTOS}

Os agradecimentos principais são direcionados ao Prof. Marcelo Urbano Ferreira pela oportunidade de ter feito parte de sua equipe e pela orientação fundamental para minha formação acadêmica. Agradeço principalmente pela experiência adquirida no trabalho de campo, conhecer e conviver com a população do Remansinho me fez encarar o mestrado de uma forma muito mais responsável e crítica.

À querida amiga Susana Barbosa pela ajuda fundamental na etapa de análise dos dados. Sua generosidade foi essencial para minha formação. Agradeço também às amigas Melissa Bastos e Priscila Rodrigues pelo auxílio com a tipagem de microssatélites e das demais técnicas moleculares utilizadas no estudo. À querida amiga Maria José Menezes pelo suporte laboratorial.

Os agradecimentos especiais são direcionados aos amigos e colaboradores do laboratório, principalmente àqueles que iniciaram o trabalho na região do Remansinho. Amanda $\mathrm{B}$. Gozze, Pablo S. Fontoura, Kézia Katiani G. Scopel, Nathália F. Lima, Carlos E. Cavasini, Vanessa C. Nicolete, Raquel M. Gonçalves, Rosely dos Santos Malafronte, Ariel M. Silber e Cristiana F. Alves de Brito pelo suporte laboratorial ao longo de todo o estudo;

À Mônica da Silva-Nunes, Carla Roberta O. Carvalho, e Mauro R. Tucci pelo cuidado clínico com a população; Cleide F. Nunes e Eusueli Arraes da Silva pelo diagnóstico de malária por microscopia; Márcio C. Santana, Andrecresa N. Duarte e Francisco Naildo C. Leitão por todo o suporte logístico;

À Carmen S. A. Takata pela ajuda na tipagem e sequenciamento de microssatélites. Agradeço também ao amigo André Guilherme da Costa Martins pelo auxílio na tipagem de microssatélites e na utilização do programa de análise dos marcadores.

Aos amigos do laboratório do Prof. Mauro Cortez pelo auxílio com equipamentos e disponibilização de espaço: Albert Bressan, Ismael Sauter, Juliana da Rocha Ávilla e Lina Borda.

Ao apoio incondicional de minha família, especialmente Juliano C. N. Lima pelo carinho e companheirismo. 
"Vinde vós das cidades para o campo onde existe a aventura da malária. Foi em agosto, o lago respirando que ouvi no sangue a mais formosa ária. E vi mais um ginete galopando num ocaso de sangue iluminado; era o tempo mais ouro das queimadas, e as geórgicas se enchiam de piratas. Deram-nos tudo: frêmitos e prata e certo afã de lírios encarnados. Que madura estação provisionada! Que lagunas noturnas sobre as frontes! Que mãos frias errando no ar parado!

Que sibilos de medos e de frontes!" (Lima, Jorge de Invenção de Orfeu - Canto I, Poema XXXVII) 


\section{RESUMO}

Para examinar como o nível de diversidade genética de Plasmodium vivax em uma comunidade varia no tempo e no espaço, investigamos a dinâmica de polimorfismos do parasito durante as primeiras fases de ocupação de um assentamento agrícola na Região Amazônica brasileira. A caracterização por microssatélites de 84 isolados de $P$. vivax, colhidos ao longo de três anos, revelou uma diversidade genética de moderada a alta (heterozigosidade esperada média, 0,699), com uma grande proporção $(78,5 \%)$ de infecções por múltiplos clones (IMC), mas também um forte desequilíbrio de ligação (DL) consistente com um raro cruzamento entre os haplótipos. Observamos uma pequena influência temporal na diversidade genética dos haplótipos do parasito e nenhum padrão de distribuição espacial dos mesmos. Em amostras consecutivas colhidas de um mesmo indivíduo observou-se uma intensa renovação de haplótipos ao longo do tempo. Um único haplótipo foi compartilhado por três indivíduos cujas amostras foram colhidas durante um surto; todos os outros 81 haplótipos foram recuperados apenas uma vez. A menor diversidade parasitária, com a menor proporção de IMC e um DL mais intenso, foi observada no momento do surto, fornecendo um claro exemplo de uma estrutura populacional epidêmica de um patógeno humano. Todos os parâmetros populacionais retornaram aos valores prévios ao surto durantes os últimos anos de estudo, apesar da queda concomitante na transmissão de malária. Sugerimos que a genotipagem do parasito pode ser útil para monitorar a propagação de novas linhagens do parasito associadas a surtos em áreas que se aproximam da eliminação da malária. 


\section{ABSTRACT}

To examine how community-level genetic diversity of the malaria parasite Plasmodium vivax varies across time and space, we investigated the dynamics of parasite polymorphisms during the early phases of occupation of a frontier settlement in the Amazon Basin of Brazil. Microsatellite characterization of 84 isolates of $P$. vivax sampled over 3 years revealed a moderate to high genetic diversity (mean expected heterozygosity, 0.699), with a large proportion (78.5\%) of multiple-clone infections $(\mathrm{MCl})$, but also a strong multilocus linkage disequilibrium (LD) consistent with rare outcrossing. Little temporal and no spatial clustering was observed in the distribution of parasite haplotypes. A single microsatellite haplotype was shared by 3 parasites collected during an outbreak; all other 81 haplotypes were recovered only once. The lowest parasite diversity, with the smallest proportion of $\mathrm{MCl}$ and the strongest $\mathrm{LD}$, was observed at the time of the outbreak, providing a clear example of epidemic population structure in a human pathogen. Population genetic parameters returned to preoutbreak values during last 2 years of study, despite the concomitant decline in malaria incidence. We suggest that parasite genotyping can be useful for tracking the spread of new parasite strains associated with outbreaks in areas approaching malaria elimination. 


\section{LISTA DE ILUSTRAÇÕES}

Figura 1 - Classificação de países em estágio de eliminação da malária, desde dezembro de 2012.

Figura 2 - Registro de casos de malária e espécies parasitárias ( $P$. falciparum e $P$. vivax), Brasil, 1959-2012. . . . . . . . . . . . . . . . 16

Figura 3 - Mapa e imagem de satélite da localização do assentamento agrícola conhecido como Remansinho, Brasil . . . . . . . . . . . . . . . . . . . . . . . . 23

Figura 4 - Mapa de distribuição dos diferentes ramais onde localizam-se os domicílios no Remansinho, Brasil . . . . . . . . . . . . . . . . . . . . . . . . . 24

Figura 5 - Incidência de malária e número de amostras tipadas com Plasmodium vivax, Remansinho, Brasil (2010-13) . . . . . . . . . . . . . . . 35

Figura 6 - Distribuição de frequências de isolados colhidos na região do Granada (2004-6) e do Remansinho (2010-13) . . . . . . . . . . . . . . . . . . . . 444

Figura 7 - Distribuição temporal dos isolados de Plasmodium vivax do Remansinho, Brasil (2010-13) . . . . . . . . . . . . . . . . . . . . . . 46

Figura 8 - Distribuição ao longo do tempo de três diferentes populações estimadas de isolados de Plasmodium vivax do Remansinho, Brasil, 2010-13. . . . . . . 47

Figura 9 - Imagem de satélite com a localização dos domicílios com casos de infecção por Plasmodium vivax genotipados ao longo do estudo na região do Remansinho, Brasil (2010-13) . . . . . . . . . . . . . . . . 48

Figura 10 - Correlação entre distância genética e distância temporal (dias) de amostras de Plasmodium vivax colhidas no Remansinho, Brasil (2010-13) . . . . . . 49

Figura 11 - Correlação entre distância genética de amostras de Plasmodium vivax e distância espacial (km) de domicílios do Remansinho, Brasil, 2010-13 . . . 50 


\section{LISTA DE TABELAS}

Tabela 1 - Oligonucleotídeos iniciadores para a amplificação de 15 marcadores genéticos específicos para $P$. vivax. . . . . . . . . . . . . . . . . . . . . . . . . . 28

Tabela 2 - Número de infecções multiclonais (IMC) segundo idade dos indivíduos participantes do estudo realizado no Remansinho, Brasil (2010-13) . . . . 37

Tabela 3 - Número de infecções multiclonais (IMC) segundo tempo de moradia na Amazônia. Remansinho, Brasil (2010-13) . . . . . . . . . . . . . . . . 37

Tabela 4 - Haplogrupos formados a partir de haplótipos recuperados de amostras colhidas ao longo dos cortes transversais realizados na região do Remansinho, Brasil (2010-13). . . . . . . . . . . . . . . . . . . . . . . . . 39

Tabela 5 - Tipos de repetição encontradas em 14 marcadores de Plasmodium vivax: isolados do Brasil (este estudo) e Sri Lanka . . . . . . . . . . . . . . . . . 40

Tabela 6 - Diversidade de 14 loci de microssatélite e um locus de região antigênica codificadora em 84 isolados de Plasmodium vivax, Remansinho, Brasil (2010-13)

Tabela 7 - Tendência temporal na diversidade genética de isolados de Plasmodium vivax do Remansinho, Brasil (2010-13) . . . . . . . . . . . . . . . . . . . 45

Tabela 8 - Haplótipos recuperados de amostras consecutivas de Plasmodium vivax de 12 indivíduos colhidas num intervalo entre três a 15 meses durante cortes transversais no Remansinho, Brasil (2010-13). . . . . . . . . . . . . . 52

Tabela 9 - Haplótipos recuperados de amostras consecutivas, colhidas com um intervalo de aproximadamente duas semanas entre si, durante infecções assintomáticas e subpatentes por Plasmodium vivax no Remansinho, Brasil (2010-13). . . 55

Tabela 10 - Número de alelos de nove microsatélites em populações de Plasmodium vivax do mundo . . . . . . . . . . . . . . . . . . . . . . . . 57 


\section{LISTA DE ABREVIATURAS E SIGLAS}

$\begin{array}{ll}\text { DNA } & \text { Ácido Desoxirribonucleico } \\ \text { DL } & \text { Desequilíbrio de Ligação } \\ H_{E} & \text { Heterozigosidade Esperada } \\ I_{A}^{S} & \text { Índice de Associação } \\ \text { IMC } & \text { Infecção por Múltiplos Clones } \\ \text { IMC }>1 & \text { Multiple Clone Infections at }>1 \text { loci (Infecção por Múltiplos Clones em >1 } \\ \text { MSAT } & \text { loci) } \\ \text { pb } & \text { Picrossatélite } \\ \text { PCR } & \text { Polymerase Chain Reaction (Reação em Cadeia da Polimerase) } \\ \text { q-PCR } & \text { Quantitative Polymerase Chain Reaction (Reação em Cadeia da Polimerase } \\ \text { R } & \text { Quantitativa) } \\ \text { SNP } & \text { Índice de Riqueza Genotípica } \\ \text { YAC } & \text { Single Nucleothide Polymorphism (Polimorfismo de Base Única) } \\ & \text { Yeast Artificial Chromosome (Cromossomo Artificial de Levedura) }\end{array}$




\section{SUMÁRIO}

INTRODUÇÃO $\ldots \ldots \ldots \ldots \ldots \ldots \ldots$

$1.1 \quad$ A malária como problema de saúde pública . . . . . . . . . 14

1.2 Estrutura populacional e diversidade genética dos plasmódios . . . 16

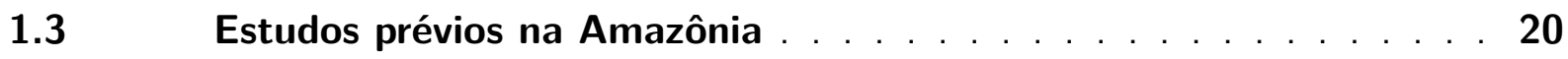

$1.4 \quad$ Explorando as lacunas . . . . . . . . . . . . . . . . 21

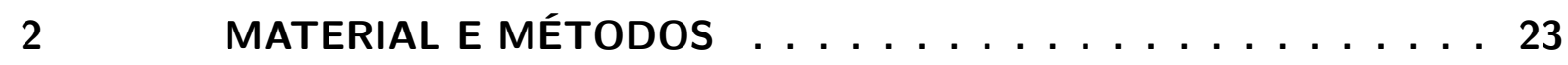

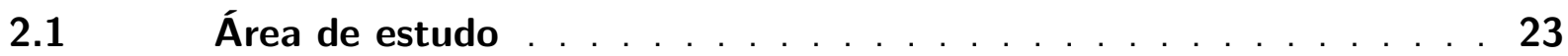

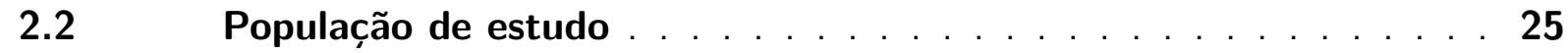

$2.3 \quad$ Amostras de parasitos . . . . . . . . . . . . . . 26

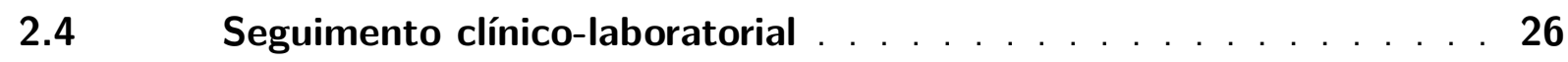

2.4.1 Diagnóstico de malária . . . . . . . . . . . . . . . . . . 26

2.4.2 Tipagem molecular de parasitos . . . . . . . . . . . . 26

2.4.3 Análise dos fragmentos de DNA microssatélite . . . . . . . . . . . . . 29

2.4.4 Sequenciamento das regiões de microssatélite . . . . . . . . . . . . . 32

2.4.5 Análises dos dados de sequenciamento . . . . . . . . . . . . . . . . 32

2.4.6 Aspectos éticos . . . . . . . . . . . . . . . . . . 33

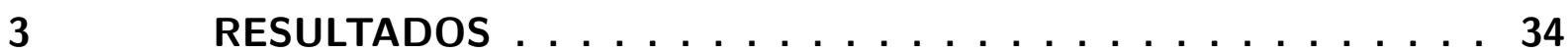

3.1 Incidência de malária e diversidade genética de Plasmodium vivax . 34

3.2 Diversidade genética no tempo e no espaço . . . . . . . . . 44

3.3 Haplótipos em amostras consecutivas de parasitos . . . . . . . 51

$3.4 \quad$ Diversidade global de microssatélites de Plasmodium vivax . . . . 56

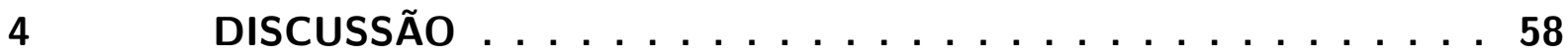

$4.1 \quad$ Microssatélites como marcadores genéticos . . . . . . . . 58

4.2 Diversidade genética . . . . . . . . . . . . . . . . 59

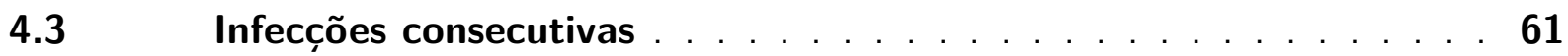

$4.4 \quad$ Genotipagem em saúde pública . . . . . . . . . . . . . . 63

$5 \quad$ CONCLUSÃO $\ldots \ldots \ldots \ldots \ldots$

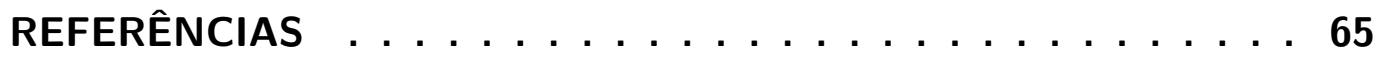




\section{INTRODUÇÃO}

\subsection{A malária como problema de saúde pública}

A malária é uma doença parasitária que faz parte do quadro de doenças negligenciadas e está claramente distribuída em regiões mais pobres e carentes do mundo. Em muitos casos está envolvida no nível socio econômico de uma população, isso se deve ao impacto na rotina das famílias, cujos membros são prejudicados pelos sintomas, e na sobrecarga de atendimento dos sistemas de saúde. Em 2012 a doença foi responsável por 207 milhões de casos e 627 mil mortes, a maioria dessas são crianças menores de cinco anos na África. Entre 2001 e 2012 estimou-se a morte de 3,3 milhões de pessoas por malária (WORLD HEALTH ORGANIZATION, 2013).

A enfermidade está distribuída de forma endêmica nas regiões tropicais e subtropicais do globo, atingindo mais de 21 países do continente americano. Durante o século $X X$, campanhas de controle permitiram uma redução de $50 \%$ dos casos da doença na distribuição global (HAY et al., 2004). De acordo com as últimas estimativas, a mortalidade causada por malária reduziu $42 \%$ em todo o mundo e cerca de $49 \%$ na região da África entre 2000 e 2012. No mesmo período, a incidência da doença diminuiu $25 \%$ no mundo e $31 \%$ na região africana. Isso se deveu principalmente ao maior controle do vetor, melhora no diagnóstico e no tratamento da doença. No entanto estima-se que 3,4 bilhões de pessoas estavam sob risco de contrair malária em 2012, desse total 2,2 bilhões estavam sob baixo risco ( $<1$ caso reportado em 1000), dos quais $94 \%$ são de outras regiões que não a África. Os 1,2 bilhões em alto risco ( $>1$ caso reportado em 1000) foram reportados em sua maioria na África (47\%) e no Sudeste Asiático $(37 \%)$. Atualmente as regiões endêmicas estão classificadas segundo à Organização Mundial da Saúde entre áreas de controle e de prevenção da reintrodução da doença (Figura 1), desde 2000 os países vem declarando seus diferentes estágios de eliminação (WHO, 2013).

A malária humana é causada por cinco espécies do parasito do gênero Plasmodium: P. falciparum, P. vivax, P. ovale, P. malariae e P. knowlesi. Desses, P. falciparum e P. vivax são as espécies mais importantes em termos epidemiológicos (WHO, 2013). A espécie que mais causa mortes é $P$. falciparum mas a que está mais amplamente distribuída é $P$. vivax. Quatro países são responsáveis por mais de $80 \%$ dos casos de malária vivax (Etiópia, Índia, Indonésia e Paquistão). Esta espécie vem sendo associada à malária grave e morte. Isso se deve principalmente à associação com outros fatores como a presença de comorbidades (por exemplo a desnutrição).

No Brasil, a incidência anual de malária teve um aumento de aproximadamente dez vezes entre 1970 e 1985, sendo que na década subsequente houve uma estabilização desta em 
Figura 1 - Classificação de países em estágio de eliminação da malária, desde dezembro de 2012.

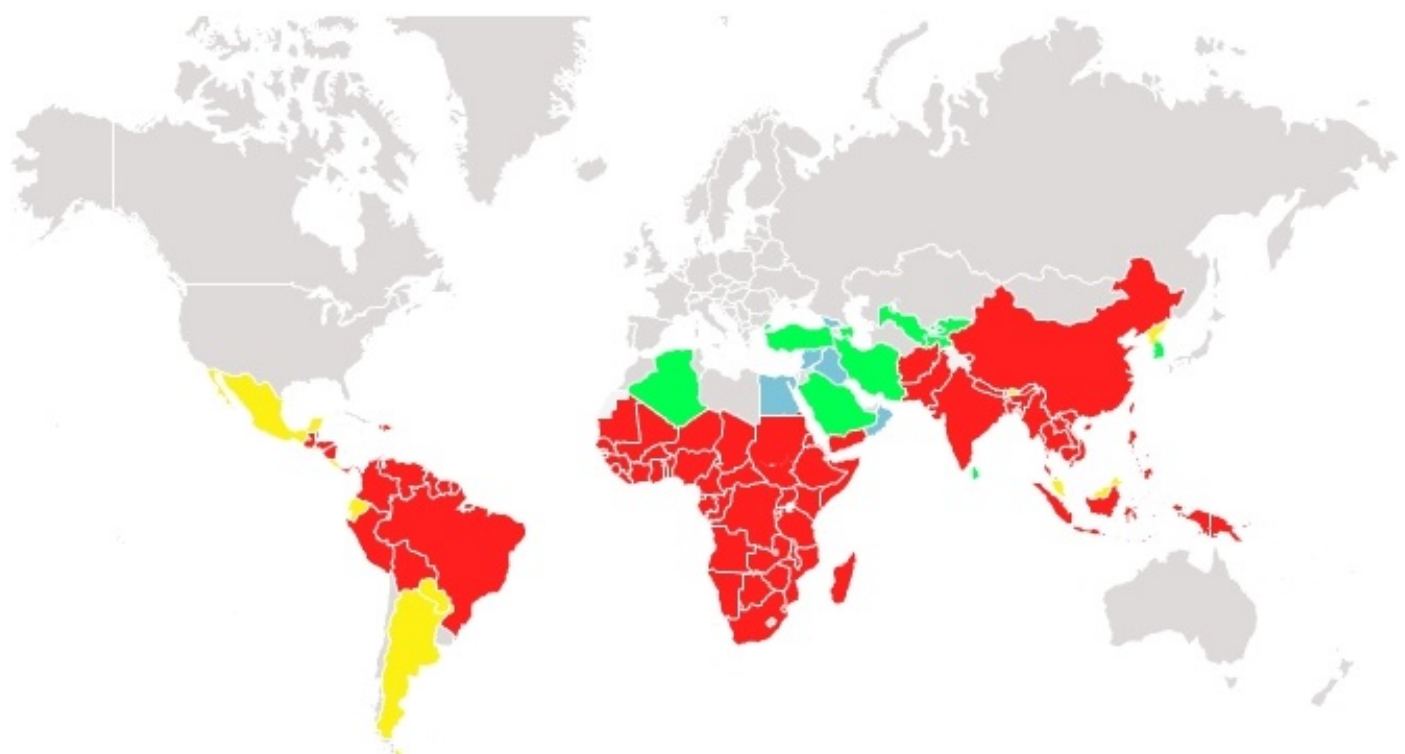

Estágio de controle do país

- Controle

Pré-eliminação

Eliminação

Prevenção de reintrodução

FONTE: (WHO, 2013)

torno de 500.000 casos anuais (LOIOLA; SILVA; TAUIL, 2002). No entanto, foram registrados 636.000 casos clínicos confirmados de malária em 1999, 600.000 em 2005 e 458.042 em 2007, indicando uma flutuação diversificada de novos casos a cada ano. Em 2010, 306.908 casos de malaria foram registrados (PEREIRA; ISHIKAWA; FONTES, 2011), sendo que a maioria desses (99,7\%) ocorreram só na Região Amazônica (OLIVEIRA-FERREIRA et al., 2010).

O atual quadro de incidência de malária deve-se, entre outros fatores, às características ambientais dessas regiões que favorecem o ciclo de vida do agente etiológico desta doença. A transmissão das formas infectantes de Plasmodium é realizada pela fêmea do mosquito do gênero Anopheles, sendo que no Brasil o Anopheles darlingi é a espécie mais importante na transmissão da doença (SINKA et al., 2010).

Ao longo do tempo observou-se também uma clara mudança na distribuição das espécies de plasmódios que causam malária no Brasil. Em meados da década de 1980 (LOIOLA; SILVA; TAUIL, 2002) as infecções por $P$. falciparum e $P$. vivax eram igualmente prevalentes (Figura 2), mas em 2010, dos casos de malária notificados $85 \%$ deviam-se a $P$. vivax (PEREIRA; ISHIKAWA; FONTES, 2011).

Embora a malária vivax seja classicamente descrita como uma doença benigna, raramente 
Figura 2 - Registro de casos de malária e espécies parasitárias ( $P$. falciparum e $P$. vivax), Brasil, 1959-2012.

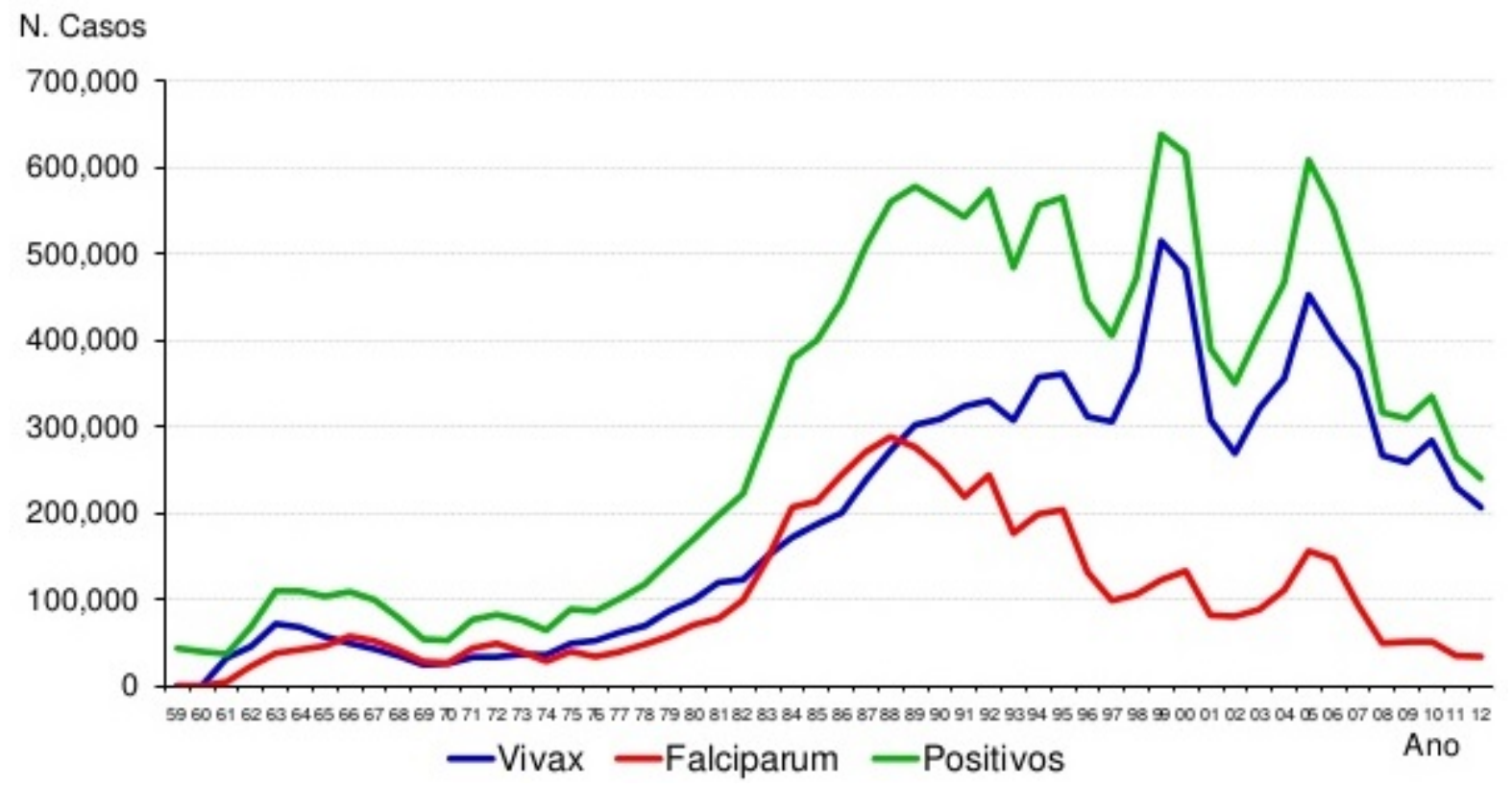

FONTE: SISMAL e SIVEP-Malária

fatal e de tratamento relativamente simples, apresenta resistência à cloroquina, sugerindo a aquisição de novas características fenotípicas por parasitos de diferentes regiões geográficas gerando casos graves (PRICE; DOUGLAS; ANSTEY, 2009). No Brasil, tanto a ocorrência de resistência à cloroquina (MARQUES et al., 2014; SANTANA-FILHO et al., 2007) como a de doença grave (ANDRADE et al., 2010; ANSTEY et al., 2012; MARTINS et al., 2014; RAPOSO et al., 2013) estão bem caracterizadas.

\subsection{Estrutura populacional e diversidade genética dos plasmódios}

Para compreender a origem e dispersão de fenótipos de interesse, como a virulência e a resistência a novos fármacos, é essencial o auxílio de estudos de genética de populações (ZILVERSMIT; HARTL, 2005). Os conhecimentos atuais sobre a biologia populacional do parasito são ainda muito limitados e não permitem prever padrões de emergência e dispersão dos diferentes fenótipos. Discussões sobre a estrutura populacional de patógenos geralmente giram em torno da clonalidade e da sexualidade dos mesmos (TIBAYRENC; AYALA, 2014).

Além disso, não se conhece a contribuição relativa de mecanismos dependentes de seleção natural e de processos evolutivamente neutros (como a deriva gênica ou a migração), tanto para a dispersão espacial quanto para a dinâmica temporal de polimorfismos com relevância clínica ou, em maior escala, para a saúde pública. 
Os MSATs são regiões de DNA que contêm repetições em série de motivos (conservados ou degenerados) de um a seis nucleotídeos. Eles representam regiões instáveis do genoma, ou seja, regiões com frequência de mutação e recombinação muito maior que as observada nas sequências de cópia única. Esta instabilidade dos MSATs resulta em marcadores altamente polimórficos. Os alelos diferem principalmente no número de repetições em série, devido a crossing over desigual, durante a meiose, ou ao deslizamento da DNA polimerase, durante a replicação do DNA.

Em estudo realizado utilizando sequenciamento Neafsey et al. (2012) comparou o genoma de cepas de $P$. vivax, de diferentes localidades, e de $P$. falciparum. Dentre os genomas analisados estavam presentes os das cepas de referência de cada espécie, Salvador I ( $P$. vivax e 3D7 ( $P$. falciparum). Eles observaram uma quantidade de SNP (single-nucleotide polymorphisms) duas vezes maior em $P$. vivax que em $P$. falciparum. Eles observaram também maior diversidade em $P$. vivax mesmo em genes ortólogos aos de $P$. falciparum além de uma diversidade em loci de microssatélites também maior em $P$. vivax.

Comparados aos SNP os microssatélites têm potencial polimórfico superior. Os microssatélites são amplamente utilizados em estudos de genética de populações de Plasmodium devido à sua neutralidade neutralidade em termos evolutivos, seu alto grau de polimorfismo (ANDERSON et al., 1999; POLLEY; CHOKEJINDACHAI; CONWAY, 2003) e sua onipresença em todos os genomas. Na maioria dos estudos, os microssatélites são selecionados pelo fato de serem altamente polimórficos. No entanto, sabe-se que o potencial polimórfico de cada marcador pode variar bastante, o que altera radicalmente como a diversidade é representada no genoma de um marcador para o outro (CROZIER et al., 1999; ELLEGREN, 2004; PRIMMER et al., 1996). Um bom painel de marcadores pode descrever a estrutura da população e da multiplicidade de infecção. Ele ainda pode investigar a associação entre nível de diversidade e endemicidade (BACHTROG et al., 2000; ECKERT; MOWERY; HILE, 2002; ECKERT; YAN; HILE, 2002; KELKAR et al., 2008; PEARSON; EDAMURA; CLEARY, 2005; RUSSELL; SUWANARUSK; LEK-UTHAI, 2006; WEBSTER; SMITH; ELLEGREN, 2002; XU et al., 2000). $\mathrm{O}$ segundo benefício derivado do uso de um painel padronizado é a capacidade de comparar parâmetros populacionais, como a diversidade e estrutura entre as regiões globais, o que é uma premissa básica de estudos de genética de populações (SUTTON, 2013).

O genoma de $P$. falciparum é rico em $A / T$ e predominam as repetições de tipo (AT)n, (TAA)n e poli-A/T.Em média, encontra-se um MSAT a cada 1.000 pares de bases (pb) com distribuição heterogênea ao longo do genoma, totalizando 507 marcadores (SU; WELLEMS, 1996). Em comparação, o genoma de $P$. vivax apresenta uma baixa abundância de MSATs, cerca de 160 MSATs identificados, sendo que a maioria deles é do tipo trinucleotídeo, com aproximadamente 19 unidades repetitivas por marcador e com conteúdo médio de 27,5G/C (CARLTON et al., 2008; FENG et al., 2003). No genoma de $P$. vivax também são abundantes as repetições polimórficas em série, com frequência de aproximadamente uma a cada três quilo 
pares de bases (kb - kilobase pairs) (FENG et al., 2003).

O principal obstáculo para o estudo da estrutura populacional de $P$. vivax foi, até recentemente, a falta de marcadores genéticos adequados para uso em larga escala. Os polimorfismos mais estudados em $P$. vivax ocorrem em genes que codificam antígenos, que podem ser informativos sobre o grau de variação intraespecífica, mas têm a desvantagem de estarem sob pressão seletiva.

A seleção natural produz um padrão de diversificação nestes genes que não reflete necessariamente o que ocorre no genoma do parasito como um todo. Como primeiro passo para superar este obstáculo e ampliar o conjunto de marcadores genéticos em $P$. vivax, foram descritas sequências de DNA minissatélite (unidades de 7 a 50 nucleotídeos) (FENG et al., 2003) e de MSAT (GOMEZ et al., 2003; IMWONG et al., 2006; KARUNAWEERA et al., 2007; LECLERC et al., 2004). Estes e outros autores vêm discutindo o verdadeiro grau de diversidade alélica apresentada por estes marcadores.

O primeiro MSAT em P. vivax foi descrito por Gomez et al. (2003). Este marcador foi obtido a partir da análise da região subtelomérica de um cromossomo artificial de levedura (YAC - Yeast Artificial Chromosome). A genotipagem deste MSAT em 89 amostras de Papua Nova Guiné (PNG) revelou uma população de $P$. vivax muito diversa. Em contraste com estes resultados Leclerc et al. (2004) selecionaram 13 candidatos de MSATs a partir de uma biblioteca de DNA enriquecida em sequências repetitivas.

Com este conjunto de marcadores, avaliaram a diversidade de 108 isolados de $P$. vivax representando diferentes regiões do mundo. Surpreendentemente, nove dos marcadores foram monomórficos e, dos quatro loci restantes, só um deles foi extensamente polimórfico. Estes achados sugeriram, inicialmente, que os MSATs de $P$. vivax além de pouco abundantes (CARLTON, 2003) eram pouco polimórficos.

Estudos recentes com novos marcadores, no entanto, vêm revelando o extenso polimorfismo de $P$. vivax em diferentes regiões. Imwong et al. (2006) descreveram 11 marcadores de MSATs através dos dados não publicados do genoma de $P$. vivax. A genotipagem de 83 amostras da Ásia e da América do Sul revelou altos índices de diversidade nesta espécie, confirmando os achados preliminares de Gomez et al. (2003).

Este trabalho atribui a ausência de diversidade observada em $P$. vivax por Leclerc et al. (2004) ao uso de marcadores inadequados. Imwong et al. (2006) discutem a importância do número de repetições nos MSATs: no trabalho de Leclerc et al. (2004) a média de unidades repetitivas nos MSATs foi de 5,5 em contraste com a média de 16 unidades encontrada por Imwong et al. (2006). O número de unidades repetitivas marca a diferença do marcador pelo simples fato de que havendo mais unidades repetitivas, os erros na replicação são mais frequentes e assim o marcador é mais polimórfico.

A alta diversidade observada por Imwong et al. (2006) foi corroborada por um trabalho 
do nosso laboratório (FERREIRA et al., 2007). Através de um conjunto de 14 MSATs de tri e tetranucleotídeos, os autores analisaram a estrutura populacional de 74 isolados de $P$. vivax coletados durante uma coorte prospectiva na Amazônia rural. Esta análise revelou que esta população de parasitas é extremadamente diversa, apresenta uma alta porcentagem de infecções geneticamente mistas e um forte desequilíbrio de ligação.

A partir destes trabalhos iniciais, outros autores têm descrito o extenso polimorfismo destes parasitos na Ásia e África (EEDE et al., 2010b; GUNAWARDENA et al., 2010; KARUNAWEERA et al., 2007). Estes trabalhos também têm realizado contribuições importantes para o entendimento da estrutura populacional de $P$. vivax. Karunaweera et al. (2007) através do conjunto de 14 marcadores já descritos analisou a estrutura populacional de 164 isolados de $P$. vivax representando quatro continentes diferentes. Os achados deste trabalho demonstraram que a alta diversidade desta espécie, o alto número infecções geneticamente mistas e a existência de desequilíbrio de ligação não se restringem às populações de $P$. vivax da Amazônia brasileira, mas também são comuns em populações asiáticas.

A análise da estrutura populacional destas amostras não revelou uma clara estruturação geográfica dos isolados, à diferença do que acontece com $P$. falciparum (ANDERSON et al., 2005). Em um trabalho recente envolvendo a genotipagem de 425 isolados de $P$. vivax de Sri Lanka, Mianmar e Etiópia usaram o conjunto de marcadores de MSAT previamente descrito por Karunaweera et al. (2007). Gunawardena et al. (2010) demonstraram que estes marcadores são uma ferramenta eficaz para mapear os isolados segundo sua ancestralidade e origem continental.

Sutton (2013) analisou uma série de marcadores microssatélite de $P$. vivax e avaliou estatisticamente a qualidade daqueles que estão atualmente em uso, gerando um painel refinado de 18 marcadores (nove de alta prioridade) distribuídos em nove cromossomos. Os marcadores descritos foram considerados ideais para o estudo da diversidade da população, à medida que descreve de forma confiável a estrutura global da população, como uma função de endemicidade, enquanto que também apresenta uma elevada variação polimórfica. Dentre os marcadores avaliados no estudo estão presentes todos os 14 microssatélites utilizados para avaliar a diversidade genética da população de plasmódios do Remansinho.

Além dos microssatélites outros marcadores vem sendo utilizados para o estudo de genética de populações de $P$. vivax tais como os genes que codificam a proteína de superfície de merozoíto $(m s p)$, o antígeno gametocítico (gam-1) e a proteína que se liga ao Duffy. Estudos vem demonstrando que a msp1 revelou ser um marcador bastante polimórfico. O gene de msp1 contém uma série de regiões conservadas e variáveis (PUTAPORNTIP et al., 2002), duas regiões vem sendo estudadas mais especificamente, msp1F1 emsp1F3 e são aquelas consideradas mais polimórficas (IMWONG et al., 2005).

O marcador msp1F3 é formado por unidades repetidivas trinucleotídicas ao longo da sequência e vem sendo utilizado no estudo de genética de populações de $P$. vivax em Papua 
Nova Guiné principalmente associado ao MS16 (KOEPFLI et al., 2011).

\subsection{Estudos prévios na Amazônia}

Ao longo dos anos os estudos realizados na Região Amazônica brasileira sobre a estrutura populacional e a dinâmica de transmissão de populações geneticamente distintas de $P$. vivax (FERREIRA et al., 2007; ORJUELA-SÁNCHEZ et al., 2009) mostraram: (a) grande diversidade genética evidenciada com o uso de MSATs; (b) elevado nível de desequilíbrio de ligação entre alelos de loci situados em cromossomos distintos; (c) elevada proporção de infecções geneticamente mistas (coexistência de mais de um clone infectando o mesmo indivíduo); (d) grande variação de haplótipos recuperados de infecções contraídas em uma mesma área ao longo do tempo.

Apesar de ser considerada uma região de baixa transmissão de malária há uma alta multiplicidade de clones de $P$. vivax (12 infecções de múltiplos clones de 25 isolados) na amazônia brasileira quando comparada a $P$. falciparum (6 infecções de múltiplos clones de 34 isolados), verificada através de genotipagem por microssatélite (FERREIRA et al., 2007).

Com estes estudos também foi realizada a tipagem de 14 marcadores de DNA microssatélite em 99 isolados de $P$. vivax obtidos de uma coorte de pacientes (77 amostras durante a infecção primária e 22 durante recorrências parasitárias em 18 pacientes). O objetivo era avaliar se essas recorrências parasitárias se deviam a parasitos geneticamente idênticos. O estudo revelou uma população de parasitos extremamente diversa, com heterozigosidade virtual, ou esperada, $\left(H_{E}\right)$ variando entre 0,868 e 0,475 entre os marcadores (média, 0,715), e grande proporção $(42,4 \%)$ de infecções envolvendo mais de um haplótipo.

Um total de 98 haplótipos foram identificados na população, sendo somente um deles compartilhado por mais de um isolado. A tipagem molecular completa de 21 infecções recorrentes observadas em 16 indivíduos da coorte revelou somente três exemplos de haplótipos semelhantes, ainda que não idênticos, aos encontrados na infecção primária. Esses dados sugerem que a grande maioria das recidivas parasitárias observadas nessa coorte não se devem a recrudescências ou a recaídas de clones originalmente presentes na infecção primária (ORJUELA-SÁNCHEZ et al., 2009).

Em estudos realizados entre 2004 e 2005 na região do Granada verificou-se que há um nível de desequilíbrio de ligação elevado entre os marcadores de $P$. vivax e que este permaneceu significante em estudos subsequentes na região. Isto sugere que este desequilíbrio observado entre os marcadores não resulta da propagação epidêmica de alguns clones, mas dos baixos níveis de recombinação meiótica prevalentes em áreas com baixas taxas endêmicas de malária.

Além disso, os estudos na região do Granada revelaram que, em comparação com $P$. falciparum, há mais infecções de múltiplos clones por $P$. vivax e ainda maior número de 
alelos por lócus e baixo $H_{E}$. Assim, a Região Amazônica brasileira é uma fonte rica de estudo populacional de $P$. vivax que ainda pode ser explorada e esclarecer muitas dúvidas.

Estrutura populacional de $P$. vivax também foi determinada por genotipagem de 16 microssatélites no Peru. Neste estudo foram utilizadas 159 amostras de sangue coletadas em quatro locais ao redor da cidade de lquitos. A proporção de infecções multiclonais variaram substancialmente entre os locais $(11 \%$ - $70 \%)$, com a heterozigosidade esperada variando entre 0,44 e 0,69; haplótipos não foram compartilhados entre as diferentes populações. Desequilíbrio de ligação estava presente em todas as populações. Foi encontrada uma forte diferenciação de população, com base em análise bayesiana (EEDE et al., 2010a).

Os microssatélites também foram usados para estudar a estrutura genética de populações de $P$. vivax da Venezuela. O estudo foi realizado em uma área de baixa transmissão, que oferece um bom modelo para entender melhor os problemas associados com a vigilância na fase final de eliminação da malária. Foram analisadas amostras coletadas em Tumeremo, Venezuela, entre Março de 2003 e Novembro de 2004. As amostras foram analisadas por um conjunto de 25 microssatélites. Uma complexa dinâmica temporal foi encontrada. Essa dinâmica pode ter sido afetada pelo número e pelo tipo de microssatélite necessário para a identificação de parasitos individuais ou grupos de parasitas ao realizar estudos transversais (CHENET et al., 2012).

\subsection{Explorando as lacunas}

Neste trabalho, objetivamos explorar algumas lacunas que persistem em nosso conhecimento sobre a estrutura populacional e a diversidade genética de $P$. vivax na Amazônia brasileira, com base em um seguimento de três anos (2010-2013) de uma coorte rural no sul do estado do Amazonas.

Um dos principais objetivos foi determinar o papel da flutuação temporal de incidência de malária nos níveis de diversidade genética de $P$. vivax. Reduções drásticas da transmissão da malária podem resultar em um efeito de gargalo de garrafa (bottleneck) populacional, com consequente contração do tamanho efetivo populacional e queda da diversidade genética dos parasitos (NKHOMA et al., 2013). Em nossa coorte populacional, observamos desde 2010 uma redução expressiva na prevalência de malária estimada em seis inquéritos transversais consecutivos. Assim, um importante objetivofoi determinar se essa redução teve algum impacto na estrutura populacional e diversidade da população de parasitos.

Um segundo objetivo e importante ponto de discussão se deve à dinâmica espacial e temporal de diferentes haplótipos de $P$. vivax durante a fase inicial de ocupação de uma assentamento agrícola situado na Região Amazônica brasileira. Objetivou-se também avaliar se o padrão de grande renovação de haplótipos de $P$. vivax ao longo do tempo, observado em estudos prévios em comunidades rurais do Acre (FERREIRA et al., 2007; ORJUELA-SÁNCHEZ 
et al., 2009), é também observado em uma comunidade rural relativamente isolada em que os indivíduos estão expostos a muitas infecções recorrentes.

Um terceiro objetivo refere-se à ocorrência de infecções assintomáticas em nossa coorte. O interesse neste tema foi revigorado desde a publicação do relato de infecções assintomáticas frequentes em populações ribeirinhas do estado de Rondônia (ALVES et al., 2002). Populações expostas a níveis relativamente baixos de transmissão de malária, quando comparados ao padrão da África subsaariana, que parecem capazes de adquirir imunidade clínica que as protege dos sintomas da malária, ainda que não necessariamente lhes permita eliminar os parasitos. Resta determinar que fatores demográficos e biológicos favorecem o desenvolvimento de imunidade clínica em populações de áreas hipoendêmicas. Por outro lado, as infecções assintomáticas servem como reservatório para a malária humana, inacessível às medidas de controle focadas no diagnóstico e tratamento precoces de infecções sintomáticas.

Além disso, uma das lacunas existentes em relação às infecções assintomáticas referese à complexidade de infecções observadas nesses pacientes. Em modelos experimentais, há evidências a favor da hipótese de que a coexistência de múltiplos clones em uma mesma infecção favoreceria a competição intra-específica, com predomínio de clones de maior virulência (BELL et al., 2006; ROODE et al., 2005). Não se sabe, entretanto, se esse fenômeno ocorreria em infecções humanas. Portanto, comparar os níveis de complexidade de infecção (coexistência de genótipos distintos em um mesmo indivíduo) em infecções assintomáticas e sintomáticas diagnosticadas na mesma população permitiria testar a hipótese de que a competição intraespecífica poderia estar associada ao risco de infecções com clones mais virulentos e, portanto, mais propensos a causarem sintomas.

Procuramos investigar a dinâmica de transmissão de cepas de $P$. vivax geneticamente distintas através da genotipagem dos parasitos recuperados de portadores assintomáticos bem como de amostras de $P$. vivax provenientes de episódios de malária. Estes dados puderam fornecer estimativas das taxas nas quais novos haplótipos emergem e se propagam nas populações locais de P. vivax. 


\section{MATERIAL E MÉTODOS}

\section{1 Área de estudo}

A população de estudo é formada pelos habitantes do assentamento agrícola conhecido como Remansinho (Figura 3), situado a 60 km do distrito de Nova Califórnia (pertencente ao Município de Porto Velho). Remansinho situa-se no extremo oeste do estado de Rondônia e no sul do estado do Amazonas, junto à fronteira com o Acre, a cerca de $120 \mathrm{~km}$ de Acrelândia (sede de município mais próxima).

Figura 3 - Mapa e imagem de satélite da localização do assentamento agrícola conhecido como Remansinho, Brasil
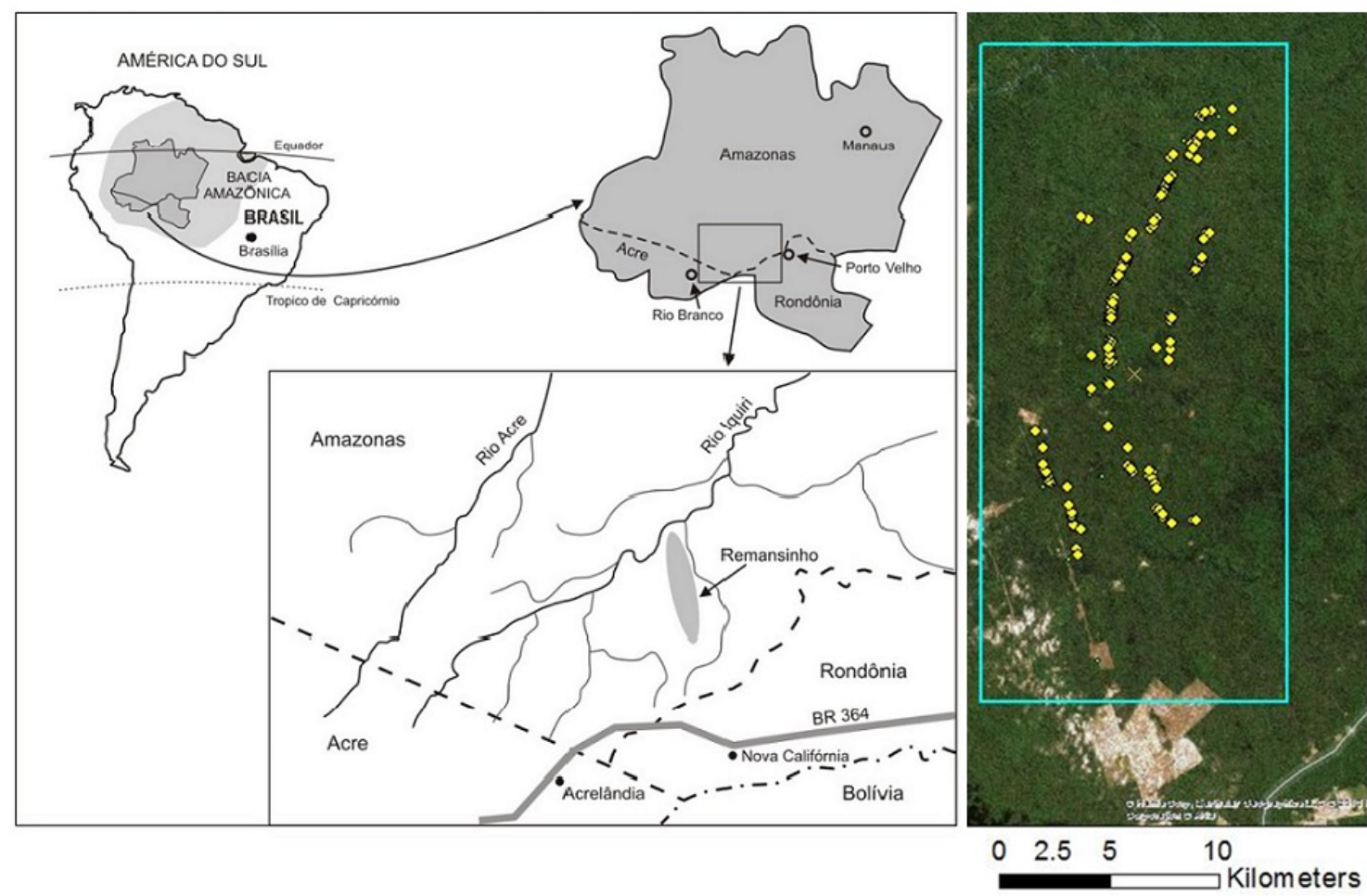

Mapa (esquerda) e imagem de satélite (direita) mostrando a localização do assentamento agrícola Remansinho, sul do estado do Amazonas. O mapa mostra também o mapa do povoado mais próximo, Nova Califórnia (oeste do estado de Rôndonia), a cidade mais próxima é Acrelândia (leste do estado do Acre), onde situa-se o laboratório de campo, e a rodovia interestadual BR-364, que liga os três estados Amazonas, Rondônia e Acre ao restante do país. Os pontos amarelos na imagem de satélite (direita) mostram a localização de cada domicílio participante do estudo determinada por GPS. 
A área estende-se desde as margens da rodovia BR-364, na fronteira entre Rondônia e Acre (a cerca de $60 \mathrm{~km}$ de Acrelândia, o município mais próximo), ao sul, até as margens do Rio lquiri, no estado do Amazonas, ao norte (Figura 3). Essa área compreende zonas de assentamento agrícola ao redor de uma estrada principal chamada Ramal do Remansinho, localizadas aproximadamente a $40 \mathrm{~km}$ da rodovia BR-364, no estado do Amazonas.

Este estudo abrange a população das margens da via principal e de mais quatro vias menores em seu entorno, conhecidas como Ramal dos Goianos, Ramal da Castanheira, Ramal da Linha 1 e Ramal dos Seringueiros (Figura 4).

Figura 4 - Mapa de distribuição dos diferentes ramais onde localizam-se os domicílios no Remansinho, Brasil.

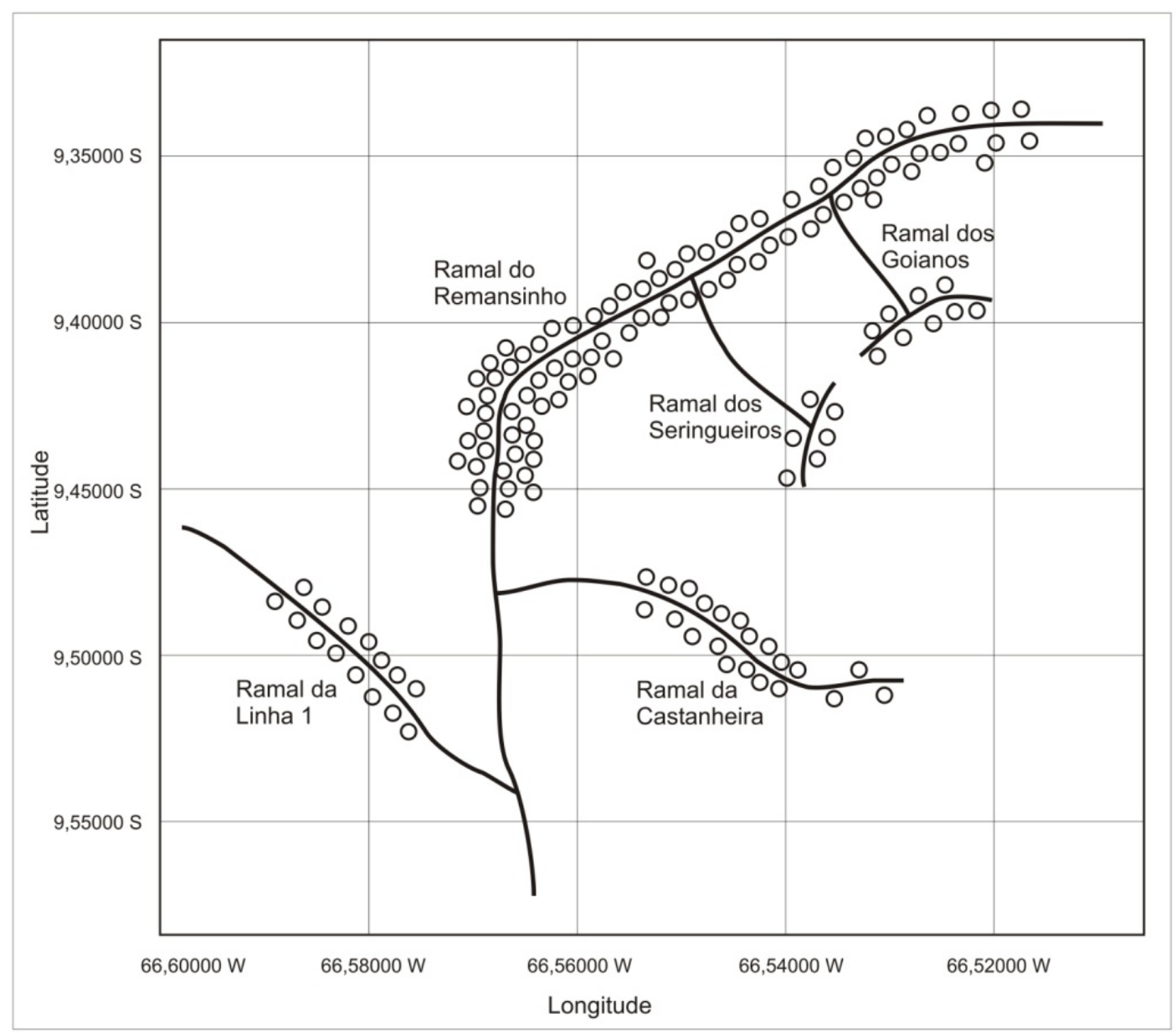

A população ocupa 12 mil hectares da área em questão (INCRA, 2014). Os lotes que foram distribuídos na área estão majoritariamente incluídos em uma área de PDS - Projeto de Desenvolvimento Sustentável, uma forma não-reformadora de distribuição de terras, que visa o reconhecimento de terras e seus beneficiários. 


\subsection{População de estudo}

A população é tipicamente formada por migrantes do centro-sul do país que se estabeleceram nesse assentamento há menos de sete anos, provenientes de outros assentamentos em Rondônia e Mato Grosso. As famílias habitam pequenos lotes agrícolas situados ao longo de $60 \mathrm{~km}$ de uma estrada de terra, originada na rodovia BR-364. Boa parte da população do estudo é composta pelos habitantes do assentamento agrícola denominado Ramal do Remansinho (também conhecido como Seringal Nova Esperança, PDS Gedeão ou Gleba lquiri).

Iniciamos em março de 2010 um estudo de coorte prospectiva, com seguimento clínico epidemiológico para a identificação de episódios incidentes de infecção sintomática, complementado por inquéritos transversais periódicos para o diagnóstico de infecção malárica, envolvendo toda a população de estudo. A linha de base foi estabelecida com o primeiro inquérito transversal (março-abril de 2010), durante o qual foi aplicado um amplo questionário sócio-demográfico e de morbidade pregressa e atual.

Dentre as diversas informações obtidas com o questionário, aquelas relacionadas aos sintomas que os indivíduos apresentaram sete dias antes da coleta sanguínea contribuíram para a análise dos dados. Foram considerados sintomáticos os indivíduos que declararam ter tido um dos seguintes sintomas: febre, calafrios, sudorese, cefaléia, mialgia, artralgia, dor abdominal, náuseas, vômitos, tonturas, tosse, dispnéia e diarréia.

$\mathrm{Na}$ linha de base do estudo, todos os indivíduos com idade superior a três meses de idade foram convidados, independentemente da presença de sintomas, a fornecer uma amostra de sangue (venoso [5 mL] ou capilar) para a realização de microscopia convencional e diagnóstico molecular de malária. Uma alíquota da amostra sanguínea colhida na linha de base foi utilizada para realização de diagnóstico microscópico de malária (no próprio campo), bem como diagnóstico molecular realizado em nosso laboratório em São Paulo. Os portadores de infecção sintomática ou assintomática diagnosticada por microscopia, no campo, foram imediatamente tratados segundo os esquemas terapêuticos preconizados pelo Ministério da Saúde.

Foram realizados inquéritos transversais subsequentes com as mesmas características do primeiro (Corte A; março-maio, 2010): Corte B (maio-julho, 2010); Corte C (março e abril, 2011); Corte D (outubro, 2011); Corte E (abril-maio, 2012), Corte F (outubro-novembro, 2012) e Corte H (abril-maio, 2013).

Os questionários fornecem também o tempo de permanência do indivíduo na Amazônia, isso permite estimar uma relação entre porcentagem de infecções multiclonais e o tempo de exposição do indivíduo, bem como o aparecimento ou não de sintomas.

O estudo na região também revelou que a proporção de malária assintomática encontrada, assim como em outros estudos semelhantes (SILVA-NUNES et al., 2008; SUÁREZ-MUTIS et al., 2007), é um indicativo de que mesmo em populações com níveis variáveis de exposição 
ao longo da vida o desenvolvimento de imunidade adquirida acontece frequentemente. $E$ em áreas hipoendêmicas isso também é possível, como mostrado por Ladeia-Andrade et al. (2009).

\subsection{Amostras de parasitos}

Ao longo de todo o estudo foram recrutados cerca de 190 indivíduos em cada corte transversal. Foram colhidas amostras de sangue venoso das quais 121 foram recuperadas de infecções agudas por $P$. vivax, tanto sintomáticas como assintomáticas, durante o período dos inquéritos realizados entre 2010 e 2013.

\subsection{Seguimento clínico-laboratorial}

\subsubsection{Diagnóstico de malária}

O diagnóstico microscópico de malária na área de estudo vem sendo realizado com o auxílio de lâminas com gotas espessas (coradas com Giemsa) em que pelo menos 100 campos microscópicos de grande aumento foram examinados antes de definir-se o resultado de cada lâmina (TRAPE, 1985).

Amostras sanguíneas de todos os indivíduos analisados nos estudos transversais e no seguimento foram testadas para a presença de DNA de plasmódios humanos e confirmação da presença de Plasmodium vivax. Para aquisição de DNA total das amostras utilizou-se o protocolo de purificação de material genético a partir de amostras sanguíneas QIAamp $\mathbb{R}$ DNA

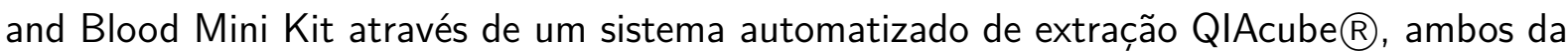

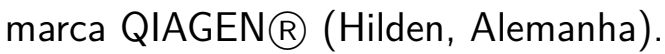

Ao longo dos cortes transversais foi realizado desde 2010 o diagnóstico molecular através do protocolo de reação em cadeia da polimerase em tempo real (qPCR), que tem como o alvo o gene $18 S$ rRNA. A reação tem um volume final de $20 \mu \mathrm{L}$ em que $2 \mu \mathrm{L}$ são de DNA da amostra, $10 \mu \mathrm{L}$ da mistura master Maxima SYBR Green qPCR 2x (Fermentas, Vilnius, Lituânia) e 0,5 $\mu \mathrm{M}$ do primer gênero específico P1 (ACG ATC AGA TAC CGT CGT AAT CTT) combinado com $0,5 \mu \mathrm{M}$ de qualquer um dos primers espécie específicos V1 (CAA TCT AAG AAT AAA CTC CGA AGA GAA A) de Plasmodium vivax ou F2 (CAA TCT AAA AGT CAC CTC GAA AGA TG) de Plasmodium falciparum.

\subsubsection{Tipagem molecular de parasitos}

Para melhorar a qualidade da amostra de DNA extraído e consequentemente o sucesso da tipagem das regiões de microssatélite foi realizada inicialmente uma amplificação do DNA genômico utilizando o kit illustra GenomiPhi HY DNA Amplification Kit (GE Healthcare). Esse procedimento assegurou uma uniformidade das amostras em termos de quantidade de material 
para trabalho e qualidade da fita de DNA gerada pela enzima, com alta fidelidade à original da amostra.

A tipagem molecular das amostras de $P$. vivax foi realizada com 15 marcadores genéticos altamente polimórficos, destes 14 foram marcadores de DNA microssatélite distribuídos em 11 cromossomos diferentes da espécie e um correspondente ao fragmento três da região codificadora da proteína de superfície de merozoíto (msp1F3). As amplificações de 13 dessas 15 regiões foram realizadas através de reação em cadeia da polimerase (PCR), utilizando os oligonucleotídeos iniciadores (primers) relacionados na Tabela 1 e o protocolo de reação descritos por Karunaweera et al. (2007). As amplificações das outras duas regiões, MS16 e msp1F3, foram realizadas utilizando o protocolo de nested PCR, descrito por Koepfli et al. (2011). 
Tabela 1 - Oligonucleotídeos iniciadores para a amplificação de 15 marcadores genéticos específicos para $P$. vivax.

\begin{tabular}{|c|c|c|}
\hline \multicolumn{3}{|c|}{ Marcador Cromossomo Oligonucleotídeo (5' - 3') } \\
\hline \multirow[t]{2}{*}{ MS1 } & 3 & F:6-FAM TCAACTGTTGGAAGGGCAAT \\
\hline & & R:ctgtcttTTGCTGCGTTTTTGTTTCTG \\
\hline \multirow[t]{2}{*}{ MS2 } & 6 & F:VIC GAGCTAGCCAAAGGTTCAACA \\
\hline & & R:ctgtcttTGGGGAGAGACTCCСTTTTC \\
\hline \multirow[t]{2}{*}{ MS3 } & 4 & F:NED GAAGATCCTGTGGAGGAGCA \\
\hline & & R:ctgtcttCTCCTTCGCTCCTTTCСТTT \\
\hline \multirow[t]{2}{*}{ MS4 } & 6 & F:FAM CGATTTACTGTTGACGCTGAA \\
\hline & & R:ctgtcttCAAAGGAACATGCTCGATGA \\
\hline \multirow[t]{2}{*}{ MS5 } & 6 & F:NED CGTCCTCTATCGCGTACACA \\
\hline & & R:ctgtcttAAAGGGAGAGGAGCGAAAAC \\
\hline \multirow[t]{2}{*}{ MS6 } & 11 & F:VIC GGTTCTTCGGTGATCTCTGC \\
\hline & & R:ctgtcttGGAGGACATCAACGGGATT \\
\hline \multirow[t]{2}{*}{ MS7 } & 12 & F:6-FAM TTGCAGAAAATGCAGAGAGC \\
\hline & & R:ctgtcttAGGGTCTTCAGCGTGTTGTT \\
\hline \multirow[t]{2}{*}{ MS8 } & 12 & F:NED AGAGGAGGCAGAAATGCAGA \\
\hline & & R:ctgtcttAGCCCCTTTGCGTTCTTTAT \\
\hline \multirow[t]{2}{*}{ MS9 } & 8 & F:6-FAM AGATGCCTACACGTTGACGA \\
\hline & & ctgtcttGAAGCTGCCCATGTGGTAAT \\
\hline \multirow[t]{2}{*}{ MS10 } & 13 & F:NED TTATCCCTGCTGGATGTGAA \\
\hline & & R:ctgtcttTCCTTCAGGTGGGACTTGTT \\
\hline \multirow[t]{2}{*}{ MS12 } & 5 & F:6-FAM AATGCGCATCCTATGTCTCC \\
\hline & & R:ctgtcttCTGCTGTTGTTGTTGCTGCT \\
\hline \multirow[t]{2}{*}{ MS15 } & 5 & F:6-FAM TGTTTGCAAAGGAATCCACA \\
\hline & & R:ctgtcttCGGCCAGATGAAAAGGATAA \\
\hline \multirow[t]{3}{*}{ MS20 } & 10 & F:VIC GCACAACAAATGCAAGATCC \\
\hline & & R:ctgtcttGTGGCAGTGGCTCATCTTCT \\
\hline & & Oligonucleotídeos aninhados \\
\hline \multirow[t]{4}{*}{ MS16 } & 9 & FP:TTCCTGATGACAATTTCGACGG \\
\hline & & RP:TCTCTTCCCATTTGAGCATCGC \\
\hline & & FN: NED CTTGTTGTGGTTGTTGATGGTG \\
\hline & & RN: AGTACGTCAACCATGTGGGTAG \\
\hline \multirow[t]{4}{*}{$m s p 1 \mathrm{~F} 3$} & 7 & FP:GGAGAACATAAGCTACCTGTCC \\
\hline & & RP:GTTGTTACTTGGTCTTCCTCCC \\
\hline & & FN:6-FAM CAAGCCTACCAAGAATTGATCCCCAA \\
\hline & & RN:ATTACTTTGTCGTAGTCCTCGGCGTAGTCC \\
\hline
\end{tabular}

Para as amostras que apresentaram uma parasitemia de um a 30 parasitos/ $\mu \mathrm{L}$ padronizamos a seguinte condição do ciclo de PCR: desnaturação inicial 2 min a $94{ }^{\circ} \mathrm{C}, 40$ ciclos com desnaturação $30 \mathrm{~s}$ a $94{ }^{\circ} \mathrm{C}$, anelamento $40 \mathrm{~s}$ a $58{ }^{\circ} \mathrm{C}$ e elongação 50 s a $72{ }^{\circ} \mathrm{C}$, e elongação final 5 min a $72{ }^{\circ} \mathrm{C}$. Isso aumentou a quantidade de DNA amplificado disponível e melhorou a capacidade de detecção dos picos de cada fragmento. Para as amostras tipadas com os nested primers não foi necessário a modificação do protocolo de condição do ciclo, pois a técnica é 
extremamente específica mesmo em amotras com baixa parasitemia.

Os fragmentos foram analisados com o uso de um sequenciador automático de DNA ABI3500 (Applied Biosystems, California, Estados Unidos), instalado no Departamento de Parasitologia do Instituto de Ciências Biomédicas da Universidade de São Paulo.

\subsubsection{Análise dos fragmentos de DNA microssatélite}

O programa GeneMapper versão 4.1 (Applied Biosystems) foi utilizado para determinar o tamanho dos fragmentos amplificados em termos de número de pares de bases e de altura dos picos (que corresponde aproximadamente à abundância relativa de parasitos na amostra), parâmetros fundamentais de análise (ANDERSON et al., 1999). Como base para as medições de tamanhos de fragmentos utilizamos o GenScan ABI GS500 ROX (Applied Biosystems).

$\mathrm{Na}$ análise os picos individuais deveriam estar numa altura mínima de fluorescência de 200 e nos isolados cujas amplificações apresentaram mais de um pico detectado consideramos infecção geneticamente mista, isto porque o parasito na fase sanguínea é haplóide, cada pico detectado é corresponde a um clone diferente. Nestes casos, se o pico obtido no segundo alelo teve altura, medida com o programa GeneMapper, correspondente a pelo menos um terço da altura do pico majoritário atribuimos um ou mais haplótipos, correspondentes aos alelos encontrados em cada marcador (ANDERSON et al., 2000).

Diversidade genética

Para avaliar a diversidade genética dessa população de parasitos utilizamos os valores dos cálculos de heterozigosidade esperada, ou virtual, $H_{E}$ e do índice de riqueza genotípica (R). Para ambos consideramos os alelos únicos ou predominantes de cada locus, como descrito por Anderson et al. (2000). Consideramos uma infecção de múltiplos clones (IMC) quando houve a detecção de mais de um alelo em um único locus ou mais nas amostras (ANDERSON et al., 2000). Também consideramos IMC quando houve detecção de mais de um alelo em mais de um loci por amostra (IMC >1) (IMWONG et al., 2007).

A heterozigosidade esperada estima a probabilidade de um alelo escolhido ao acaso na população ser diferente de outro pertecente ao mesmo locus. $O$ cálculo de $H_{E}$ é definido como:

$$
H_{E}=\frac{n}{n-1}\left(1-\sum p i^{2}\right)
$$

, onde $n$ é o número de isolados analisados e pi é a frequência de cada alelo na população, este parâmetro varia entre 0 e 1 , sendo 1 o máximo de diversidade que se pode esperar na população, para o teste da hipótese nula utilizamos a simulação de Monte Carlo. Para o cálculo de $H_{E}$ foi usado o programa LIAN 3.6, desenvolvido por Haubold e Hudson (2000). Na comparação entre cortes utilizamos a média de $H_{E}$ dos diferentes loci encontrados na população. 
O cálculo do índice de riqueza genotípica mede a proporção de haplótipos presentes nas amostras e é estimado como

$$
R=(G-1)-(N-1)
$$

, onde G é o número de haplótipos e N é o número de amostras (DORKEN; ECKERT, 2001; NKHOMA et al., 2013).

Variação genética ao longo do tempo e no espaço

Para identificação dos diferentes haplótipos presentes na população de plasmódio consideramos apenas as amostras que foram completamente tipadas com os 15 marcadores, comparamos a proporção de alelos compartilhados entre eles e assim atribuímos o mesmo haplótipo àqueles cujo compartilhamento foi completo com todos os marcadores.

Utilizamos o programa eBURST v3 (FEIL et al., 2004) para procurar por haplótipos próximos entre si comparando os 15 loci diferentes, aqueles que eram idênticos em pelo menos 13 dos 15 loci foram alocados no mesmo haplogrupo e examinamos a distribuição desses no tempo.

Em seguida utilizamos os programa STRUCTURE 2.3.1 (HUBISZ et al., 2009) para identificar populações $(K)$ de isolados geneticamente relacionados utilizando o modo de análise Bayesiano (FALUSH; STEPHENS; PRITCHARD, 2003; PRITCHARD; STEPHENS; DONNELLY, 2000). Ele fornece os números de $K$ assumindo equilíbrio de Hardy-Weinberg e equilíbrio de ligação dentro das populações e estima a frequência alélica de cada população e de seus membros individualmente. Corremos o programa 10 vezes para cada valor de $K$ que variou entre um e seis, sendo que cada análise envolveu 100.000 interações, com 50.000 ciclos, usando o modelo de frequências de alelos independentes para $K=3$. Para que o isolado fosse alocado em uma determinada população ele deveria ser formado por mais de $70 \%$ do ancestral da mesma.

Após a identificação dos diferentes haplótipos presentes na população fizemos o cálculo da distância genética que é dada por: 1 - (Proporção de alelos compartilhados) com o auxílio do programa MEGA 6 (TAMURA et al., 2013) que fornece uma matriz contendo todas as possíveis combinações de distâncias entre as amostras tipadas em pares e levando em consideração todos os 15 loci.

Com os valores de distância genética testamos a hipótese de haver uma correlação entre estes valores e sua variação no tempo, ou seja, se as distâncias genéticas entre os isolados tendem a aumentar a medida em que a distância entre suas datas de coleta aumentam. Utilizamos o teste de Mantel (MANTEL, 1967), uma matriz de correlação não paramétrica, e a significância do coeficiente de correlação $(r)$ foi testado com 500 permutações usando o pacote ade4 do programa estatístico R v3.0.3 (R-CORE-TEAM, 2013). 
Para testar a hipótese de haver alguma variação da distância genética relacionada ao espaço utilizamos os dados fornecidos pela matriz de distância genética e os dados de distâncias espaciais entre os domicílios dos quais as amostras eram provenientes. Fizemos o teste de correlação com o auxílio do teste de Spearman. Foi estabelecida uma distância linear entre os domicílios com base nos dados fornecidos pelas coordenadas de GPS colhidas no Remansinho.

De diferentes cortes recuperamos amostras consecutivas de indivíduos com infecção por $P$. vivax, com as quais a partir dos dados de tipagem de microssatélite calculamos a proporção de alelos compartilhados entre eles e estimamos a similaridade genética.

Desequilíbrio de Ligação

Avaliamos os diferentes loci distribuídos em diferentes cromossomos do parasito quanto ao desequilíbrio de ligação $(\mathrm{DL})$ utilizando o cálculo do índice de associação padrão $I_{A}^{S}$. Este teste compara a variância $\left(V_{D}\right)$ do número de alelos que podem ser encontrados entre todos os pares de haplótipos de uma população $(D)$ e a variância experada $\left(V_{E}\right)$ de uma associação rândomica de alelos, é definido como:

$$
I_{A}^{S}=\frac{V_{D}}{V_{E}-1}(r-1)
$$

,onde $r$ é o número de loci analisados. Os cálculos foram feitos com o auxílio do programa LIAN 3.6.

Tamanho da população

Avaliamos também em que proporção os alelos mais raros estão distribuídos na população, através do cálculo da frequência alélica realizado no programa SPSS 16.0 - Statistical Package for the Social Sciences - (SPSS Inc., Chicago, Illinois, Estados Unidos), o gráfico com as proporções é uma forma qualitativa de avaliar se houve perda de alelos raros na população. Os dados representam a combinação entre todos os loci analisados. Em populações que tenham sofrido uma recente redução do seu tamanho efetivo exibem também uma redução no número de alelos e na heterozigosidade de loci polimórficos. A distribuição das frequências alélicas em um formato de $L$ é esperado em populações que não estejam sofrendo bottleneck (efeito de gargalo de garrafa) (LUIKART et al., 1998). Utilizamos o teste do $\chi^{2}$ para comparar as proporções de alelos raros de $P$. vivax (frequência $<5 \%$ ) entre Granada, outro assentamento agrícola próximo ao Remansinho (SILVA-NUNES et al., 2008).

Outro método de análise que usamos para avaliar o tamanho da população de estudo foi o cálculo de M-ratio (GARZA; WILLIAMSON, 2001). O teste leva em consideração os diferentes alelos possíveis de serem encontrados em cada locus e estima a quantidade encontrada na população de estudo, partindo da premissa de que se uma população está sob pressão seletiva 
há pouca variabilidade alélica. $\mathrm{O}$ valor de $M$-ratio é dado por:

$$
M-\text { ratio }=\frac{k}{r}
$$

, onde $k$ é o número de alelos encontrados e $r$ é o número de alelos possíveis de serem encontrados na população de estudo.

Análises de sintomas

Em nosso estudo avaliamos também a proporção de indivíduos sintomáticos e assintomáticos recuperada de infecções com diferentes parasitemias. Avaliamos também a proporção de infecções mistas com os dados de cada marcador tipado, se ao menos um marcador apresentasse mais de um alelo tipado consideramos esta uma infecção geneticamente mista. Além disso, avaliamos a proporção de infecções mistas recuperadas a partir de mais de um marcador com mais de um alelo. Essas análises foram realizadas no programa SPSS 16.0.

\subsubsection{Sequenciamento das regiões de microssatélite}

Para avaliar melhor como ocorre a inserção e deleção de motivos repetitivos dos microssatélites utilizados no estudo fizemos o sequenciamento dessas regiões. O principal objetivo era saber se naqueles microssatélites cujos motivos repetitivos são muito degenerados ocorre inserção ou deleção de blocos formados por mais de três ou quatro bases. As amostras selecionadas para o sequenciamento deveriam conter apenas um clone de $P$. vivax presente, isso foi verificado a partir das análises de microssatélite que garantiram uma amplificação e leitura específica.

Utilizamos o protocolo de sequenciamento já publicado (KARUNAWEERA et al., 2007) para leitura de regiões com tamanhos entre 100 a 400 pares de bases (pb), que é a variação de tamanho dos fragmentos dos 14 marcadores microssatélite utilizados no nosso estudo.

O produto contendo as sequências passou por um processo de precipitação utilizando Isopropanol em diferentes concentrações, garantindo uma melhor qualidade de leitura da fita de DNA, e em seguida foram levadas ao sequenciador ABI3500.

\subsubsection{Análises dos dados de sequenciamento}

As sequências obtidas a partir das amplificações utilizando os primers forward e reverse foram analisadas inicialmente no programa BioEdit (HALL, 2000) e transformadas em formato FASTA, em seguida essas sequências foram alinhadas no programa ClustalX2 (LARKIN et al., 2007) e analisadas quanto às regiões repetitivas.

As sequências desses amplicons foram comparadas àquelas publicadas por Karunaweera et al. (2007) para valiar o modo de inserção e deleção das sequências repetitivas com motivos de 
tri e tetranucleotídeos das amostras provenientes do Sri Lanka (número de acesso das sequências depositadas no GenBank: DQ676626-DQ676681). As sequências também foram classificadas segundo o tipo de arranjo dos motivos repetitivos em perfeito, composto, interrompido ou complexo (SUTTON, 2013).

\subsubsection{Aspectos éticos}

Os protocolos de estudo foram aprovados pelo Conselho do Hospital Universitário da Universidade de São Paulo (1025/10) e pelo Comitê de Ética em Pesquisa com Seres Humanos do Ministério da Saúde (551/2010). O projeto e os termos de consentimento foram aprovados também pelo Comitê de Ética em Pesquisas com Seres Humanos do ICB/USP de acordo com a resolução 96/06 do Conselho Nacional da Saúde. 


\section{RESULTADOS}

\subsection{Incidência de malária e diversidade genética de Plasmodium vivax}

Entre março de 2010 e outubro de 2013, foram diagnosticados por microscopia 529 casos de infecção por $P$. vivax e dois por $P$. falciparum tanto por busca passiva quanto ativa de indivíduos com malária (6966 casos/pessoas-mês do seguimento). A Figura 5 mostra a incidência de malária clínica por mês durante o período do estudo. Observamos um surto de malária ocasionada por P. vivax em outubro de 2012, com 0,4 casos/pessoas-mês, seguido por queda na transmissão bastante significativa e que se manteve até o fim do estudo. 
Figura 5 - Incidência de malária e número de amostras tipadas com Plasmodium vivax, Remansinho, Brasil (2010-13)

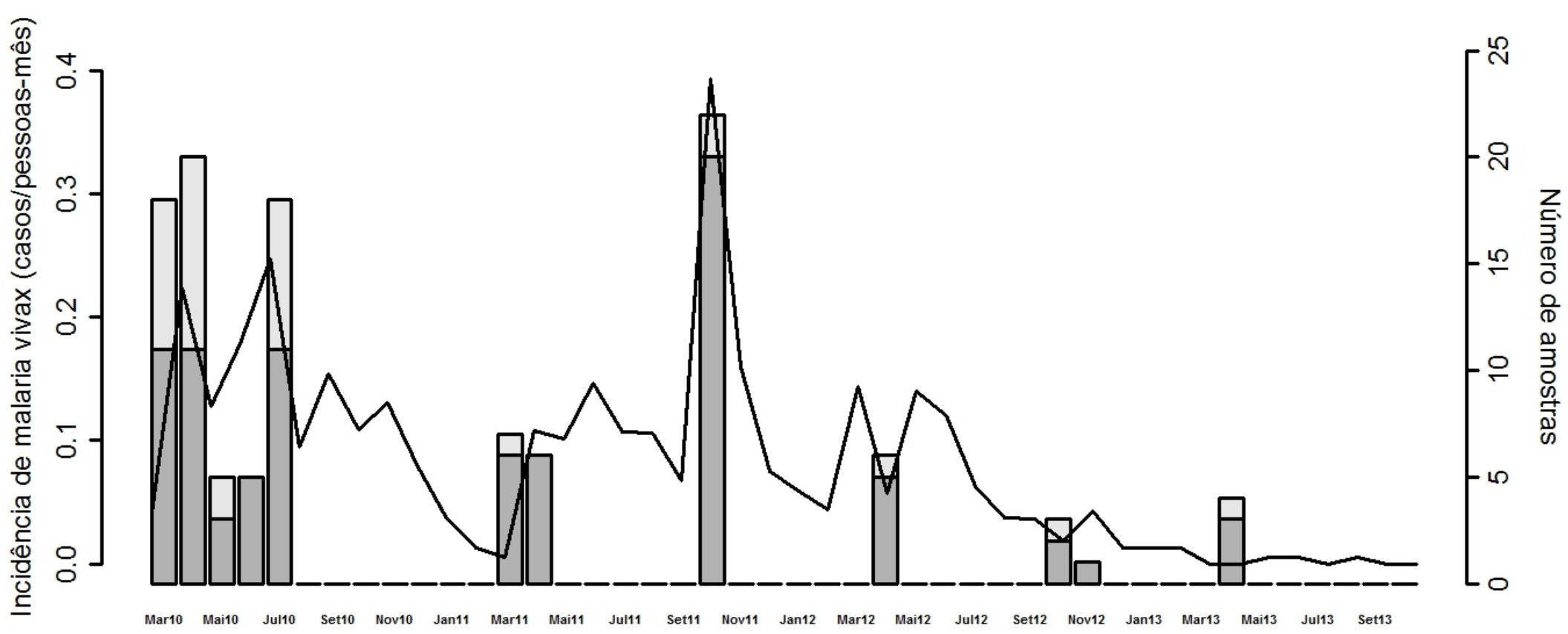

Incidência de malária vivax, calculada com base nos registros de exames de microscopia realizados no Remansinho entre março de 2010 e outubro de 2013 (linha contínua, valores representados no eixo $\mathrm{Y}$ à esquerada do gráfico), e número de amostras de Plasmodium vivax colhidas durante os cortes realizados na área (barras, valores representados no eixo $\mathrm{Y}$ à direita do gráfico). As barras em cinza escuro representam as amostras que foram completamente tipadas com 15 marcadores moleculares, enquanto que as barras em cinca claro representam o número de amostras que foram parcialmente tipadas com 10 - 14 desses marcadores. 
Obtivemos um total de 116 amostras de DNA de $P$. vivax confirmadas por qPCR diagnosticadas durante os cortes transversais, destas, 84 amostras de DNA (72,4\%) foram tipadas completamente pelos 15 marcadores moleculares utilizados no estudo, enquanto que $32(27,6 \%)$ foram tipadas com 10-14 marcadores (Figura 5). Em nossas análises consideramos apenas os dados de isolados completamente tipados, exceto naquela em que comparamos isolados diferentes do mesmo indivíduo em infecções consecutivas, em que consideramos as amostras completamente e parcialmente tipadas.

Dos isolados completamente tipados em nosso estudo $42,9 \%$ eram provenientes de indivíduos sintomáticos, ou seja, que declararam ter tido algum dos 13 sintomas relacionados à malária sete dias antes da data de coleta da amostra, e 57\% eram provenientes de indivíduos assintomáticos, ou seja, que declararam não terem tido nenhum sintoma nos sete dias anteriores à coleta. Essas infecções recuperadas no estudo eram tanto patentes (infecções com número de parasitos suficiente para serem diagnosticadas por microscopia, tivemos $45,23 \%$ ) quanto subpatentes (infecções não diagnosticada por microscopia, tivemos 54,76\%). Das infecções patentes $21(56,75 \%)$ foram de indíviduos que declararam apresentar sintomas nos sete dias anteriores a coleta. Sabe-se que a capacidade de detecção mínima aproximada de parasitos por microlitro detectadas por microscopia é de 20 parasitos por $u \mathrm{~L}$, assim, esses dados nos levaram a investigar se a parasitemia (número de parasitos por microlitro de sangue) estava diretamente relacionada à presença de sintomas; observamos uma correlação linear entre essas duas variáveis $\left(\chi^{2}=9,95\right.$, com um grau de liberdade, $P=0,002$; a parasitemia determinada por qPCR foi estratificada em quartis para essa análise).

Essa população de parasitos apresentou uma diversidade genética moderada, um alto desequilíbrio de ligação $(\mathrm{DL})$ e uma alta proporção de infecções por múltiplos clones (IMC) (Tabela 6). Proporções de IMC similares foram encontradas em infecções consideradas sintomáticas $(80,5 \%)$ e assintomáticas $(72,9 \%)$ usando a correção de Yates $\left(\chi^{2}=0,31\right.$, com um grau de liberdade, $\mathrm{P}=0,58)$. As proporções de IMC $>1$ loci também não variaram significativamente entre as infecções sintomáticas (52,8\%) e assintomáticas (54,2\%) (correção de Yates $\chi^{2}=0,01$, com um grau de liberdade, $\mathrm{P}=0,92$ ). Com esses dados não foi possível encontrar associação entre infecção por múltiplos clones e presença de sintomas relacionados à malária nessa comunidade.

Em seguida decidimos investigar se havia associação entre a idade dos indivíduos (com variação entre dois a 67 anos) e a presença de infecção por múltiplos clones. As proporções de IMC não variaram de acordo com a idade dos indivíduos (Tabela 2), que foi estratificada em quartis $\left(\chi^{2}=0,27\right.$, com três graus de liberdade, $\left.\mathrm{P}=0,65\right)$. Também não houve variação entre as proporções de IMC $>1$ e a idade dos indivíduos $\left(\chi^{2}=0,77\right.$, com três graus de liberdade, $\mathrm{P}=0,49)$.

Sabendo que a idade do indivíduo não influencia o fato de ter infecções com múltiplos clones investigamos se o tempo de permanência na Região Amazônica (que variou de 0,16 a 52 
anos) tinha associação com esse tipo de infecção (Tabela 3). Mais uma vez não encontramos associação entre a proporção de IMC na população e o tempo de permanência dos indivíduos na Região Amazônica ( $\chi^{2}=3,93$, com três graus de liberdade, $\mathrm{P}=1,52$; o tempo de amazônia calculado em anos foi estratificado em quartis). Assim como não houve associação da proporção de IMC $>1$ com o tempo de amazônia $\left(\chi^{2}=1,13\right.$, com três graus de liberdade, $\left.\mathrm{P}=2,37\right)$.

Tabela 2 - Número de infecções multiclonais (IMC) segundo idade dos indivíduos participantes do estudo realizado no Remansinho, Brasil (2010-13).

\begin{tabular}{lccccc}
\hline \multicolumn{5}{c}{ Idade (anos) } \\
\hline \multirow{3}{*}{ IMC } & Sim & $1(2-14)$ & $2(14-26,5)$ & $3(26,5-41)$ & $4(41-67)$ \\
& Não & 6 & 20 & 13 & 12 \\
\multirow{3}{*}{ IMC $>1$} & Sim & 12 & 2 & 8 & 2 \\
& Não & 15 & 14 & 11 & 9 \\
& & & 8 & 10 & 5 \\
\hline
\end{tabular}

Tabela 3 - Número de infecções multiclonais (IMC) segundo tempo de moradia na Amazônia. Remansinho, Brasil (2010-13).

\begin{tabular}{llcccc}
\hline \multicolumn{5}{c}{ Idade (anos) } \\
\hline \multirow{4}{*}{ IMC } & \multicolumn{1}{c}{$1(0,16-6,58)$} & $2(6,58-14)$ & $3(14-24,98)$ & $4(24,98-52)$ \\
& Sim & 14 & 18 & 19 & 13 \\
\multirow{3}{*}{ IMC $>1$} & Não & 5 & 2 & 5 & 5 \\
& Sim & 7 & 14 & 12 & 12 \\
& Não & 12 & 6 & 5 & 6 \\
\hline
\end{tabular}

Dentre todos os isolados analisados no estudo três compartilhavam o mesmo haplótipo. Os isolados foram colhidos no período do corte D realizado em outubro de 2011 , sendo que os outros 81 haplótipos foram recuperados em amostras únicas. Com esses dados classificamos a população de $P$. vivax do Remansinho em haplogrupos (Tabela 4), contendo entre duas a sete amostras cada. Para fazer parte de um haplogrupo, a amostra deveria compartilhar pelo menos 13 alelos com outra amostra do grupo, a classificação em haplogrupos foi realizada com a ajuda do programa eBURST. O maior haplogrupo encontrado na população continha seis amostras, das quais três compreendem o mesmo haplótipo, colhidas em outubro de 2011 e uma amostra colhida em abril de 2012 (corte E). O segundo maior haplogrupo foi composto por três amostras de cortes diferentes $(A, C$ e $G)$ e compartilharam entre si de 13 a 14 alelos. 
Os outros haplogrupos eram formados por pares de amostras que compartilhavam entre si 13 alelos, sendo que um par de amostras era proveniente do corte $C$ e os outros três pares de amostras eram provenientes do corte D. Com esses dados pudemos observar que a maior parte das amostras que formaram os haplogrupos eram provenientes do corte $D$, inclusive aquelas que compartilharam o número máximo de alelos entre si, ou seja, as amostras foram colhidas no período do surto de malária que ocorreu em outubro de 2011. 
Tabela 4 - Haplogrupos formados a partir de haplótipos recuperados de amostras colhidas ao longo dos cortes transversais realizados na região do Remansinho, Brasil (2010-13).

\begin{tabular}{|c|c|c|c|c|c|c|}
\hline \multirow[t]{2}{*}{ Haplogrupos } & \multirow[t]{2}{*}{ Amostras } & \multirow[t]{2}{*}{ Corte } & \multicolumn{4}{|c|}{$\begin{array}{l}\mathrm{N}^{\circ} \text { de amostras } \\
\text { segundo numero } \\
\text { de alelos } \\
\text { compartilhados }\end{array}$} \\
\hline & & & 15 & 14 & 13 & 12 \\
\hline \multirow[t]{7}{*}{1} & 374 & $\mathrm{D}$ & 2 & 3 & 1 & 0 \\
\hline & 241 & D & 2 & 3 & 1 & 0 \\
\hline & 451 & D & 2 & 3 & 1 & 0 \\
\hline & 154 & $\mathrm{D}$ & 0 & 2 & 2 & 0 \\
\hline & 49 & $\mathrm{D}$ & 0 & 1 & 2 & 1 \\
\hline & 131 & $E$ & 0 & 1 & 2 & 1 \\
\hline & 159 & D & 0 & 1 & 1 & 2 \\
\hline \multirow[t]{3}{*}{2} & 481 & $\mathrm{H}$ & 0 & 1 & 1 & 0 \\
\hline & 98 & $A$ & 0 & 1 & 0 & 1 \\
\hline & 273 & C & 0 & 0 & 1 & 1 \\
\hline \multirow[t]{2}{*}{3} & 293 & $\mathrm{D}$ & 0 & 0 & 1 & 0 \\
\hline & 263 & $\mathrm{D}$ & 0 & 0 & 1 & 0 \\
\hline \multirow[t]{2}{*}{4} & 182 & $\mathrm{D}$ & 0 & 0 & 1 & 0 \\
\hline & 43 & D & 0 & 0 & 1 & 0 \\
\hline \multirow[t]{2}{*}{5} & 131 & D & 0 & 0 & 1 & 0 \\
\hline & 480 & D & 0 & 0 & 1 & 0 \\
\hline \multirow[t]{2}{*}{6} & 263 & $\mathrm{C}$ & 0 & 0 & 1 & 0 \\
\hline & 290 & $\mathrm{C}$ & 0 & 0 & 1 & 0 \\
\hline
\end{tabular}

Os dados recuperados de amostras tipadas com microssatélites levam em consideração o tamanho do alelo encontrado em cada haplótipo. Muitos dos cálculos realizados para investigação de diversidade de alelos encontrados nas populações de $P$. vivax baseiam-se no fato de que essas diversificações nos tamanhos ocorrem devido a inserção ou deleção de motivos repetitivos. No entanto, sabe-se que os microssatélites não são formados apenas por motivos repetitivos constantes na sequência. Para isso realizamos o sequenciamento das regiões de microssatélites utilizadas no estudo e como já verificado em outro estudo (KARUNAWEERA et al., 2007) as regiões apresentaram padrões de repetição bem diferentes. Encontramos seis microssatélites com sequências repetitivas trinucleotídicas perfeitas (MS1, MS3, MS4, MS7, MS9 e MS15) e oito contendo sequências repetitivas imperfeitas (Tabela 5). Essas sequências repetitivas imperfeitas podem ser interrompidas, compostas ou ainda complexas (compostas e interrompidas). 
Tabela 5 - Tipos de repetição encontradas em 14 marcadores de Plasmodium vivax: isolados do Brasil (este estudo) e Sri Lanka (KARUNAWEERA et al., 2007).

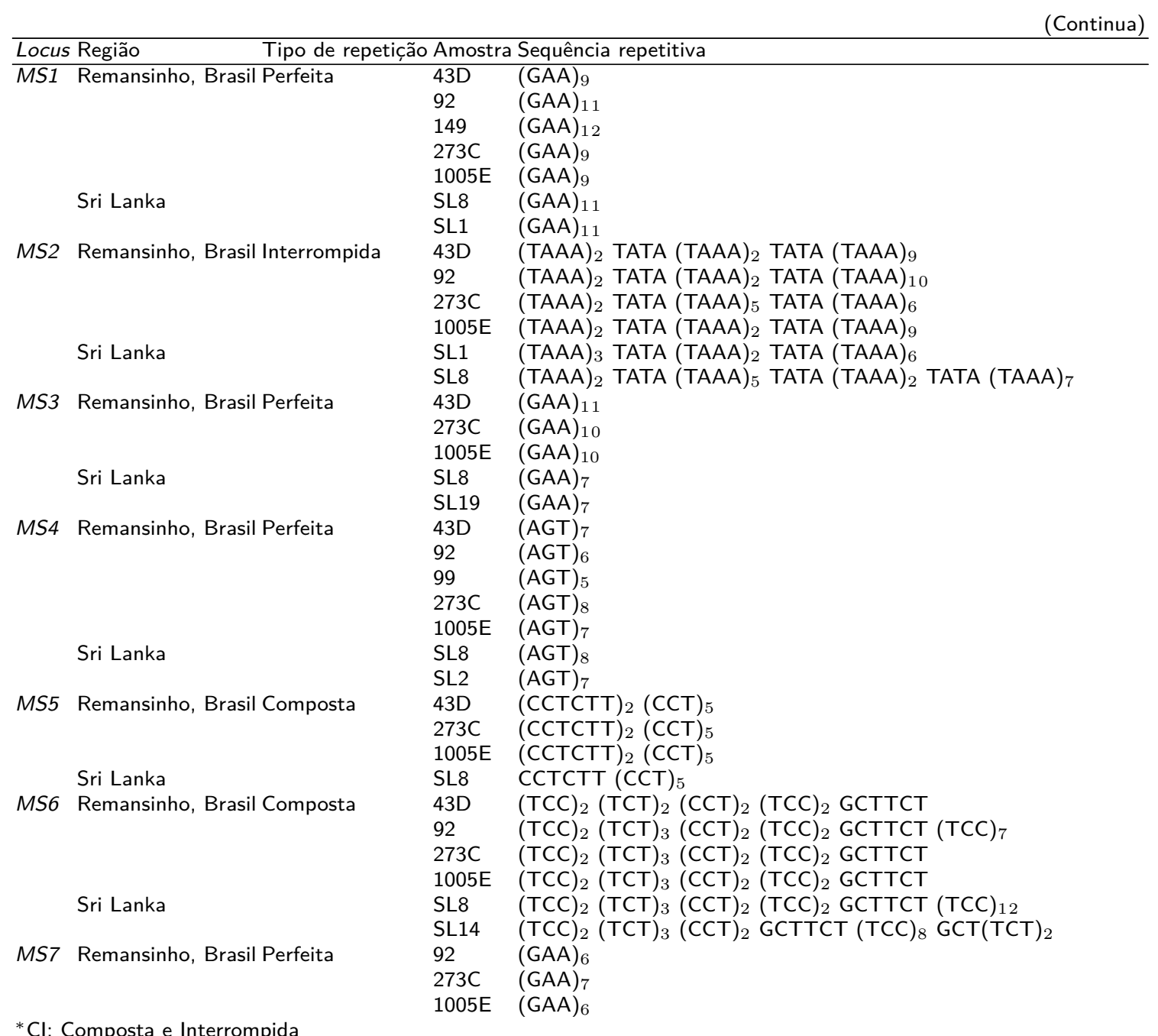


Tabela 5 - Tipos de repetição encontradas em 14 marcadores de Plasmodium vivax: isolados do Brasil (este estudo) e Sri Lanka (KARUNAWEERA et al., 2007).

\begin{tabular}{|c|c|c|c|}
\hline \multirow{2}{*}{\multicolumn{4}{|c|}{ Tino de reneticão Amostra Sequência renetitiva }} \\
\hline & & & \\
\hline \multicolumn{2}{|r|}{ Sri Lanka } & $\begin{array}{l}\text { SL6 } \\
\text { SL14 }\end{array}$ & $(\text { GAA })_{6}$ \\
\hline \multirow[t]{4}{*}{ MS8 } & \multirow[t]{2}{*}{ Remansinho, Brasil Composta } & $43 \mathrm{D}$ & $(\mathrm{CAG})_{2}(\mathrm{CAA})_{16}$ \\
\hline & & $273 C$ & $(\mathrm{CAG})_{2}(\mathrm{CAA})_{29}$ \\
\hline & \multirow[t]{2}{*}{ Sri Lanka } & SL8 & $(\mathrm{CAG})_{5}(\mathrm{CAA})_{17}$ \\
\hline & & SL19 & $(\mathrm{CAG})_{5}(\mathrm{CAA})_{17}$ \\
\hline \multirow[t]{4}{*}{ MS9 } & \multirow[t]{2}{*}{ Remansinho, Brasil Perfeita } & $273 C$ & $(\mathrm{GAA})_{7}$ \\
\hline & & $1005 \mathrm{E}$ & $(\mathrm{GAA})_{5}$ \\
\hline & \multirow[t]{2}{*}{ Sri Lanka } & SL1 & $(\mathrm{GAA})_{10}$ \\
\hline & & SL2 & $(\mathrm{GAA})_{7}$ \\
\hline \multirow[t]{13}{*}{ MS10 } & \multirow{12}{*}{ Sri Lanka } & 43D & $\begin{array}{l}\text { GAA (GGA) })_{2} \text { AGA }(\mathrm{GGA})_{4} \text { AGA }(\mathrm{GGA})_{4} \text { AGAGGAAAA }(\mathrm{GGA})_{2} \\
(\mathrm{AGA})_{11}(\mathrm{GGA})_{3}(\mathrm{AGA})_{2} \text { GGAAGA }(\mathrm{GGA})_{2}\end{array}$ \\
\hline & & 92 & $\begin{array}{l}\text { GAA }(\mathrm{GGA})_{2} \text { AGA }(\mathrm{GGA})_{4} \text { AGA }(\mathrm{GGA})_{4} \text { AGAGGAAAA }(\mathrm{GGA})_{2} \\
(\mathrm{AGA})_{10}(\mathrm{GGA})_{3}(\mathrm{AGA})_{2} \text { GGAAGA }(\mathrm{GGA})_{2}\end{array}$ \\
\hline & & 99 & $\begin{array}{l}\left.\text { GAA (GGA) AGA }(\mathrm{GGA})_{4} \text { AGA (GGA) }\right)_{4} \text { AGAGGAAAA }(\mathrm{GGA})_{2} \\
(\mathrm{AGA})_{7} \mathrm{AGG}(\mathrm{AGA})_{2}(\mathrm{GGA})_{3}(\mathrm{AGA})_{2} \text { GGAAGA }(\mathrm{GGA})_{2}\end{array}$ \\
\hline & & $273 C$ & $\begin{array}{l}\left.\text { GAA (GGA) })_{2} \text { AGA (GGA) }\right)_{4} \text { AGA (GGA) } 11 \text { AGAGGAAGA } \\
(\text { GGAAAA })_{4}(\mathrm{GGA})_{2}(\mathrm{AGA})_{10}(\mathrm{GGA})_{3}(\mathrm{AGA})_{2} \text { GGAAGA }(\mathrm{GGA})_{2}\end{array}$ \\
\hline & & SL1 & $\begin{array}{l}\text { GAA (GGA) })_{2} \text { AGA }(\mathrm{GGA})_{4} \text { AGA }(\mathrm{GGA})_{9} \text { AGAGGAAGA } \\
(\mathrm{GGAAAA})_{2} \mathrm{GGA}(\mathrm{AGA})_{13}(\mathrm{GGA})_{3}(\mathrm{AGA})_{2} \text { GGAAGA }(\mathrm{GGA})_{2}\end{array}$ \\
\hline & & SL2 & $\begin{array}{l}\left.\text { GAA }(\text { GGA })_{4} \text { AGAGGAAGA (GGAAA }\right)_{2} \text { GGA }(\text { AGA })_{13}(\mathrm{GGA})_{3} \\
(\mathrm{AGA})_{2} \text { GGAAGA }(\mathrm{GGA})_{2}\end{array}$ \\
\hline & & SL3 & $\begin{array}{l}\left.\text { GAA (GGA) })_{4} \text { AGAGGAAGA (GGAAAA) }\right)_{2} \text { GGA }(\text { AGA })_{13}(\mathrm{GGA})_{3} \\
(\mathrm{AGA})_{2} \text { GGAAGA }(\mathrm{GGA})_{2}\end{array}$ \\
\hline & & SL6 & $\begin{array}{l}\text { GAA (GGA) })_{2} \text { AGA }(\mathrm{GGA})_{4} \text { AGA }(\mathrm{GGA})_{6} \text { AGAGGAAGA } \\
(\mathrm{GGAAAA})_{2} \mathrm{GGA}(\mathrm{AGA})_{12}(\mathrm{GGA})_{3}(\mathrm{AGA})_{2} \text { GGAAGA }(\mathrm{GGA})_{2}\end{array}$ \\
\hline & & SL14 & $\begin{array}{l}\left.\left.\text { GAA }(\mathrm{GGA})_{2} \text { AGA (GGA) }\right)_{4} \text { AGA (GGA) }\right)_{4} \text { AGAGGAAAA }(\mathrm{GGA})_{2} \\
(\mathrm{AGA})_{6}(\mathrm{GGA})_{3}(\mathrm{AGA})_{2} \text { GGAAGA }(\mathrm{GGA})_{2}\end{array}$ \\
\hline & & SL16 & $\begin{array}{l}\left.\text { GAA (GGA) })_{2} \text { AGA (GGA) }\right)_{4} \text { AGA }(\text { GGA })_{6} \text { AGAGGAAGA } \\
(\text { GGAAAA })_{2} \text { GGA }(\text { AGA })_{8}(\mathrm{GGA})_{3}(\mathrm{AGA})_{2} \text { GGAAGA }(\mathrm{GGA})_{2}\end{array}$ \\
\hline & & SL19 & $\begin{array}{l}\left.\text { GAA }(\text { GGA })_{2} \text { AGA (GGA) }\right)_{4} \text { AGA (GGA) AGAGGAAAA }(\mathrm{GGA})_{2} \\
(\mathrm{AGA})_{6}(\mathrm{GGA})_{3}(\mathrm{AGA})_{2} \text { GGAAGA }(\mathrm{GGA})_{2}\end{array}$ \\
\hline & & SL20 & $\begin{array}{l}\left.\text { GAA (GGA) })_{2} \text { AGA (GGA) }\right)_{4} \text { AGA (GGA) AGAGGAAAA }(\mathrm{GGA})_{2} \\
(\mathrm{AGA})_{6}(\mathrm{GGA})_{3}(\mathrm{AGA})_{2} \mathrm{GGAAG}(\mathrm{GGA})_{2}\end{array}$ \\
\hline \multirow{5}{*}{\multicolumn{2}{|c|}{ MS12 Remansinho, Brasil Composta }} & 43D & $(\mathrm{GCA})_{4}(\mathrm{GAA})_{15}$ \\
\hline & & 92 & $(\mathrm{GCA})_{4}(\mathrm{GAA})_{8}$ \\
\hline & & 149 & $(\mathrm{GCA})_{4}(\mathrm{GAA})_{7}$ \\
\hline & & $273 C$ & $(\mathrm{GCA})_{4}(\mathrm{GAA})_{6}$ \\
\hline & & 1005E & $(\mathrm{GCA})_{4}(\mathrm{GAA})_{15}$ \\
\hline
\end{tabular}


Tabela 5 - Tipos de repetição encontradas em 14 marcadores de Plasmodium vivax: isolados do Brasil (este estudo) e Sri Lanka (KARUNAWEERA et al., 2007).

\begin{tabular}{|c|c|c|}
\hline & & (Conclusão \\
\hline \multirow{2}{*}{$\begin{array}{l}\text { Locus Região } \\
\text { Sri Lanka }\end{array}$} & \multicolumn{2}{|c|}{ Amostra Sequência repetitiva } \\
\hline & & $(\mathrm{GCA})_{4}(\mathrm{GAA})_{8}$ \\
\hline & SL4 & $(\mathrm{GCA})_{3}(\mathrm{GAA})_{6}$ \\
\hline & SL6 & $(\mathrm{GCA})_{5}(\mathrm{GAA})_{10}$ \\
\hline & SL10 & $(\mathrm{GCA})_{4}(\mathrm{GAA})_{12}$ \\
\hline & SL12 & $(\mathrm{GCA})_{4}(\mathrm{GAA})_{12}$ \\
\hline & SL14 & $(\mathrm{GCA})_{4}(\mathrm{GAA})_{9}$ \\
\hline & SL20 & $(\mathrm{GCA})_{4}(\mathrm{GAA})_{8}$ \\
\hline & 43D & $(\mathrm{TCT})_{5}$ \\
\hline \multirow{3}{*}{ MS15 Remansinho, Brasil Perfeita } & 92 & $(\mathrm{TCT})_{12}$ \\
\hline & $273 C$ & $(\mathrm{TCT})_{4}$ \\
\hline & $1005 \mathrm{E}$ & $(\mathrm{TCT})_{12}$ \\
\hline \multirow[t]{2}{*}{ Sri Lanka } & SL14 & $(\mathrm{TCT})_{12}$ \\
\hline & SL19 & $(\mathrm{TCT})_{12}$ \\
\hline \multirow[t]{2}{*}{ MS16 Remansinho, Brasil Complexa $(\mathrm{Cl})^{*}$} & 43D & $\begin{array}{l}(\text { ACA })_{11} \text { GCAATC }(\text { ACA })_{2}(\mathrm{GCA})_{2}(\mathrm{ACA})_{4} \text { ACC }(\mathrm{ACA})_{3} \\
\text { GCAATC }(\text { ACA })_{2} \text { ACC }(\text { ACA })_{6} \text { AAA }(\text { ACA })_{7}\end{array}$ \\
\hline & $273 C$ & $\begin{array}{l}(\text { ACA })_{7} \text { GCA }(\text { ACA })_{4}(\mathrm{GCA})_{7}(\mathrm{ACA})_{11}(\mathrm{GCA})_{2}(\mathrm{ACA})_{6} \text { ACC } \\
(\mathrm{ACA})_{5} \text { GCAATC }(\mathrm{ACA})_{2} \text { GCA }(\text { ACA })_{3}(\mathrm{GCA})_{2}(\mathrm{ACA})_{6} \text { ACC } \\
(\mathrm{ACA})_{3} \text { GCAATC }(\mathrm{ACA})_{15}\end{array}$ \\
\hline \multirow[t]{2}{*}{ Sri Lanka } & SL14 & $\begin{array}{l}\mathrm{ACC}(\mathrm{ACA})_{4} \text { ACC }(\mathrm{ACA})_{2} \mathrm{ACC}(\mathrm{ACA})_{2} \mathrm{ACC}(\mathrm{ACA})_{2} \\
\mathrm{ACC}(\mathrm{ACA})_{2} \mathrm{ACC}(\mathrm{ACA})_{8}\end{array}$ \\
\hline & SL12 & $\begin{array}{l}(\text { ACA })_{2} \text { ACGGCA }(\text { ACA })_{2} \text { ACGGCA }(\text { ACA })_{5} \text { ACGGCA }(\text { ACA })_{4} \\
\text { GGTGCATTATAACC }(\text { ACA })_{4} \text { ACC }(\text { ACA })_{2} \text { ACC }(\text { ACA })_{2} \\
\text { ACC }(\text { ACA })_{2} \text { ACC }(\text { ACA })_{4} \\
(\text { ACA })_{2} \text { ACGGCA }(\text { ACA })_{2} \text { ACGGCA }(\text { ACA })_{5} \text { ACGGCA }(\text { ACA })_{5} \\
\text { GTTGCATTATAACCC }(\text { ACA })_{4} \text { ACC }(\text { ACA })_{4} \text { ACC }(\text { ACA })_{2} \\
\text { ACC }(\text { ACA })_{2} \text { ACC }(A C A)_{2} \text { ACC }(\text { ACA })_{2}\end{array}$ \\
\hline \multirow[t]{4}{*}{ MS20 Remansinho, Brasil Complexa $(\mathrm{Cl})^{*}$} & 43D & $(\mathrm{GAA})_{12}$ GAG $(\mathrm{GAA})_{10}(\mathrm{CAA})_{8}$ \\
\hline & 92 & $(\mathrm{GAA})_{8}$ AAA $(\mathrm{GAA})_{3}$ GAG $(\mathrm{GAA})_{9}(\mathrm{CAA})_{9}$ \\
\hline & 149 & $(\mathrm{GAA})_{12}$ GAG $(\mathrm{GAA})_{9}(\mathrm{CAA})_{9}$ \\
\hline & $273 C$ & $(\mathrm{GAA})_{13}$ GAG $(\mathrm{GAA})_{8}(\mathrm{CAA})_{9}$ \\
\hline \multirow[t]{2}{*}{ Sri Lanka } & SL14 & $(\mathrm{GAA})_{11}$ GAG $(\mathrm{GAA})_{10}(\mathrm{CAA})_{17}$ \\
\hline & SL19 & $(\mathrm{GAA})_{8}(\mathrm{CAA})_{9}$ \\
\hline
\end{tabular}


O teste de M-ratio forneceu valores abaixo de 0,68 para os marcadores de microssatélite MS3, MS6, MS8, MS10, MS16 e MS20, incluindo o marcador msp1F3 (Tabela 6). No entanto em microssatélites cujos padrões mutacionais são mais complexos MS6, MS8, MS10, MS16 e MS20 (Tabela 6) não é possível assumir com segurança os valores do teste de $M$ ratio, já que este assume que as unidades repetitivas seguem o modelo de stepwise mutation. Além disso, a variação dos motivos repetitivos de msp1F3 é afetada pela seleção natural já que está em uma região antigênica e tem um importante papel na invasão dos eritrócitos.

Tabela 6 - Diversidade de 14 loci de microssatélite e um locus de região antigênica codificadora em 84 isolados de Plasmodium vivax, Remansinho, Brasil (2010-13)

\begin{tabular}{lccccc}
\hline Locus & Cromossomo $\begin{array}{l}\text { Intervalo de tamanho } \\
\text { dos alelos }(r)\end{array}$ & $N^{\circ}$ de alelos Média $H_{E}{ }^{a}$ & M-ratio $(k / r)$ \\
\hline MS1 & 3 & $216-243(10)$ & 9 & 0,53 & 0,90 \\
MS2 & 6 & $198-246(13)$ & 9 & 0,69 & 0,69 \\
MS3 & 4 & $161-221(21)$ & 11 & 0,79 & 0,53 \\
MS4 & 6 & $192-216(9)$ & 7 & 0,68 & 0,78 \\
MS5 & 6 & $163-205(15)$ & 13 & 0,87 & 0,87 \\
MS6 & 11 & $210-249(14)$ & 7 & 0,50 & 0,50 \\
MS7 & 12 & $136-160(9)$ & 7 & 0,53 & 0,78 \\
MS8 & 12 & $207-297(31)$ & 12 & 0,79 & 0,39 \\
MS9 & 8 & $152-173(8)$ & 8 & 0,77 & 1,00 \\
MS10 & 13 & $183-270(30)$ & 15 & 0,78 & 0,50 \\
MS12 & 5 & $209-236(10)$ & 8 & 0,72 & 0,80 \\
MS15 & 5 & $233-272(14)$ & 11 & 0,76 & 0,78 \\
MS16 & 9 & $117-303(63)$ & 16 & 0,86 & 0,25 \\
MS20 & 10 & $198-219(22)$ & 7 & 0,43 & 0,32 \\
msp1F3 & 7 & $97-280(62)$ & 10 & 0,78 & 0,16 \\
\hline
\end{tabular}

${ }^{a} \mathrm{H}_{E}=$ Heterozigosidade esperada

Assim, consideramos que este baixo valor do teste de M-ratio encontrado para MS3, que não faz parte dos microssatélites com regiões repetitivas mais complexas, pode indicar um bottleneck recente na população do Remansinho. No entanto, caracterizamos a distribuição das frequências alélicas (Figura 6) das amostras de $P$. vivax colhidas na região do Remansinho, entre 2010 e 2013, e na região do Granada (um assentamento de fronteira cerca de $150 \mathrm{~km}$ do Remansinho), entre 2004 e 2006. Os dados representam a combinação entre todos os loci analisados e a distribuição das frequências alélicas se deu em um formato de $L$, ou seja, os alelos raros não foram perdido. Esse tipo de distribuição é esperada em populações que não estejam sofrendo bottleneck (efeito de gargalo de garrafa) (LUIKART et al., 1998). 
Figura 6 - Distribuição de frequências de isolados colhidos na região do Granada (2004-6) e do Remansinho (2010-13).

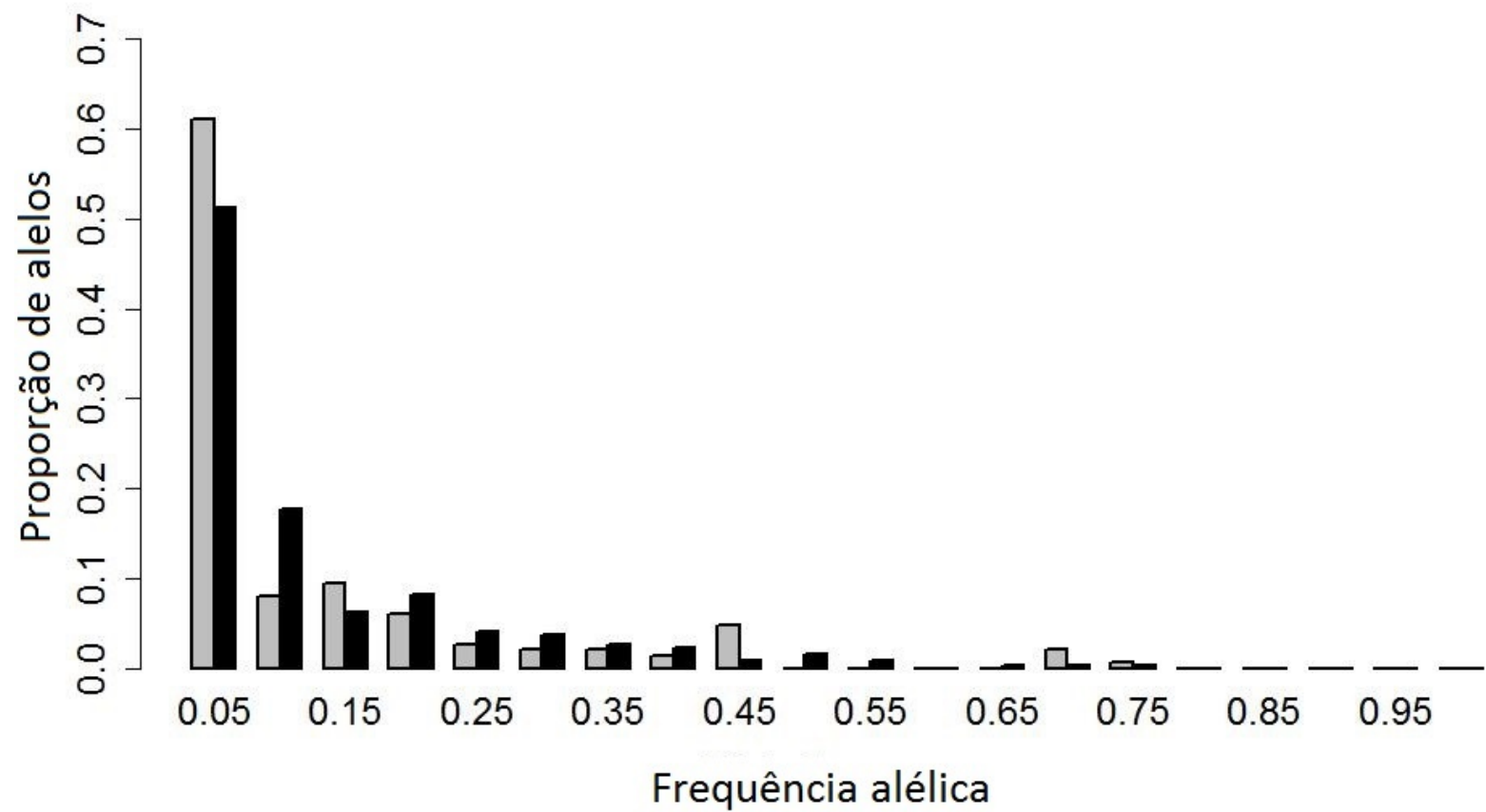

Distribuição das frequências alélicas de amostras de Plasmodium vivax colhidas na comunidade rural do Remansinho, entre 2010 e 2013 ( $n=84$, barras em cinza) e na região do Granada (um assentamento de fronteira cerca de 150km do Remansinho) entre 2004 e 2006 ( $n=148$, barras em preto), Brasil. Os dados representam a combinação entre todos os loci analisados. A distribuição das frequências alélicas em um formato de $L$ é esperada em populações que não estejam sofrendo bottleneck (efeito de gargalo de garrafa)

\subsection{Diversidade genética no tempo e no espaço}

Os níveis de diversidade genética e a proporção de IMC variaram muito pouco ao longo dos três anos de estudo na população do Remansinho, exceto durante o corte D (Tabela 7). As análises feitas com as amostras colhidas deste corte mostraram-se diferentes das análises dos demais cortes, apresentou o menor valor de $H_{E}$ médio, o menor valor de $\mathrm{R}$ e a menor distância genética entre suas amostras. Além disso, as amostras colhidas no corte $\mathrm{D}$ apresentaram as menores proporções de IMC e IMC >1, com um alto valor de DL (Tabela 7). Esses dados condizem com o surto de malária vivax ocorrido em outubro de 2011. 
Tabela 7 - Tendência temporal na diversidade genética de isolados de Plasmodium vivax do Remansinho, Brasil (2010-13).

\begin{tabular}{|c|c|c|c|c|c|c|c|c|}
\hline Corte & $\begin{array}{l}\mathrm{N}^{\circ} \\
\text { de amostras }\end{array}$ & $\begin{array}{l}\text { Média } \\
\mathrm{n}^{\circ} \text { alelos (DP) }\end{array}$ & $\begin{array}{l}\text { Média } \\
H_{E}(\mathrm{DP})\end{array}$ & IMC II & IC $>1$ loci & $I_{A}^{S}$ & $\begin{array}{l}\text { Distância } \\
\text { genética }\end{array}$ & $\begin{array}{l}\text { Riqueza } \\
\text { genotípica (R) }\end{array}$ \\
\hline A & 21 & $5,333(1,783)$ & $0,674(0,207)$ & 85,7 & 66,6 & 0,007 & 0,68 & 1,00 \\
\hline B & 19 & $5,866(1,499)$ & $0,723(0,127)$ & 94,7 & 73,6 & $0,033^{*}$ & 0,71 & 1,00 \\
\hline C & 12 & $4,733(1,181)$ & $0,725(0,114)$ & 83,3 & 50,0 & $0,052^{*}$ & 0,72 & 1,00 \\
\hline D & 21 & $4,000(1,932)$ & $0,496(0,222)$ & 57,1 & 23,8 & $0,157^{*}$ & 0,52 & 0,89 \\
\hline $\mathrm{E}, \mathrm{F}$ e $\mathrm{H}$ & 11 & $4,266(1,436)$ & $0,670(0,169)$ & 72,7 & 54,5 & $0,032 * *$ & 0,68 & 1,00 \\
\hline Todos & 84 & $10,000(2,852)$ & $0,699(0,132)$ & 78,5 & 51,2 & $0,040 *$ & 0,69 & 0,98 \\
\hline
\end{tabular}

Com o auxílio da análise bayesiana (Figura 7) foi possível detectar três subpopulações diferentes com alto suporte estatístico, uma delas foi observada quase que exclusivamente no corte D (Figura 8).

Com isso, nossa hipótese é de que a população de parasitos do Remansinho vem se modificando ao longo do tempo devido ao intenso processo de migração dos indivíduos, deriva genética, mutação e recombinação. 
Figura 7 - Distribuição temporal dos isolados de Plasmodium vivax do Remansinho, Brasil (2010-13).
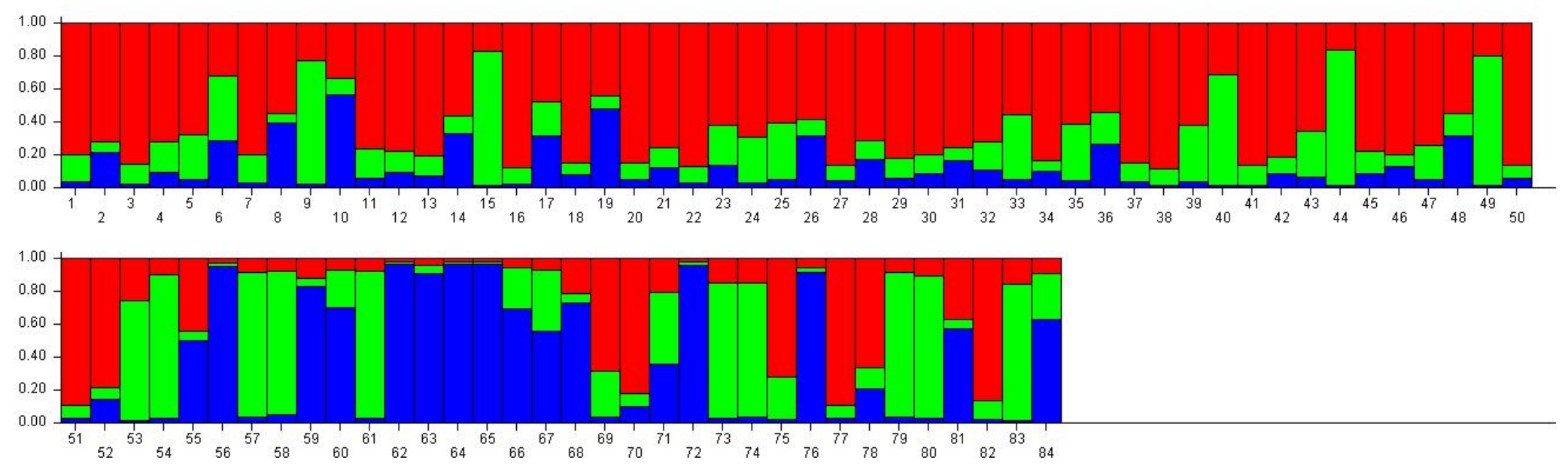

Distribuição temporal dos isolados de Plasmodium vivax do Remansinho (Brasil, 2010-13) segundo sua população de origem. Cada isolado foram categorizados como membros de uma população em particular segundo sua porcentagem de ancestralidade $(70 \%)$ estimada pelo método de análise bayesiana implementado no STRUCTURE. Foram definidas três populações (azul, vermelho ou verde). 
Figura 8 - Distribuição ao longo do tempo de três diferentes populações estimadas de isolados de Plasmodium vivax do Remansinho, Brasil, 2010-13.

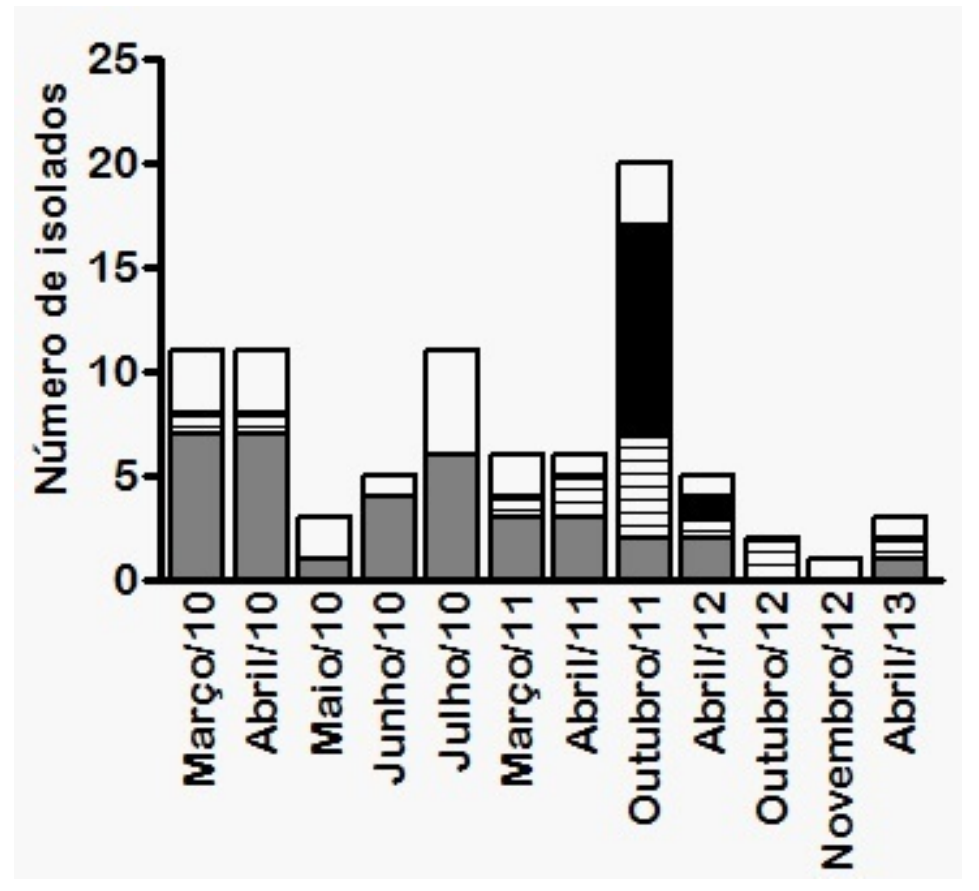

Distribuição ao longo do tempo de três diferentes populações de Plasmodium vivax estimadas de isolados do Remansinho, Brasil, 2010-13. Os isolados foram agrupados de acordo com o ancestral predominante das populações estimadas. Eles foram considerados membros de uma das três populações (cinza, hachurado ou preto) se este apresentava $70 \%$ do ancestral da população em questão, determinada pela análise bayesiana implementada no programa STRUCTURE. Quando não houve o predomínio de nenhum ancestral das três populações estimadas os isolados foram considerados mistos, ou seja, possui ancestral das três populações, e estão representados em branco.

Em seguida testamos se os parasitos geneticamente próximos do Remansinho estão relacionados à sua distribuição no espaço, levando e consideração que o possível local de infecção foi a de residência do indivíduo. Para isso, inicialmente tivemos que recuperar os dados dados de GPS colhidos de cada domicílio participante do estudo e transformar as coordenadas geográficas em latidude e longitude para graus decimais, isso foi feita com o auxílio do programa R. Em seguida plotamos as coordenadas no Google Earth, e verificamos se o satélite utilizado pelo programa retornava a imagem condizente com a localidade dos domicílios (Figura 9).

É possível perceber que a imagem se assemelha bastante ao mapa de distribuição dos domicílios visualisados na Figura 4. Na imagem é possível perceber que as casas são construídas basicamente à margem da estrada principal do Ramal do Remansinho e das estradas adjacentes, chamadas localmente de ramais, em torno das casas há uma região de clareira, decorrente do recente desmatamento, em geral feito pelo próprio morador para cultivo de subsistência, sendo portanto uma clara região de fronteira com a floresta amazônica. A distância máxima em linha reta encontrada entre um domicílio e outro foi de $18 \mathrm{~km}$. 
Figura 9 - Imagem de satélite com a localização dos domicílios com casos de infecção por Plasmodium vivax genotipados ao longo do estudo na região do Remansinho, Brasil (2010-13).

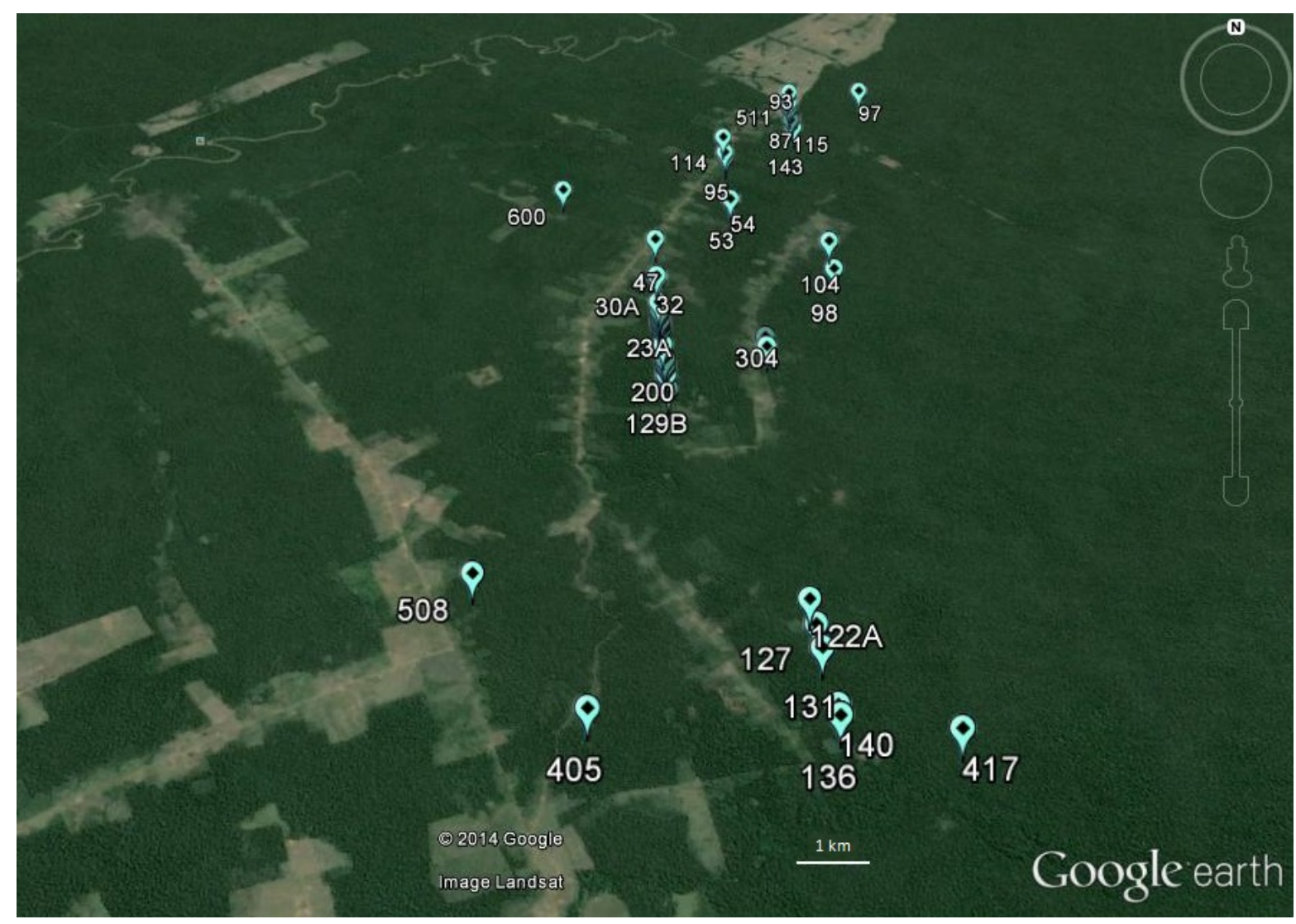

Imagem de satélite construída a partir de dados de GPS colhidos de cada domicílio participante do estudo no Remansinho, Brasil.

Encontramos uma fraca mas significativa correlação entre distância genética e distância temporal (em dias) entre as datas de coleta $(r=0,06, P=0,03$, teste de correlação de matrizes de Mantel, Figura 10) o que pode auxiliar na sustentação da hipótese de que a população de parasitos do Remansinho vem se modificando ao longo do tempo devido ao intenso processo de migração dos indivíduos, deriva genética, mutação e recombinação.

Em seguida, fomos verificar se de fato essas distâncias espaciais entre os domicílios estão relacionadas às distâncias genéticas entre os parasitos. Nessas análises consideramos apenas as distâncias genéticasentre as amostras colhidas no mesmo inquérito, para evitar a provável influência do tempo na avaliação da variabilidade genética dos parasitos. Não encontramos correlação entre os parasitos genteticamente distantes e a distância espacial (em km) entre os domicílios dos indivíduos infectados $(r=-0,017, P>0,05$, utilizando o teste de correlação de Spearman, Figura 11). 
Figura 10 - Correlação entre distância genética e distância temporal (dias) de amostras de Plasmodium vivax colhidas no Remansinho, Brasil (2010-13).

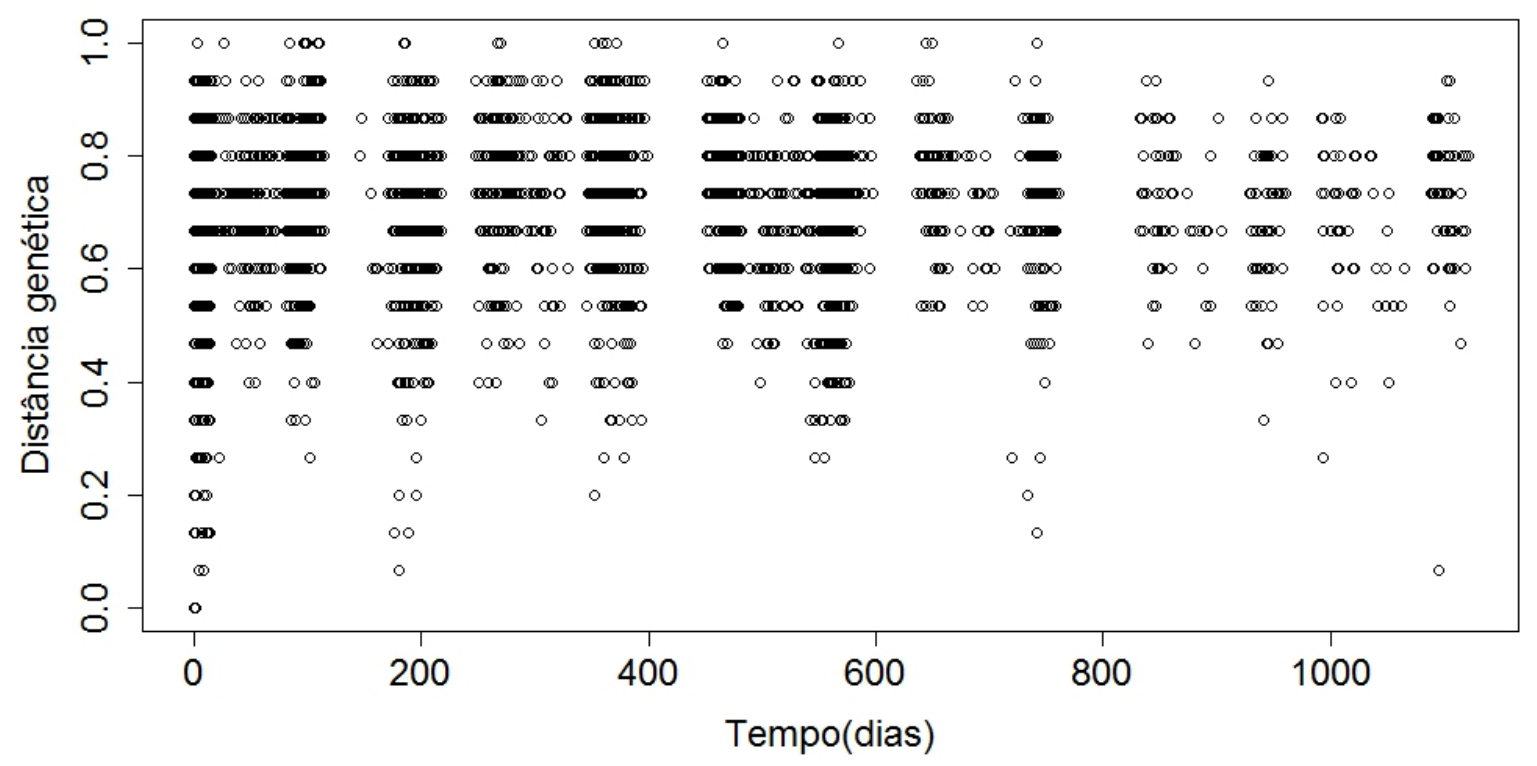

Correlação entre distância genética (1- Proporção de alelos compartilhados) e a distância temporal (em dias) entre datas de coleta das 84 amostras recuperadas de infecções por Plasmodium vivax isoladas do Remansinho, Brasil, 2010-13. 
Figura 11 - Correlação entre distância genética de amostras de Plasmodium vivax e distância espacial (km) de domicílios do Remansinho, Brasil, 2010-13.

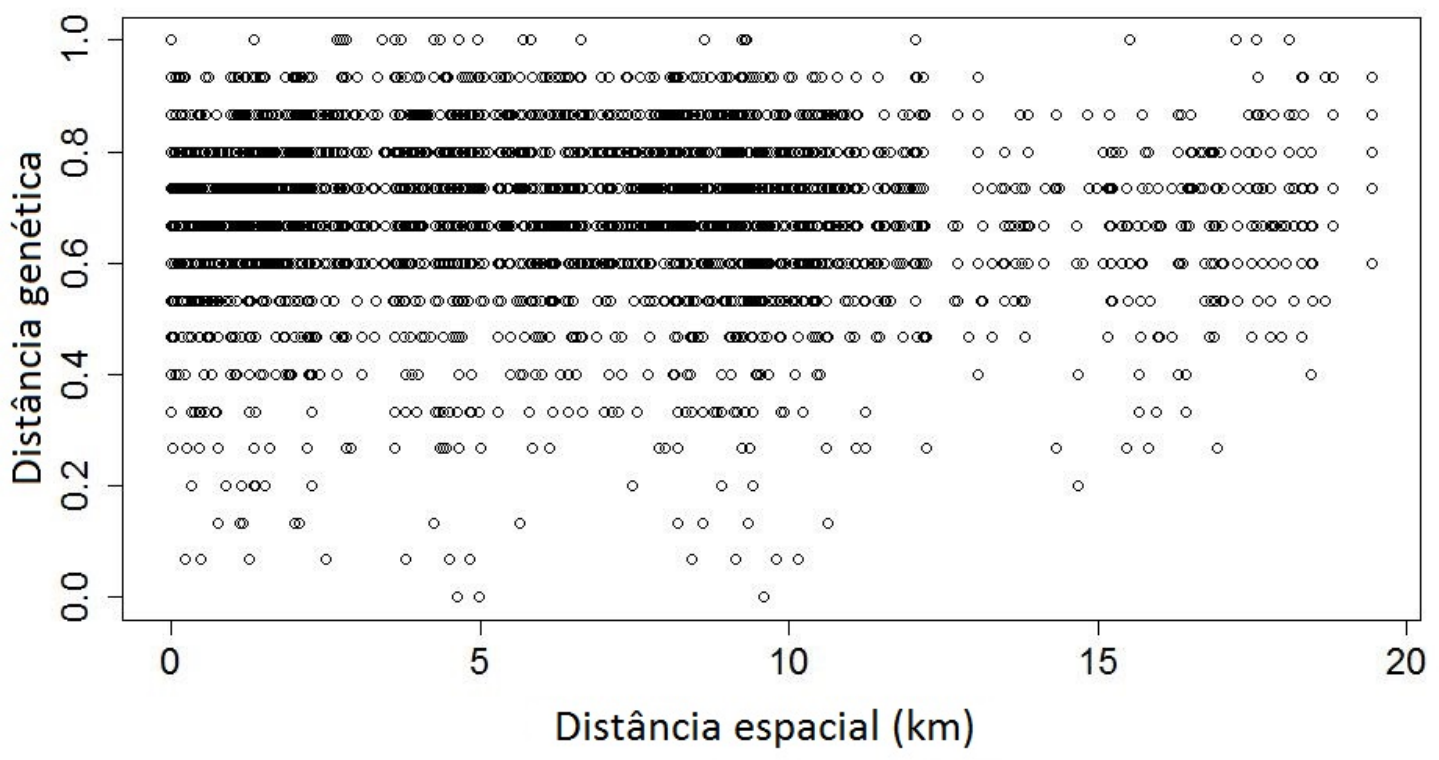

Correlação entre distância genética (1- Proporção de alelos compartilhados) e a distância espacial (km) entre os domicílios dos indivíduos infectados. Dados analisados a partir de 84 amostras positivas para Plasmodium vivax isoladas do Remansinho, Brasil, 2010-13. Consideramos apenas as distâncias espaciais entre os domicílios participantes no mesmo corte, o que elimina a influência do tempo na diversidade genética. 


\subsection{Haplótipos em amostras consecutivas de parasitos}

Ao longo do período de estudo no Remansinho foi possível recuperar amostras de indivíduos que estavam infectados por $P$. vivax em diferentes cortes, esses episódios consecutivos de malária podem ter sido consequência de recrudescências, recaídas ou ainda novas infecções. Comparamos os haplótipos de $P$. vivax isolados de 12 indivíduos cujas amostras subsequentes foram colhidas num intervalo que variou de três a 15 meses. A Tabela 8 mostra o tamanho dos alelos em pares de bases, A1 (alelo predominante) e A2 (alelo menos detectado), encontrados com a tipagem dos marcadores. Quando uma amostra apresentou detecção em A1 e A2 em mais de um marcador foi considerada uma infecção multiclonal. Foram tipados de 11 a 15 marcadores por par de amostra do mesmo indivíduo e nenhum deles compartilhou completamente os alelos entre si. A proporção de alelos compartilhados entre esses pares de amostras variou entre 13,3 a $66,6 \%$ e as distâncias genéticas variaram entre 0,23 e 0,67 (Tabela 8). Esses dados são consistentes com estudos prévios realizados na Região Amazônica (FERREIRA et al., 2007; ORJUELA-SÁNCHEZ et al., 2009), mostrando uma alta taxa de substituição (turnover) de haplótipos de $P$. vivax nessas populações. 
Tabela 8 - Haplótipos recuperados de amostras consecutivas de Plasmodium vivax de 12 indivíduos colhidas num intervalo entre três a 15 meses durante cortes transversais no Remansinho, Brasil (2010-13).

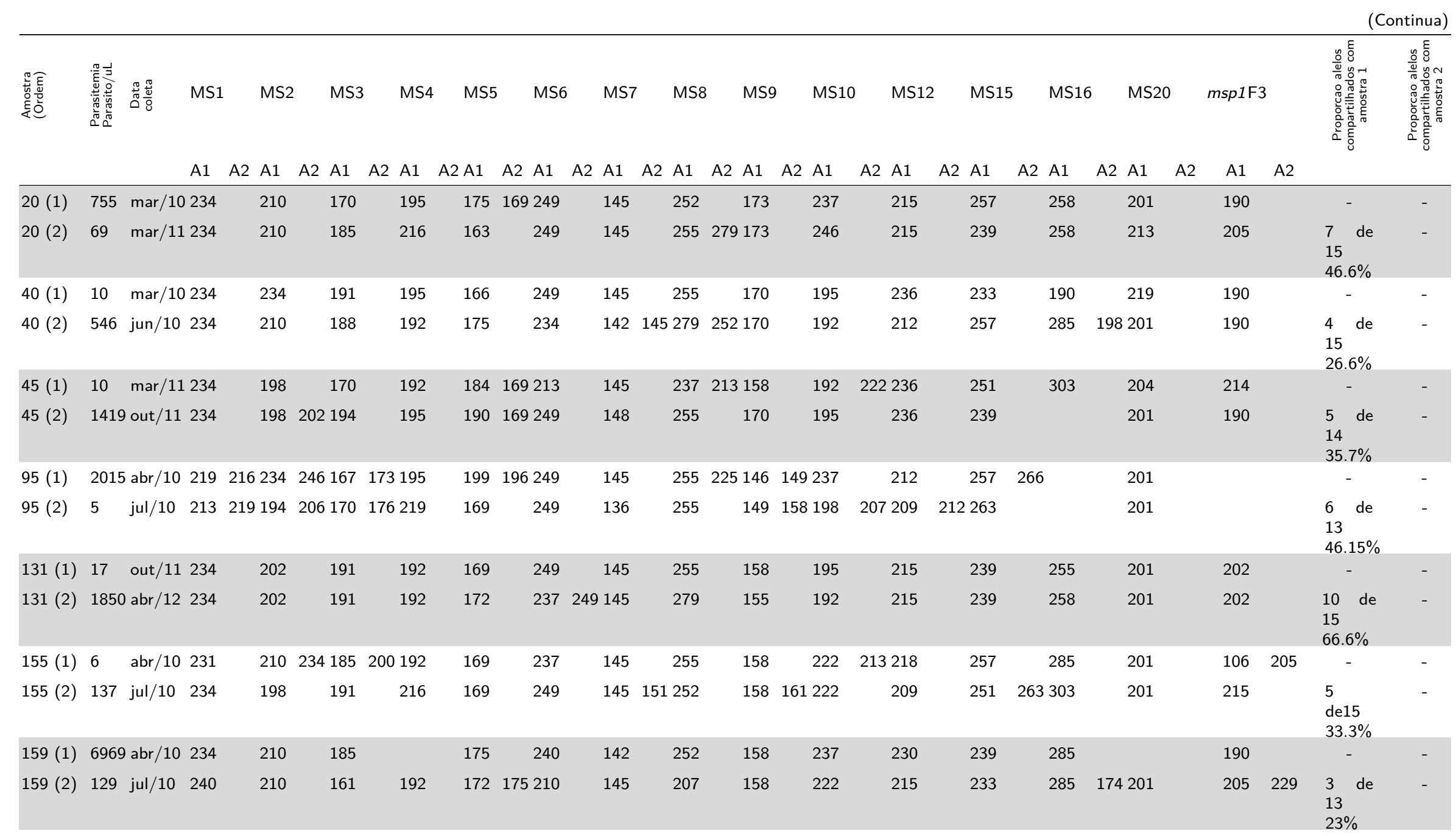




\begin{tabular}{|c|c|c|c|c|c|c|c|c|c|c|c|c|c|c|c|c|c|}
\hline 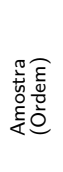 & 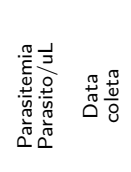 & MS1 & MS2 & MS3 & MS4 & MS5 & MS6 & MS7 & MS8 & MS9 & MS10 & MS12 & MS15 & MS16 & MS20 & $m s p 1 \mathrm{~F} 3$ & 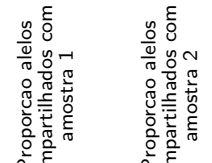 \\
\hline
\end{tabular}

$\begin{array}{lllllllllllllllllllllllllllllllllllll}\text { A1 } & \text { A2 } & \text { A1 } & \text { A2 } & \text { A1 } & \text { A2 } & \text { A1 } & \text { A2 } & \text { A1 } & \text { A2 } & \text { A1 } & \text { A2 } & \text { A1 } & \text { A2 } & \text { A1 } & \text { A2 } & \text { A1 } & \text { A2 } & \text { A1 } & \text { A2 } & \text { A1 } & \text { A2 } & \text { A1 } & \text { A2 } & \text { A1 } & \text { A2 } & \text { A1 } & \text { A2 } & \text { A1 } & \text { A2 }\end{array}$

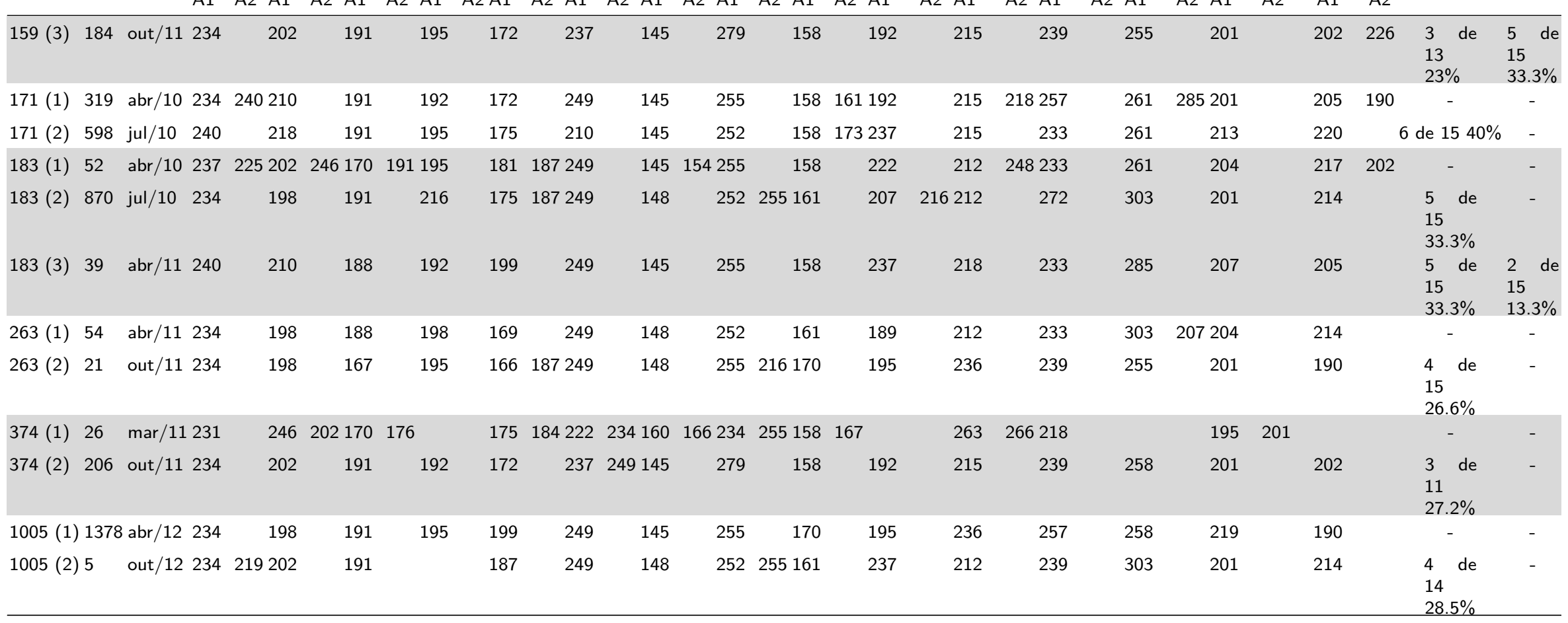


Nessa população também comparamos amostras consecutivas de três indivíduos assintomáticos recuperadas de infecções subpatentes por $P$. vivax, as datas de coleta das amostras variaram entre si em duas semanas (Tabela 9). Com isso pudemos encontrar um pequeno compartilhamento de alelos entre os pares de amostras (8,3 a 73,3\%), com distâncias genéticas que variaram entre 0,19 e 0,92. Como já descrito em populações de $P$. falciparum (FÄRNERT, 2008), sugerimos que possam coexistir no mesmo indivíduo assintomático haplótipos com dinâmicas temporais diferentes. Dessa forma, as análises que levam em consideração uma única amostra colhida dos indivíduos podem subestimar a multiplicidade de infecções por $P$. vivax no Remansinho e em regiões endêmicas similares. 
Tabela 9 - Haplótipos recuperados de amostras consecutivas, colhidas com um intervalo de aproximadamente duas semanas entre si, durante infecções assintomáticas e subpatentes por Plasmodium vivax no Remansinho, Brasil (2010-13).

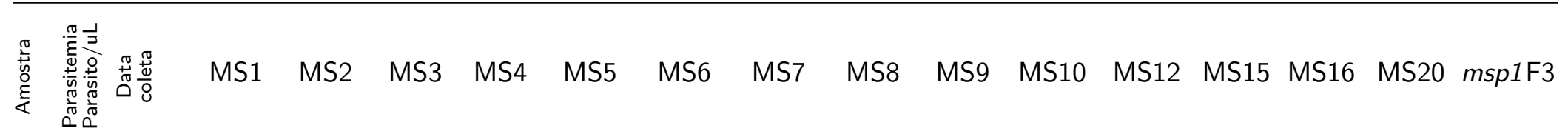

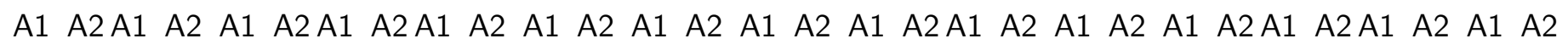

\begin{tabular}{|c|c|c|c|c|c|c|c|c|c|c|c|c|c|c|c|}
\hline 40018 & 21/out 234 & 202 & 170 & 192 & 178 & 249 & 145 & 255 & 158 & 192 & 215 & 239 & 255 & 201 & 202 \\
\hline 4 & 07 / nov 234 & 202 & 191 & 192 & & 246 & 142 & 255279 & 158 & & 215 & 239 & 258 & 192201 & 1202 \\
\hline 17 & $07 /$ dez 234 & 20221 & 3164 & 195 & & 249 & 145 & 279 & 161 & 192 & 209218 & 3215 & 255 & 201 & 202 \\
\hline 4328 & 21/out 234 & 19821 & 164 & 195 & 199193 & 249 & 145154 & 255 & 161 & 183 & 212 & 233 & 267 & 201 & 202 \\
\hline 6 & $07 /$ nov 234 & 190 & 188 & & & 213231 & & 252246 & 158 & 192198 & 3218224 & 218 & 258 & 189237 & 7190 \\
\hline 45614 & 20/out 234 & 202 & 167 & 192 & 169 & 249 & 145 & 216 & 158 & 237 & 215 & 239 & 255 & 201 & 202 \\
\hline 99 & $04 /$ nov 234 & 202 & 191 & 192 & 172175 & 249 & 145 & 279 & 158 & 237 & 212 & 239 & 255 & 201 & 202 \\
\hline
\end{tabular}




\subsection{Diversidade global de microssatélites de Plasmodium vivax}

Comparamos nossos dados com outros 10 estudos que utilizaram marcadores de microssatélite para caracterizar populações de $P$. vivax. A Tabela 10 mostra a média do número de alelos por locus e do cálculo de $H_{E}$ para os nove microssatélites mais comumente utilizados. Os estudos foram ordenados segundo o número de $H_{E}$. A diversidade genética estimada para o Remansinho foi muito similar a encontrada em estudos prévios no Brasil (FERREIRA et al., 2007; ORJUELA-SÁNCHEZ et al., 2009) e na Venezuela (CHENET et al., 2012), tem valor intermediário entre regiões hipoendêmicas como o Peru (EEDE et al., 2010a) e a Coréia do Sul (IWAGAMI et al., 2013), e entre regiões meso e hiperendêmicas da África (GUNAWARDENA et al., 2010), Sudeste da Ásia (EEDE et al., 2010b; GUNAWARDENA et al., 2010; ??) e Oceania (KOEPFLI et al., 2009).

A diversidade genética de populações de $P$. vivax em geral tende a se correlacionar positivamente com níveis de endemicidade de malária de cada região estudada, com exceção do Sri Lanka, onde mesmo com a diminuição da população de parasitos há altos níveis de diversidade genética, detectadas não só com marcadores de microssatélite (GUNAWARDENA et al., 2014) mas também com polimorfismos de base única (SNP) (ORJUELA-SÁNCHEZ et al., 2010). As potenciais implicações desses achados para eliminação da malária no Sri Lanka vem sendo recentemente revisados (GUNAWARDENA et al., 2014). 
Tabela 10 - Número de alelos de nove microsatélites em populações de Plasmodium vivax do mundo

\begin{tabular}{|c|c|c|c|c|c|c|c|c|c|c|c|c|}
\hline \multirow{2}{*}{ Locais de estudo (ano) } & \multirow{2}{*}{$\begin{array}{l}\mathrm{N}^{\circ} \text { de } \\
\text { amostras }\end{array}$} & \multicolumn{9}{|c|}{$\mathrm{N}^{\circ}$ de alelos por locus } & \multirow{2}{*}{$\begin{array}{c}\text { Média } \\
H_{E}\end{array}$} & \multirow{2}{*}{ Referências $^{c}$} \\
\hline & & MS1 & MS2 & MS5 & 5 MS7 & 7 MS8 & MS10 & MS12 & MS15 & 5 MS20 & & \\
\hline San Carlos, Peru (2008) & 31 & 2 & 4 & 2 & 2 & 3 & 2 & 3 & 4 & 4 & 0,37 & [4] \\
\hline Coréia do Sul $\left(Z^{2} M^{a}\right)(1994-2008)$ & 163 & 5 & 12 & 6 & 9 & 4 & 2 & 3 & 5 & 1 & 0,37 & [7] \\
\hline Remansinho, Brasil (2010-13) & 84 & 9 & 9 & 13 & 7 & 12 & 15 & 8 & 11 & 7 & 0,68 & Este estudo \\
\hline Tumeremo, Venezuela (2003-04) & 107 & 6 & 13 & 5 & 4 & 6 & 12 & 9 & 10 & 16 & 0,71 & [5] \\
\hline Granada, Brasil (2004-06) & 148 & 5 & 9 & 16 & 4 & 25 & 14 & 10 & 17 & 13 & 0,74 & {$[2,3]$} \\
\hline Asendabo, Etiópia (2006) & 118 & 13 & 13 & 6 & 9 & 37 & 23 & 19 & 8 & 30 & 0,80 & [1] \\
\hline Pursat, Camboja (2008) & 87 & 8 & 21 & 16 & 14 & 26 & 22 & 16 & 16 & 18 & 0,84 & [9] \\
\hline PNG $^{b}$ e Illhas Salomão (2003-09) & 295 & 9 & 24 & 15 & 17 & 39 & 20 & 10 & 20 & 28 & 0,85 & [10] \\
\hline Binh Thuan, Vietnã (1999-2000) & 69 & 11 & 32 & 17 & 11 & 24 & 14 & 9 & 21 & 14 & 0,88 & [8] \\
\hline Sri Lanka (diversos locais) (2003-07) & 185 & 16 & 18 & 19 & 17 & 46 & 20 & 21 & 14 & 31 & 0,89 & [6] \\
\hline Mianmar (diversos locais) (2007) & 167 & 17 & 21 & 16 & 17 & 44 & 23 & 24 & 9 & 30 & 0,90 & [1] \\
\hline
\end{tabular}

${ }^{a}$ ZDM $=$ Zona Desmilitarizada (fronteira entre Coréia do Sul e Coréia do Norte)

${ }^{b}$ PNG $=$ Papua Nova Guiné

${ }^{c}$ Referências: [1] Van den Eede et al. (2010b); [2] Iwagami et al. (2013); [3] Chernet et al. (2012); [4] Ferreira et al. (2007); [5] Orjuela-Sánchez et al. (2009);

[6] Gunawardena et al. (2010); [7] Orjuela-Sánchez et al. (2013); [8] Koepfli et al. (2013); [9] Van den Eede et al. (2010a); [10] Gunawardena et al. (2014). 


\section{DISCUSSÃO}

\subsection{Microssatélites como marcadores genéticos}

Os microssatélites estão presentes no genoma de diferentes organismos e são amplamente utilizados como marcadores genéticos. Isso se deve ao fato de possuirem um elevado nível de polimorfismo, um tamanho relativamente pequeno e serem facilmente detectáveis em protocolos de biologia molecular. Por isso são extensivamente utilizados em estudos de genética e principalmente estudos de genética de populações. No entanto, a escolha do marcador para esses estudos envolve o entendimento de como ocorrem as variações intrínsecas da sequência do marcador em cada indivíduo da população. É preciso saber a taxa de mutação da sequência, o tamanho do passo mutacional e o tipo de arranjo que a sequência tem, pois isso é o que gera variação do tamanho. Os microssatélites possuem uma taxa de mutação muito elevada e isso pode ser explicado pela ocorrência de dois mecanismos mutacionais, o primeiro envolve o deslizamento da fita de DNA durante a replicação na meiose (TACHIDA; IIZUKA, 1992; TAUTZ; SCHLÖTTERER, 1994) e o segundo envolve recombinação entre as fitas de DNA (HARDING; BOYCE; CLEGG, 1992).

O deslizamento da fita de DNA durante a replicação é um dos principais enventos mutacionais em cada loci. O que pode ocorrer é o despareamento entre a fita molde e a fita filha durante a meiose, levando a uma deleção ou adição de unidades repetitivas na sequência. Outro evento mutacional que pode interferir no tamanho da sequência é a recombinação. Isso pode ocorrer tanto por um crossing over assimétrico (HANCOCK, 1999) ou por uma recombinação não recíproca entre genes (JAKUPCIAK; WELLS, 1999; ZHIVOTOVSKY; FELDMAN, 1995).

Assume-se geralmente que os padrões mutacionais em microssatélite seguem o modelo de stepwise mutation, uma perda ou ganho de unidades repetitivas, que ao longo do tempo geram variações no tamanho da sequência (VALDES; SLATKIN; FREIMER, 1993; ZHIVOTOVSKY; FELDMAN, 1995). Este modelo é bastante atrativo para análises de genética de populações pois leva em consideração apenas a mudança no tamanho das sequências e pode estabelecer uma relação entre os diferentes alelos dos indivíduos. Além disso, os estudos baseados neste modelo tem uma base estatística muito forte para interpretação dos dados populacionais, mas dados que desviem desse modelo podem não estimar adequadamente os parâmetros destes estudos populacionais (GOLDSTEIN; POLLOCK, 1997).

Análises realizadas em um recente estudo concluíram que a estrutura de regiões repetitivas pode afetar a taxa de mutação dos microssatélies de $P$. vivax, loci com repetições imperfeitas parecem ser mais polimórficas, com um alto número de alelos por locus e um alto valor de $H_{E}$ (SUTTON, 2013). Em nosso estudo utilizamos seis microssatélites com sequências 
repetitivas trinucleotídicas perfeitas (MS1, MS3, MS4, MS7, MS9 e MS15) e oito contendo sequências repetitivas não perfeitas (Tabela 5).

Essas sequências repetitivas não perfeitas podem ser interrompidas (como por exemplo no marcador MS2 cujas sequências repetitivas TAAA são interrompidas por um motivo não repetitivo TATA), compostas (como exemplo MS5 composta por repetições do motivo trinucleotídico CCT e do motivo hexanucleotídico CCTCTT) ou ainda complexas (como exemplo - MS10 que apresenta uma sequência interrompida e composta, com motivos repetivos GGA e AGA interrompidas por motivos não repetitivos). $O$ interessante é que quatro dos cinco microssatélites que apresentaram maiores valores de $H_{E}$ e os maiores números de alelos na população do Remansinho (Tabela 6 ) possuem um arranjo repetitivo não perfeito. Esses marcadores contendo arranjos repetitivos complexos podem estar superestimando os valores de diversidade genética dos microssatélites de $P$. vivax quando comparado a outras espécies do parasito.

\subsection{Diversidade genética}

A diversidade de $P$. vivax é influenciada por padrões locais de transmissão, se correlacionando positivamente (exceto no caso da população do Sri Lanka) com níveis de endemicidade de malária quando comparamos diversas regiões do globo. No entanto, um surto recente resultante de uma expansão clonal de parasitos geneticamente relacionados pode afetar diferentes parâmetros que mensuram a diversidade populacional, como $H_{E}$, DL e proporção de IMC.

Apesar do alto nível de renovação de haplótipos, observamos que a mais baixa diversidade genética dos isolados do Remansinho ocorreu no mesmo período do surto de malária na região, levando em consideração a menor proporção de IMC e um forte DL. Isso é um exemplo clássico da estrutura epidêmica por patógeno humano (SMITH et al., 1993). Isso muito provavlemente se deveu ao fato de boa parte dos inidvíduos eram assintomáticos, ou seja, expressavam uma imunidade clínica aos haplótipos que circulavam na região por uma determinado período. $\mathrm{O}$ que pode ter havido é a introdução de um novo haplótipo, ao qual a população nunca havia sido exposta anteriormente, ou mesmo a recombinação (SMITH et al., 1993) dos haplótipos circulantes na região e sua consequente expansão clonal.

Os parâmetros que mensuram a diversidade genética de populações de $P$. vivax geralmente retornam valores que incluem um alta diversidade e uma alta proporção de infecções multiclonais. Além disso o parasito também produz muito precocemente gametócitos, logo na primeira geração de merozoítos (BOYD, $1935^{1}$ apud (BOUSEMA; DRAKELEY, 2011)) (BOYD; KITCHEN, 1937; SINDEN; GILLES, 2002; MCKENZIE; JEFFERY, 2007), podendo ser detectáveis na circulação antes mesmo de aparecerem os sintomas de malária. Por isso não

1 BOYD, M. F., STRATMAN-THOMAS, W. K., MUENCH, H. 1935 - The occurence of gametocytes of Plasmodium vivax during the primary attack. Am. J. Trop. Med. Hyg. 16:133-138. 
são eliminados por meio de tratamento e ficam disponíveis para recombinações, desde que o mosquito se infecte com esses clones. Porém, as populações de $P$. vivax apresentam um forte desequilíbrio de ligação. Um forte DL é uma das principais características de populações de $P$. falciparum cujas regiões de transmissão apresentam baixa endemicidade (ANDERSON et al., 2000), onde IMC são raras e gametas com haplótipos idênticos podem se fundir no intestino do mosquito vetor durante a reprodução sexuada do parasito.

Um estudo realizado no sul do México com $P$. vivax apresentou evidências de que a distribuição espacial de três populações distintas refletia a dos mosquitos vetores. Além disso, mostraram que populações do parasito são mais compatíveis com espécies de mosquitos simpátricas. Sugerindo que há uma seleção recíproca entre os parasitos da malária e mosquitos vetores e isso levou à adaptação local do parasito. Adaptação aos vetores locais podem desempenhar um papel importante na geração de estrutura populacional em Plasmodium (JOY et al., 2008).

As infecções por $P$. vivax são caracterizadas por apresentarem recaídas decorrentes de hipnozoítos do fígado. São caracterizadas também por longos períodos de incubação e longo período de latência entre a primeira infecção e sua recaída (WHITE, 2011). De modo que, até o indivíduo apresentar sintoma, ele pode ter sido reinfectado por diferentes clones e tê-los concomitantemente em sua circulação. Do mesmo modo que o indivíduo pode ter se infectado num dado momento por um clone e ao mesmo tempo ter circulante o clone decorrente de uma recaída. Assim, a presença de diferentes clones na circulação pode ser um potente mecanismo de diversidade em $P$. vivax.

Uma série de experimentos com $P$. chabaudi mostrou que a competição intraespecífica que ocorre em um mesmo hospedeiro favorece cepas mais virulentas, levando ao aumento da morbidade relacionada à malária em camundongos (BELL et al., 2006; MIDEO, 2009; ROODE et al., 2005). Ainda não se sabe se pode ocorrer efeito similar em infecções genotipicamente mistas por P. vivax (HAVRYLIUK; FERREIRA, 2009, 2009). Verificou-se que esta coinfecção com uma ou mais cepas não afeta o risco de ocorrer malária clínica no Remansinho. Dados de estudos realizados com $P$. falciparum na África e em Papua Nova Guiné também são inconclusivos, já que o aumento da complexidade de infecções vem sendo associado tanto a altos quanto a baixos riscos de morbidade (AL-YAMAN et al., 1997; BECK et al., 1997; BERECZKY et al., 2007; BRANCH et al., 2001; HENNING et al., 2004; OWUSU-AGYEI et al., 2002).

Em nosso estudo bem como em outros realizados vem sendo mostrado que uma alta prevalência de IMC em populações de $P$. vivax não traduz necessariamente uma frequente troca de informações genéticas entre os diferentes clones presentes na população, o que poderia perturbar a ideia de um significante LD encontrado no Remansinho e em outras regiões da Amazônia (CHENET et al., 2012; EEDE et al., 2010a; FERREIRA et al., 2007; ORJUELA-SÁNCHEZ et al., 2009; REZENDE et al., 2010). 
Uma possível explicação para o forte DL observado no Remansinho pode estar associada à estratificação da população, com acasalamento não randômico entre os membros das diferentes subpopulações. Um estudo prévio utilizando SNP revelou uma clara subdivisão em populações simpátricas de $P$. vivax de outro assentamento agrícola da região amazônica do Brasil (ORJUELA-SÁNCHEZ et al., 2010), embora as razões para uma recombinação restrita entre elas ainda não sejam claras. Além do mais, o sequenciamento de genoma mitocondrial mostrou clados divergente de $P$. vivax circulando na América do Sul, possivelmente como uma consequência de eventos de migração de parasitos (TAYLOR et al., 2013). Porém, não encontramos nenhuma evidência de que populações de $P$. vivax são estruturadas de forma estável, com haplótipos tipados por microssatélite que permaneçam por um longo período na população.

Essa explicação para uma frequente endogamia sob baixos níveis de transmissão de $P$. falciparum vem sendo chamada de hipótese da "falta de sexo"(do inglês "starving sex") ou da "Clonalidade passiva"(TIBAYRENC; AYALA, 2014). No entanto, não é esperado que em uma população onde haja persistência de um forte $\mathrm{DL}$, como encontrado em populações extremamente diversas de $P$. vivax, e que apresenta com frequência IMC esteja sob efeito da clonalidade passiva. Alternativamente, $P$. vivax pode ter algum grau de "clonalidade ativa"ou "clonalidade intrínseca"(TIBAYRENC; AYALA, 2014), o que permitiria o parasito reduzir seus níveis de recombinação, definido como perda de fitness por exemplo combinações entre alelos benéficos que ocorrem separadamente por meiose (CHARLESWORTH; CHARLESWORTH, 1975).

\subsection{Infecções consecutivas}

Em nosso estudo pudemos observar uma quantidade considerável de infecções geneticamente mistas (75\%) em amostras consecutivas do mesmo indivíduo. Isso ocorreu tanto em amostras colhidas num intervalo de meses quanto num intervalo de dias. Observamos também uma renovação de haplótipos bastante alta, mesmo em períodos curtos de tempo entre a coleta das amostras. Um estudo realizado na Região Amazônica brasileira envolvendo microssatélites de P. falciparum (ORJUELA-SÁNCHEZ et al., 2009) recuperou o mesmo haplótipo em infecções distintas, ocorridas em períodos diferentes e em regiões diferentes. Por outro lado, amostras colhidas de $P$. falciparum de um mesmo indivíduo podem variar seus haplótipos num período de horas (CONTAMIN et al., 1995; FÄRNERT et al., 2001), tanto em indivíduos sintomáticos quanto em assintomáticos.

Isso se deve a um mecanismo bastante conhecido da espécie que é o sequestro de eritrócitos infectados (como exemplo a citoaderência de eritrócitos infectados no endotélio do indivíduo parasitado). O momento do sequestro pode coincidir com o da coleta da amostra e assim ocorrer essa variabilidade de haplótipos num mesmo indivíduo (DELLEY et al., 2000). 
Essa alta taxa de renovação de haplótipos em $P$. vivax ainda é bastante especulada, ela pode se dever a uma característica intrínseca e peculiar do parasito, a uma escolha de marcadores que sejam variáveis demais, e assim superestimam a variabiliadade das populações ou mesmo uma questão que envolva a técnica de PCR. Sabe-se que a técnica de PCR pode variar em sensibilidade dependendo da disponibilidade de DNA de cada clone na amostra (CONTAMIN et al., 1995; FÄRNERT et al., 2001) e ainda, como bem descrito com amostras de P. falciparum, uma recombinação in vitro de DNA durante o PCR (TANABE et al., 2002).

Até o presente momento encontramos um curto tempo de vida de haplótipos tipados por microssatélite nesta e em outras populações de $P$. vivax analisadas longitudinalmente (FERREIRA et al., 2007; ORJUELA-SÁNCHEZ et al., 2009). O alto nível de mutação de microssatélites de $P$. vivax contendo arranjos repetitivos complexos pode explicar, pelo menos em parte, o curto tempo de vida de certos haplótipos nestas comunidades. Além disso, não encontramos nenhuma evidência de um padrão de distribuição espacial de haplótipos tipados por microssatélite (Figura 11), sugerindo que um isolamento por distância seria uma explicação plausível para a redução da recombinação meiótica em parasitos do Remansinho.

Fazendo uma avaliação do possível efeito da distância geográfica na diversidade genética de $P$. vivax, esperávamos encontrar alguma diferença entre aqueles parasitos recuperados de domicílios com uma distância de mais de cinco quilômetros entre si. Estudos realizados na região amazônica (CHARLWOOD; ALECRIM; MARTINS, 1989) com a captura de Anopheles darlingi mostraram que a abilidade de voo do vetor varia entre dois a sete quilômetros. Além disso, outros estudos apontam que a maior parte de captura deste vetor ocorre na região do intra e peridomicílio, mostrando uma capacidade dispersão relativamente baixa (GAMA et al., 2009; ROBERTS et al., 1987). Esses trabalhos também demonstraram que o vetor pode ser capturado em períodos do dia que variam entre o fim da tarde (18hs) e o início da manhã (6hs) (GAMA et al., 2009; ROBERTS et al., 1987). Como pudemos observar na Figura 9 os domicílios dos indivíduos participantes do estudo podem estar distantes entre si em até $18 \mathrm{~km}$, assim esperávamos encontrar uma maior diversidade genética entre os haplótipos colhidos em domicílios distantes uns dos outros. No entanto, outros fatores podem ser de extrema importância para a dispersão desses haplótipos, tais como intenso fluxo migratório dos indivíduos, que pode variar muito num curto espaço de tempo e mudança de domicílio.

Todos os parâmetros genéticos que obtivemos no estudo retornaram aos valores encontrados antes do surto, durante os dois anos de estudo. Isso ocorreu concomitante à queda na incidência da malária que houve após o surto. Além do mais, sempre recuperamos diferentes haplótipos de infecções consecutivas do mesmo indivíduo, assim como amostras consecutivas diferentes durante a mesma infecção. Portanto, apesar de estudos transversais poderem oferecer uma avaliação da diversidade parasitária em diferentes configurações de transmissão, mais estudos longitudinais são necessários para examinar a complexa dinâmica temporal de polimorfismos de $P$. vivax em indivíduos e em diferentes comunidades. 


\subsection{Genotipagem em saúde pública}

A diversidade genética em populações de $P$. vivax é um dos maiores obstáculos para o controle e eliminação da malária. Esta diversidade influencia a estabilidade da transmissão, o desenvolvimento de imunidade e tem consequências para o surgimento e expansão de mutações ligadas à resistência aos fármacos. Informações sobre a diversidade dessas populações podem também informar sobre padrões migratórios dos patógenos, o impacto de medidas de controle da doença e controle de fronteiras. Desde 1980 vem sendo relatadas cepas de $P$. vivax resitentes à cloroquina em Papua Nova Guiné (RIECKMANN; DAVIS; HUTTON, 1989) e mais recentemente na América do Sul (MARQUES et al., 2014; SANTANA-FILHO et al., 2007) o que interfere nos eforços globais de controle e eliminação da malária. No entanto o conhecimento sobre mecanismos e marcadores moleculares de resistência à cloroquina são ainda limitados (GONÇALVES; CRAVO; FERREIRA, 2014).

Os estudos de genética de populações podem, teoricamente, fornecer medidas de monitoramento do efeito que os esforços de controle de malária tem sob as populações do parasito (NKHOMA et al., 2013). É esperado que a diminuição da população de parasitos leve a uma redução na diversidade genética, com uma baixa proporção de IMC, um baixo cruzamento e um forte DL. No presente estudo, a queda acentuada nos casos de transmissão de malária no Remansinho, desde outubro de 2011, não foi acompanhada de alterações nestes parâmetros. No entanto, a genotipagem de parasitos provou ser útil para o acompanhamento de um surto de malária associado a uma única ou poucas cepas de $P$. vivax relacionadas introduzidas na comunidade. Monitorar a origem e a disperção de novas cepas do parasito que pode causar surtos é um dos principais desafio em regiões e países que se aproximam a eliminação da malária, uma tarefa que pode ser muito facilitada pelo uso criterioso de genotipagem molecular no contexto da saúde pública. 


\section{CONCLUSÃO}

Este estudo foi capaz de identificar um surto de malária ocasionada por $P$. vivax em outubro de 2012 na região do Remansinho. Com os dados obtidos foi possível realizar o cálculo de incidência de malária. Com base nos registros de exames de microscopia realizados no Remansinho entre março de 2010 e outubro de 2013 foi possível observar uma queda na transmissão bastante significativa e que se manteve até o fim do estudo. A genotipagem de parasitos provou ser útil para o acompanhamento de um surto de malária associado a uma única ou poucas cepas de $P$. vivax relacionadas introduzidas na comunidade.

No período do surto também foi possível observar que os parâmetros que mensuram a diversidade genética de uma população apresentaram valores muito diferentes daqueles encontrados nos outros períodos do estudo. As amostras colhidas nesse período apresentaram o menor valor de $H_{E}$ médio, o menor valor de $\mathrm{R}$ e a menor distância genética entre suas amostras. Além disso, as amostras colhidas nesse período apresentaram as menores proporções de IMC e IMC $>1$, com um alto valor de DL. O que nos leva a concluir que esse tipo de estudo é capaz de detectar surto ocorrido por uma expansão clonal.

No estudo também consideramos que o baixo valor do teste de M-ratio encontrado para MS3, que não faz parte dos microssatélites com regiões repetitivas mais complexas, indicou um bottleneck recente na população do Remansinho. A diversidade genética estimada para o Remansinho foi comparável à encontrada em estudos prévios no Brasil e na Venezuela. Além disso teve valores comparáveis com regiões hipoendêmicas como o Peru e a Coréia do Sul, e entre regiões meso e hiperendêmicas da África, Sudeste da Ásia e Oceania.

Com a tipagem de microssatélites de amostras consecutivas colhidas do mesmo indivíduo foi possível concluir que há uma renovação de haplótipos de $P$. vivax elevada na região. Foi possível detectar essa alta renovação de haplótipos também em amostras consecutivas provenientes de uma mesma infecção. 


\section{REFERÊNCIAS}

AL-YAMAN, F.; GENTON, B.; REEDER, J. C.; ANDERS, R. F.; SMITH, T.; ALPERS, M. P. Reduced risk of clinical malaria in children infected with multiple clones of Plasmodium falciparum in a highly endemic area: a prospective community study. Trans. R. Soc. Trop. Med. Hyg., v. 91, n. 5, p. 602-605, 1997.

ALVES, F. P.; DURLACHER, R. R.; MENEZES, M. J.; KRIEGER, H.; SILVA, L. H.; CAMARGO, E. P. High prevalence of asymptomatic Plasmodium vivax and Plasmodium falciparum infections in native Amazonian populations. Am. J. Trop. Med. Hyg., v. 66, n. 6, p. 641-648, 2002.

ANDERSON, T. J.; HAUBOLD, B.; WILLIAMS, J. T.; ESTRADA-FRANCO, J. G.; RICHARDSON, L.; MOLLINEDO, R.; BOCKARIE, M.; MOKILI, J.; MHARAKURWA, S.; FRENCH, N.; WHITWORTH, J.; VELEZ, I. D.; BROCKMAN, A. H.; NOSTEN, F.; FERREIRA, M. U.; DAY, K. P. Microsatellite markers reveal a spectrum of population structures in themalaria parasite Plasmodium falciparum. Mol. Biol. Evol., p. 1467-82, 2000.

ANDERSON, T. J.; NAIR, S.; SUDIMACK, D.; JEFF, W.; MAYXAY, M.; NEWTON, P. N.; GUTHMANN, J.-P.; SMITHUIS, F. M.; HIEN, T. T.; BROEK, I. V. van den; WHITE, N. J.; NOSTEN, F. Geographical distribution of selected and putatively neutral SNPs in Southeast Asian malaria parasites. Mol. Biol. Evol., v. 22, n. 12, p. 2362-2374, 2005.

ANDERSON, T. J. C.; SU, X.-Z.; BOCKARIE, M.; LAGOG, M.; DAY, K. P. Twelve microsatellite markers for characterization of Plasmodium falciparum from finger-prick blood samples. Parasitology, p. 113-25, 1999.

ANDRADE, B. B.; REIS-FILHO, A.; SOUZA-NETO, S. M.; CLARÊNCIO, J.; CAMARGO, L. M.; BARRAL, A.; BARRAL-NETTO, M. Severe Plasmodium vivax malaria exhibits marked inflammatory imbalance. Malar. J., v. 9, n. 1, p. 13, 2010.

ANSTEY, N. M.; DOUGLAS, N. M.; POESPOPRODJO, J. R.; PRICE, R. N. Plasmodium vivax: Clinical Spectrum, Risk Factors and Pathogenesis. In: . [S.I.]: Adv. Parasitol., 2012. p. $151-201$.

BACHTROG, D.; AGIS, M.; IMHOF, M.; SCHLÖTTERER, C. Microsatellite variability differs between dinucleotide repeat motifs-evidence from Drosophila melanogaster. Mol. Biol.

Evol., v. 17, n. 9, p. 1277-1285, 2000.

BECK, H. P.; FELGER, I.; HUBER, W.; STEIGER, S.; SMITH, T.; WEISS, N.; ALONSO, P.; TANNER, M. Analysis of multiple Plasmodium falciparum infections in Tanzanian children during the phase III trial of the malaria vaccine SPf66. J. Infect. Dis., v. 175, n. 4, p. 921-926, 1997.

BELL, A. S.; ROODE, J. C. de; SIM, D.; READ, A. F. Within-hostcompetition in genetically diverse malaria infections: parasite virulence and competitive success. Evolution, v. 60, n. 7 , p. 1358, 2006.

BERECZKY, S.; LILJANDER, A.; ROOTH, I.; FARAJA, L.; GRANATH, F.; MONTGOMERY, S. M.; FÄRNERT, A. Multiclonal asymptomatic Plasmodium falciparum infections predict a 
reduced risk of malaria disease in a Tanzanian population. Microbes Infect., v. 9, n. 1, p. $103-110,2007$.

BOUSEMA, T.; DRAKELEY, C. Epidemiology and infectivity of Plasmodium falciparum and Plasmodium vivax gametocytes in relation to malaria control and elimination. Clin. Microbiol. Rev., v. 24, n. 2, p. 377-410, 2011.

BOYD, M. F.; KITCHEN, S. F. On the infectiousness of patients infected with Plasmodium vivax and Plasmodium falciparum. Am. J. Trop. Med. Hyg., s1-17, n. 2, p. 253-262, 1937.

BRANCH, O. H.; TAKALA, S.; KARIUKI, S.; NAHLEN, B. L.; KOLCZAK, M.; HAWLEY, W.; $\mathrm{LAL}, \mathrm{A}$. A. Plasmodium falciparum genotypes, low complexity of infection, and resistance to subsequent malaria in participants in the Asembo Bay Cohort Project. Infect. Immun., v. 69, n. 12, p. 7783-7792, 2001.

CARLTON, J. The Plasmodium vivax genome sequencing project. Trends Parasitol., v. 19, n. 5, p. 227-231, 2003.

CARLTON, J. M.; ADAMS, J. H.; SILVA, J. C.; BIDWELL, S. L.; LORENZI, H.; CALER, E.; CRABTREE, J.; ANGIUOLI, S. V.; MERINO, E. F.; AMEDEO, P.; CHENG, Q.; COULSON, R. M.; CRABB, B. S.; PORTILLO, H. A. del; ESSIEN, K.; FELDBLYUM, T. V.; FERNANDEZ-BECERRA, C.; GILSON, P. R.; GUEYE, A. H.; GUO, X.; KANG'A, S.; KOOIJ, T. W.; KORSINCZKY, M.; MEYER, E. V.; NENE, V.; PAULSEN, I.; WHITE, O.; RALPH, S. A.; REN, Q.; SARGEANT, T. J.; SALZBERG, S. L.; STOECKERT, C. J.; SULLIVAN, S. A.; YAMAMOTO, M. M.; HOFFMAN, S. L.; WORTMAN, J. R.; GARDNER, M. J.; GALINSKI, M. R.; BARNWELL, J. W.; FRASER-LIGGETT, C. M. Comparative genomics of the neglected human malaria parasite Plasmodium vivax. Nature, v. 455, n. 7214, p. 757-763, 2008.

CHARLESWORTH, B.; CHARLESWORTH, D. An experiment on recombination load in Drosophila melanogaster. Genet. Res., v. 25, p. 267-273, 1975.

CHARLWOOD, J. D.; ALECRIM, W. A.; MARTINS, V. J. Capture-recapture studies with the South American malaria vector Anopheles darlingi, Root. Ann. Trop. Med. Parasitol., v. 83, n. 6, p. 569-76, 1989.

CHENET, S.; SCHNEIDER, K.; VILLEGAS, L.; ESCALANTE, A. Local population structure of Plasmodium: impact on malaria control and elimination. Malar. J., v. 11, n. 1, p. 412, 2012.

CONTAMIN, H.; FANDEUR, T.; BONNEFOY, S.; SKOURI, F.; NTOUMI, F.; MERCEREAUPUIJALON, O. PCR typing of field isolates of Plasmodium falciparum. J. Clin. Microbiol., v. 33, n. 4, p. 944-51, 1995.

CROZIER, R. H.; KAUfMANN, B.; CAREW, M. E.; CROZIER, Y. C. Mutability of microsatellites developed for the ant Camponotus consobrinus. Mol. Ecol., v. 8, n. 2, p. 271-276, 1999.

DELLEY, V.; BOUVIER, P.; BRESLOW, N.; DOUMBO, O.; SAGARA, I.; DIAKITE, M.; MAURIS, A.; DOLO, A.; ROUGEMONT, A. What does a single determination of malaria parasite density mean? A longitudinal survey in Mali. Trop. Med. Int. Health., v. 5, n. 6, p. 404-412, 2000.

DORKEN, M. E.; ECKERT, C. G. Severely reduced sexual reproduction in Northern populations of a clonal plant, Decodon verticillatus (Lythraceae). J. Ecology, v. 89, n. 3, 2001. 
ECKERT, K. A.; MOWERY, A.; HILE, S. E. Misalignment-mediated DNA polymerase beta mutations: comparison of microsatellite and frame-shift error rates using a forward mutation assay. Biochemistry, v. 41, n. 33, p. 10490-10498, 2002.

ECKERT, K. A.; YAN, G.; HILE, S. E. Mutation rate and specificity analysis of tetranucleotide microsatellite DNA alleles in somatic human cells. Mol. Carcinog., v. 34, n. 3, p. 140-150, 2002.

EEDE, P. V. van; EEDE, P. van den; AUWERA, G. van der; DELGADO, C.; HUYSE, T.; SOTO-CALLE, V. E.; AUWERA, G. V. van; GAMBOA, D.; GRANDE, T.; RODRIGUEZ, H.; LLANOS, A.; ANNÉ, J.; ERHART, A.; D'ALESS, U. Multilocus genotyping reveals high heterogeneity and strong local population structure of the Plasmodium vivax population in the Peruvian Amazon. Malar. J., v. 9, n. 1, p. 151, 2010.

EEDE, P. van den; ERHART, A.; AUWERA, G. d.; OVERMEIR, C. V.; THANG, N. D.; HUNG, L. X.; ANNE, J.; D'ALESSANDRO, U. High complexity of Plasmodium vivax infections in symptomatic patients from a rural community in central Vietnam detected by microsatellite genotyping. Am. J. Trop. Med. Hyg., v. 82, n. 2, p. 223-227, 2010.

ELLEGREN, H. Microsatellites: simple sequences with complex evolution. Nat. Rev. Genet., v. 5, n. 6, p. $435-445,2004$.

FALUSH, D.; STEPHENS, M.; PRITCHARD, J. K. Inference of population structure using multilocus genotype data: linked loci and correlated allele frequencies. Genetics, v. 164, n. 4, p. 1567-1587, 2003.

FÄRNERT, A. Plasmodium falciparum population dynamics: only snapshots in time? Trends Parasitol., v. 24, n. 8, p. $340-344,2008$.

FÄRNERT, A.; AREZ, A.; BABIKER, H.; BECK, H.; BENITO, A.; BJÖRKMAN, A.; BRUCE, M.; CONWAY, D.; DAY, K.; HENNING, L.; MERCEREAU-PUIJALON, O.; RANFORD-CARTWRIGHT, L.; RUBIO, J.; SNOUNOU, G.; WALLIKER, D.; ZWETYENGA, J.; ROSARIO, V. D. Genotyping of Plasmodium falciparum infections by PCR: a comparative multicentre study. Trans. R. Soc. Trop. Med. Hyg., v. 95, n. 2, p. 225-32, 2001.

FEIL, E. J.; LI, B. C.; AANENSEN, D. M.; HANAGE, W. P.; SPRATT, B. G. eBURST: Inferring patterns of evolutionary descent among clusters of related bacterial genotypes from multilocus sequence typing data. J. Bacteriol., v. 186, n. 5, p. 1518-1530, 2004.

FENG, X.; CARLTON, J. M.; JOY, D. A.; MU, J.; FURUYA, T.; SUH, B. B.; WANG, Y.; BARNWELL, J. W.; SU, X.-Z. Single-nucleotide polymorphisms and genome diversity in Plasmodium vivax. Proc. Natl. Acad. Sci. U S A., v. 100, n. 14, p. 8502-8507, 2003.

FERREIRA, M. U.; KARUNAWEERA, N. D.; SILVA-NUNES, M. D.; SILVA, N. S. D.; WIRTH, D. F.; HARTL, D. L. Population structure and transmission dynamics of Plasmodium vivax in Rural Amazonia. J. Infect. Dis., v. 195, n. 8, p. 1218-1226, 2007.

GAMA, R. A.; SANTOS, R. L. C.; SANTOS, F. dos; SILVA, I. M.; RESENDE, M. C.; EIRAS, Á. E. Periodicidade de captura de Anopheles darlingi Root (Diptera: Culicidae) em Porto Velho, RO. Neotrop. Entomol., v. 38, n. 5, p. 677-682, 2009.

GARZA, J. C.; WILLIAMSON, E. G. Detection of reduction in population size using data from microsatellite loci. Mol. Ecol., p. 305-318, 2001. 
GOLDSTEIN, D. B.; POLLOCK, D. D. Launching microsatellites: areview of mutation processes and methods of phylogenetic inference. J. Hered., v. 88, n. 5, p. 335-342, 1997.

GOMEZ, J. C.; MCNAMARA, D. T.; BOCKARIE, M. J.; BAIRD, J. K.; CARLTON, J. M.; ZIMMERMAN, P. A. Identification of a polymorphic Plasmodium vivax microsatellite marker. Am. J. Trop. Med. Hyg., v. 69, n. 4, p. 377-379, 2003.

GONÇALVES, L. A.; CRAVO, P.; FERREIRA, M. U. Emerging Plasmodium vivax resistance to chloroquine in South America: an overview. Mem. Inst. Oswaldo Cruz, v. 0, n. ahead, p. 0-0, 2014.

GUNAWARDENA, S.; FERREIRA, M. U.; KAPILANANDA, G. M.; WIRTH, D. F.; KARUNAWEERA, N. D. The Sri Lankan paradox: high genetic diversity in Plasmodium vivax populations despite decreasing levels of malaria transmission. Parasitology, FirstView, p. 880-90, 2014.

GUNAWARDENA, S.; KARUNAWEERA, N. D.; FERREIRA, M. U.; PHONE-KYAW, M.; POLLACK, R. J.; ALIFRANGIS, M.; RAJAKARUNA, R. S.; KONRADSEN, F.; AMERASINGHE, P. H.; SCHOUSBOE, M. L.; GALAPPATHTHY, G. N.; ABEYASINGHE, R. R.; HARTL, D. L.; WIRTH, D. F. Geographic structure of Plasmodium vivax: microsatellite analysis of parasite populations from Sri Lanka, Myanmar, and Ethiopia. Am. J. Trop. Med. Hyg., v. 82, n. 2, p. 235-242, 2010.

HALL, T. A. BioEdit: a user-friendly biological sequence alignment editor and analysis program for Windows 95/98/NT. Nucleic Acids Symposium Series, p. 95-98, 2000.

HANCOCK, J. Microsatellites and other simple sequences: genomic context and mutational mechanisms. Oxford: Oxford University Press, 1999.

HARDING, R. M.; BOYCE, A. J.; CLEGG, J. B. The evolution of tandemly repetitive DNA: recombination rules. Genetics, v. 132, n. 3, p. 847-59, 1992.

HAUBOLD, B.; HUDSON, R. R. LIAN 3.0: detecting linkage disequilibrium in multilocus data. Bioinformatics, v. 16, n. 9, p. 847-848, 2000.

HAVRYLIUK, T.; FERREIRA, M. U. A closer look at multiple-clone Plasmodium vivax infections: detection methods, prevalence and consequences. Mem. Inst. Oswaldo Cruz., v. 104, n. 1, p. $67-73,2009$.

HAY, S. I.; GUERRA, C. A.; TATEM, A. J.; NOOR, A. M.; SNOW, R. W. The global distribution and population at risk of malaria: past, present, and future. Lancet Infect. Dis., v. 4, n. 6, p. 327-336, 2004.

HENNING, L.; SCHELLENBERG, D.; SMITH, T.; HENNING, D.; ALONSO, P.; TANNER, M.; MSHINDA, H.; BECK, H. P.; FELGER, I. A prospective study of Plasmodium falciparum multiplicity of infection and morbidity in Tanzanian children. Trans. R. Soc. Trop. Med. Hyg., v. 98, n. 12, p. 687-694, 2004.

HUBISZ, M. J.; FALUSH, D.; STEPHENS, M.; PRITCHARD, J. K. Inferring weak population structure with the assistance of sample group information. Mol. Ecol. Resour., v. 9, n. 5, p. 1322-1332, 2009. 
IMWONG, M.; NAIR, S.; PUKRITTAYAKAMEE, S.; SUDIMACK, D.; WILLIAMS, J. T.; MAYXAY, M.; NEWTON, P. N.; KIM, J. R.; NANDY, A.; OSORIO, L.; CARLTON, J. M.; WHITE, N. J.; DAY, N. P.; ANDERSON, T. J. Contrasting genetic structure in Plasmodium vivax populations from Asia and South America. Int. J. Parasitol., v. 37, n. 8-9, p. 1013-1022, 2007.

IMWONG, M.; PUKRITTAYAKAMEE, S.; GRUNER, A.; RENIA, L.; LETOURNEUR, F.; LOOAREESUWAN, S.; WHITE, N.; SNOUNOU, G. Practical PCR genotyping protocols for Plasmodium vivax using Pvcs and Pvmsp1. Malar. J., v. 4, n. 1, p. 20, 2005.

IMWONG, M.; SUDIMACK, D.; PUKRITTAYAKAMEE, S.; OSORIO, L.; CARLTON, J. M.; DAY, N. P.; WHITE, N. J.; ANDERSON, T. J. Microsatellite variation, repeat array length, and population history of Plasmodium vivax. Mol. Biol. Evol., v. 23, n. 5, p. 1016-1018, 2006.

INCRA. Incra atua para resolver conflito fundiário no Sul de Lábrea (AM). Disponível em: <http://www.incra.gov.br/index.php/noticias-sala-de-imprensa/noticias/6827-incraatua-para-resolver-conflito-fundiario-no-sul-de-labrea-am>. Acesso em: 15 mar.: [s.n.], 2014.

IWAGAMI, M.; HWANG, S.-Y.; KIM, S.-H.; PARK, S.-J.; LEE, G.-Y.; MATSUMOTOTAKAHASHI, E. L. A.; KHO, W.-G.; KANO, S. Microsatellite DNA analysis revealed a drastic genetic change of Plasmodium vivax population in the Republic of Korea during 2002 and 2003. PLoS Negl. Trop. Dis., v. 7, n. 10, p. e2522, 2013.

JAKUPCIAK, J. P.; WELLS, R. D. Genetic instabilities in (CTG.CAG) repeats occur by recombination. J. Biol. Chem., v. 274, n. 33, p. 23468-23479, 1999.

JOY, D. A.; GONZALEZ-CERON, L.; CARLTON, J. M.; GUEYE, A.; FAY, M.; MCCUTCHAN, T. F.; SU, X.-Z. Local adaptation and vector-mediated population structure in Plasmodium vivax malaria. Mol. Biol. Evol., v. 25, n. 6, p. 1245-1252, 2008.

KARUNAWEERA, N. D.; FERREIRA, M. U.; HARTL, D. L.; WIRTH, D. F. Fourteen polymorphic microsatellite DNA markers for the human malaria parasite Plasmodium vivax. Mol. Ecol. Notes., v. 7, n. 1, p. 172-175, 2007.

KELKAR, Y. D.; TYEKUCHEVA, S.; CHIAROMONTE, F.; MAKOVA, K. D. The genome-wide determinants of human and chimpanzee microsatellite evolution. Genome Res., v. 18, n. 1, p. 30-38, 2008.

KOEPFLI, C.; MUELLER, I.; MARFURT, J.; GOROTI, M.; SIE, A.; OA, O.; GENTON, B.; BECK, H.-P.; FELGER, I. Evaluation of Plasmodium vivax genotyping markers for molecular monitoring in clinical trials. J. Infect. Dis., v. 199, n. 7, p. 1074-1080, 2009.

KOEPFLI, C.; ROSS, A.; KINIBORO, B.; SMITH, T.; ZIMMERMAN, P.; SIBA, P.; MUELLER, I.; FELGER, I. Multiplicity and diversity of Plasmodium vivax infections in a highly endemic region in Papua New Guinea. PLoS neglected tropical diseases, v. 5, n. 12, p. e1424, dez. 2011.

LADEIA-ANDRADE, S.; FERREIRA, M. U.; CARVALHO, M. E. de; CURADO, I.; COURA, J. R. Age-Dependent Acquisition of Protective Immunity to Malaria in Riverine Populations of the Amazon Basin of Brazil. The American Journal of Tropical Medicine and Hygiene, v. 80, n. 3, p. 452-459, 2009. 
LARKIN, M. A.; BLACKSHIELDS, G.; BROWN, N. P.; CHENNA, R.; MCGETTIGAN, P. A.; MCWILLIAM, H.; VALENTIN, F.; WALLACE, I. M.; WILM, A.; LOPEZ, R.; THOMPSON, J. D.; GIBSON, T. J.; HIGGINS, D. G. Clustal W and Clustal X version 2.0. Bioinformatics, v. 23, n. 21, p. 2947-2948, 2007.

LECLERC, M. C.; DURAND, P.; GAUTHIER, C.; PATOT, S.; BILLOTTE, N.; MENEGON, M.; SEVERINI, C.; AYALA, F. J.; RENAUD, F. Meager genetic variability of the human malaria agent Plasmodium vivax. Proc. Natl. Acad. Sci. U S A., v. 101, n. 40, p. 14455-14460, 2004.

LOIOLA, C. C.; SILVA, C. J. D.; TAUIL, P. L. Controle da malária no Brasil: 1965 a 2001. Pan. Am. J. Public Health, v. 11, n. 4, p. 1-10, 2002.

LUIKART, G.; ALLENDORF, F.; CORNUET, J.-M.; SHERWIN, W. Distortion of allele frequency distributions provides a test for recent population bottlenecks. J. Hered., v. 89, n. 3, p. 238-247, 1998.

MANTEL, N. The detection of disease clustering and a generalized regression approach. Cancer Res., v. 27, n. 2 Part 1, p. 209-220, 1967.

MARQUES, M. M.; COSTA, M. R. F.; FILHO, F. S. S.; VIEIRA, J. L. F.; NASCIMENTO, M. T. S.; BRASIL, L. W.; NOGUEIRA, F.; SILVEIRA, H.; REYES-LECCA, R. C.; MONTEIRO, W. M.; LACERDA, M. G. V.; ALECRIM, M. G. C. Plasmodium vivax chloroquine resistance and anemia in the western Brazilian Amazon. Antimicrob. Agents Chemother., v. 58, n. 1, p. 342-347, 2014.

MARTINS, A.; LINS, J.; SANTOS, L.; FERNANDES, L.; MALAFRONTE, R.; MAIA, T.; RIBERA, M.; RIBERA, R.; SILVA-NUNES, M. D. Vivax malaria in an Amazonian child with dilated cardiomyopathy. Malar. J., v. 13, n. 1, p. 61, 2014.

MCKENZIE, F.; JEFFERY, G. Gametocytemia and fever in human malaria infections. J. Parasitol., v. 93, n. 3, p. 627-633, 2007.

MIDEO, N. Parasite adaptations to within-host competition. Trends Parasitol., v. 25, n. 6, p. $261-268,2009$.

NEAFSEY, D. E.; GALINSKY, K.; JIANG, R. H. Y.; YOUNG, L.; SYKES, S. M.; SAIF, S.; GUJJA, S.; GOLDBERG, J. M.; YOUNG, S.; QI; ZENG, o.; CHAPMAN, S. B.; DASH, A. P.; ANVIKAR, A. R.; SUTTON, P. L.; BIRREN, B. W.; ESCALANTE, A. A.; BARNWELL, J. W.; CARLTON, J. M.; ZENG, Q. The malaria parasite Plasmodium vivax exhibits greater genetic diversity than Plasmodium falciparum. Nat. Genet., v. 44, n. 9, p. 1046-1050, 2012.

NKHOMA, S. C.; NAIR, S.; AL-SAAI, S.; ASHLEY, E.; MCGREADY, R.; PHYO, A. P.; NOSTEN, F.; ANDERSON, T. J. Population genetic correlates of declining transmission in a human pathogen. Mol. Ecol., v. 22, n. 2, p. 273-285, 2013.

OLIVEIRA-FERREIRA, J.; LACERDA, M. V.; BRASIL, P.; LADISLAU, J. L.; TAUIL, P. L.; DANIEL-RIBEIRO, C.; BRASIL, P.; LADISLAU, J. L.; DANIEL-RIBEIRO, C. T. Malaria in Brazil: an overview. Malar. J., v. 9, n. 1, p. 115, 2010.

ORJUELA-SÁNCHEZ, P.; KARUNAWEERA, N.; SILVA-NUNES, M. D.; SILVA, N. D.; SCOPEL, K.; GONCALVES, R.; AMARATUNGA, C.; SA, J.; SOCHEAT, D.; FAIRHUST, R.; GUNAWARDENA, S.; THAVAKODIRASAH, T.; GALAPATHTHY, G.; ABEYSINGHE, 
R.; KAWAMOTO, F.; WIRTH, D.; FERREIRA, M. Single-nucleotide polymorphism, linkage disequilibrium and geographic structure in the malaria parasite Plasmodium vivax: prospects for genome-wide association studies. BMC Genet., v. 11, n. 1, p. 65, 2010.

ORJUELA-SÁNCHEZ, P.; SILVA, N. S. D.; SILVA-NUNES, M. D.; FERREIRA, M. U. Recurrent parasitemias and population dynamics of Plasmodium vivax polymorphisms in rural Amazonia. Am. J. Trop. Med. Hyg., v. 81, n. 6, p. 961-968, 2009.

ORJUELA-SÁNCHEZ, P.; SILVA-NUNES, M. D.; SILVA, N. S. D.; SCOPEL, K. K.; GONÇALVES, R. M.; MALAFRONTE, R. S.; FERREIRA, M. U. Population dynamics of genetically diverse Plasmodium falciparum lineages: community-based prospective study in rural Amazonia. Parasitology, v. 136, p. 1097-1105, 2009.

OWUSU-AGYEI, S.; SMITH, T.; BECK, H.-P.; AMENGA-ETEGO, L.; FELGER, I. Molecular epidemiology of Plasmodium falciparum infections among asymptomatic inhabitants of a holoendemic malarious area in northern Ghana. Trop. Med. Int. Health., v. 7, n. 5, p. 421-428, 2002.

PEARSON, C. E.; EDAMURA, K. N.; CLEARY, J. D. Repeat instability: mechanisms of dynamic mutations. Nat. Rev. Genet., v. 6, n. 10, p. 729-742, 2005.

PEREIRA, E.; ISHIKAWA, E.; FONTES, C. Adherence to Plasmodium vivax malaria treatment in the Brazilian Amazon Region. Malar. J., v. 10, n. 1, p. 355, 2011.

POLLEY, S. D.; CHOKEJINDACHAI, W.; CONWAY, D. J. Allele frequency-based analyses robustly map sequence sites under balancing selection in a malaria vaccine candidate antigen. Genetics, v. 165, n. 2, p. 555-561, 2003.

PRICE, R. N.; DOUGLAS, N. M.; ANSTEY, N. M. New developments in Plasmodium vivax malaria: severe diseaseand the rise of chloroquine resistance. Curr. Opin. Infect. Dis., v. 22, p. $430-435,2009$.

PRIMMER, C.; SAINO, N.; MØLLER, A.; ELLEGREN, H. Directional evolution in germline microsatellite mutations. Nat. Genet., v. 13, n. 4, p. 391-3, 1996.

PRITCHARD, J. K.; STEPHENS, M.; DONNELLY, P. Inference of population structure using multilocus genotype data. Genetics, v. 155, n. 2, p. 945-959, 2000.

PUTAPORNTIP, C.; JONGWUTIWES, S.; SAKIHAMA, N.; FERREIRA, M. U.; KHO, W. G.; KANEKO, A.; KANBARA, H.; HATTORI, T.; TANABE, K. Mosaic organization and heterogeneity in frequency of allelic recombination of the Plasmodium vivax merozoite surface protein-1 locus. Proc. Natl. Acad. Sci. U S A., v. 99, n. 25, p. 16348-16353, 2002.

\section{R-CORE-TEAM, R. R: A Language and Environment for Statistical Computing.} Vienna, Austria, 2013.

RAPOSO, C.; SANTOS, J.; EDA, G. G.; SILVA, A. Plasmodium vivax malaria: related factors to severity in the State of Maranhão, Brazil. Rev. Soc. Bras. Med. Trop., v. 46, n. 1, p. 67-72, 2013.

REZENDE, A. M.; TARAZONA-SANTOS, E.; FONTES, C. J. F.; SOUZA, J. M.; COUTO, A. D.; CARVALHO, L. H.; BRITO, C. F. A. Microsatellite loci: determining the genetic variability of Plasmodium vivax. Trop. Med. Int. Health., v. 15, n. 6, p. 718-726, 2010. 
RIECKMANN, K. H.; DAVIS, D. R.; HUTTON, D. C. Plasmodium vivax resistance to chloroquine? Lancet, v. 334, n. 8673, p. 1183 - 1184, 1989.

ROBERTS, D. R.; ALECRIM, W. D.; TAVARES, A. M.; RADKE, M. G. The house-frequenting, host-seeking and resting behavior of Anopheles darlingi in southeastern Amazonas, Brazil. J. Am. Mosq. Control Assoc., v. 3, n. 3, p. 433-41, 1987.

ROODE, J. C. de; PANSINI, R.; CHEESMAN, S. J.; HELINSKI, M. E.; HUIJBEN, S.; WARGO, A. R.; BELL, A. S.; CHAN, B. H.; WALLIKER, D.; READ, A. F. Virulence and competitive ability in genetically diverse malaria infections. Proc. Natl. Acad. Sci. U S A., v. 102, n. 21, p. 7624-7628, 2005.

RUSSELL, B.; SUWANARUSK, R.; LEK-UTHAI, U. Plasmodium vivax genetic diversity: microsatellite length matters. Trends Parasitol., v. 22, n. 9, p. $399-401,2006$.

SANTANA-FILHO, F. de; ARCANJO, A. R. de; CHEHUAN, Y. M.; COSTA, M. R.; MARTINEZ-ESPINOSA, F. E.; VIEIRA, J. L.; BARBOSA, M. G. das; ALECRIM, W. D.; ALECRIM, M. G. das. Chloroquine resistant Plasmodium vivax, Brazilian Amazon. Emerg. Infect. Dis., v. 13, p. 1125-1126, 2007.

SILVA-NUNES, M. D.; CODEÇO, C. T.; MALAFRONTE, R. S.; SILVA, N. S. D.; JUNCANSEN, C.; MUNIZ, P. T.; FERREIRA, M. U. Malaria on the amazonian frontier: transmission dynamics, risk factors, spatial distribution, and prospects for control. Am. J. Trop. Med. Hyg., v. 79, n. 4, p. 624-635, 2008.

SINDEN, R.; GILLES, H. The malaria parasites. 4. ed. Warrel, D. A.; Gilles, H. M. Hodder Arnold, London, United Kingdom: Essential malariology, 2002.

SINKA, M.; RUBIO-PALIS, Y.; MANGUIN, S.; PATIL, A.; TEMPERLEY, W.; GETHING, P.; BOECKEL, T. van; KABARIA, C.; HARBACH, R.; HAY, S. The dominant Anopheles vectors of human malaria in the Americas: occurrence data, distribution maps and bionomic precis.

Parasit. Vectors, v. 3, n. 1, p. 72, 2010.

SMITH, J. M.; SMITH, N. H.; O'ROURKE, M.; SPRATT, B. G. How clonal are bacteria? Proc. Natl. Acad. Sci. U S A., v. 90, n. 10, p. 4384-4388, 1993.

SU, X.-z.; WELLEMS, T. E. Toward a high-resolution Plasmodium falciparum linkage map: polymorphic markers from hundreds of simple sequence repeats. Genomics, v. 33, n. 3, p. 430 - 444, 1996.

SUÁREZ-MUTIS, M. C.; CUERVO, P.; LEORATTI, F. M.; MORAES-AVILA, S. L.; FERREIRA, A. W.; FERNANDES, O.; COURA, J. R. Cross sectional study reveals a high percentage of asymptomatic Plasmodium vivax infection in the Amazon Rio Negro area, Brazil. Rev. Inst. Med. Trop. S. Paulo., v. 49, n. 3, p. 159-164, 2007.

SUTTON, P. L. A call to arms: on refining Plasmodium vivax microsatellite marker panels for comparing global diversity. Malar. J., v. 12, n. 1, p. 447, 2013.

TACHIDA, H.; IIZUKA, M. Persistence of repeated sequences that evolve by replication slippage. Genetics, v. 131, n. 2, p. 471-8, 1992.

TAMURA, K.; STECHER, G.; PETERSON, D.; FILIPSKI, A.; KUMAR, S. MEGA6: Molecular evolutionary genetics analysis version 6.0. Mol. Biol. Evol., v. 30, n. 12, p. 2725-2729, 2013. 
TANABE, K.; SAKIHAMA, N.; FÄRNERT, A.; ROOTH, I.; BJÖRKMAN, A.; WALLIKER, D.; RANFORD-CARTWRIGHT, L. In vitro recombination duringPCR of Plasmodium falciparum DNA: a potential pitfall in molecular population genetic analysis. Mol. Biochem. Parasitol., v. 122 , n. 2 , p. $211-216,2002$.

TAUTZ, D.; SCHLÖTTERER, C. Simple sequences. Curr. Opin. Genet. Dev., v. 4, n. 6, p. $832-837,1994$.

TAYLOR, J. E.; PACHECO, M. A.; BACON, D. J.; BEG, M. A.; MACHADO, R. L. D.; FAIRHURST, R. M.; HERRERA, S.; KIM, J.-Y.; MENARD, D.; PÓVOA, M. M.; VILLEGAS, L.; MULYANTO; SNOUNOU, G.; CUI, L.; ZEYREK, F. Y.; ESCALANTE, A. A. The evolutionary history of Plasmodium vivax as inferred from mitochondrial genomes: parasite genetic diversity in the Americas. Mol. Biol. Evol., v. 30, n. 9, p. 2050-64, 2013.

TIBAYRENC, M.; AYALA, F. J. New insights into clonality and panmixia in Plasmodium and Toxoplasma. Adv. Parasitol., v. 84, p. 253-268, 2014.

TRAPE, J. F. Rapid evaluation of malaria parasite density and standardization of thick smear examination for epidemiological investigations. Trans. R. Soc. Trop. Med. Hyg., v. 79, n. 2, p. 181-184, 1985.

VALDES, A. M.; SLATKIN, M.; FREIMER, N. B. Allele frequencies at microsatellite loci: the stepwise mutation model revisited. Genetics, v. 133, p. 737-749, 1993.

WEBSTER, M. T.; SMITH, N. G. C.; ELLEGREN, H. Microsatellite evolution inferred from human- chimpanzee genomic sequence alignments. Proc. Natl. Acad. Sci. U S A., v. 99, n. 13, p. 8748-8753, 2002.

WHITE, N. Determinants of relapse periodicity in Plasmodium vivax malaria. Malar. J., v. 10, n. 1 , p. $297,2011$.

WHO. World Health Organization - World Malaria Report 2013. Geneva: World Health Organization, p. 1-286, 2013.

XU, X.; PENG, M.; FANG, Z.; XU, X. The direction of microsatellite mutations is dependent upon allele length. Nat. Genet., v. 24, n. 4, p. 396-9, 2000.

ZHIVOTOVSKY, L. A.; FELDMAN, M. W. Microsatellite variability and genetic distances.

Proc. Natl. Acad. Sci. U S A., v. 92, n. 25, p. 11549-11552, 1995.

ZILVERSMIT, M.; HARTL, D. L. Evolutionary history and population genetics of human malaria parasites. Molecular approaches to malaria, p. 95-109, 2005.

1 De acordo com: ASSOCIAÇÃO BRASILEIRA DE NORMAS TÉCNICAS. NBR 6023: informação e documentação: referências: elaboração. Rio de Janeiro, 2002. 